\title{
OPTIMIZATION AND DESIGN PRINCIPLES OF A MINIMAL-WEIGHT, WEARABLE HYDRAULIC POWER SUPPLY
}

\author{
A THESIS SUBMITTED TO \\ THE UNIVERSITY OF MINNESOTA
}

\section{JONATHAN NATH}

\author{
IN PARTIAL FULFILLMENT OF THE \\ REQUIREMENTS FOR THE DEGREE OF \\ MASTER OF SCIENCE, \\ MECHANICAL ENGINEERING
}

\author{
ADVISOR \\ WILLIAM DURFEE
}

DECEMBER, 2017 
(C) Jonathan Nath

2017 


\begin{abstract}
The field of wearable hydraulics for human-assistive devices is expanding. One of the major challenges facing development of these systems is creating lightweight, portable power units. This project's goal was to develop design strategies and guidelines with the use of analytical modeling to minimize the weight of portable hydraulic power supplies in the range of 50-350 W. Steadystate, analytical models were developed and validated for a system containing a lithium-polymer battery, brushless DC motor, and axial-piston pump. Component parameters such as motor size, pump size, and swashplate angle were varied to develop four design guidelines that can be used by designers to minimize system weight. First, the smallest electric motor that can provide the required torque and speed may not result in minimum system weight. Second, cooling systems do not reduce overall system weight. Third, the gearbox between the electric motor and pump should be eliminated to reduce system weight. Fourth, iterative modeling is necessary to determine the various range of component parameters necessary to result in a minimal-weight system. The analytical model developed takes inputs of desired flowrate, pressure, and runtime, and outputs the combination of pump size, swashplate angle, and motor size that results in a minimal-weight system. The four design principles and the computer simulation are tools that can be used to either design a fully-custom, weight-optimized power supply or to aid in the selection of commercially available components for a low-weight power supply.
\end{abstract}




\section{Table of Contents}

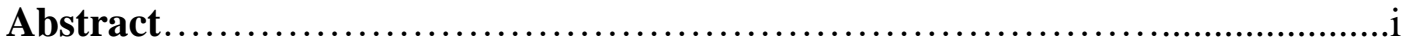

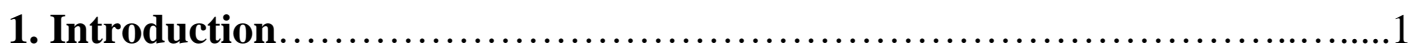

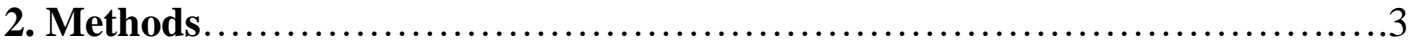

2.1 Component Type Selection..........................................

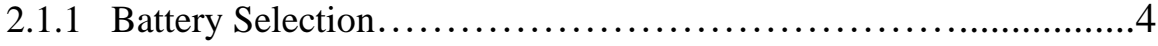

2.1.2 Electric Motor Selection.......................................5

2.1.3 Pump Selection...............................................

2.2 Computational Model Development...............................6

2.2.1 Battery Model..............................................6

2.2.2 Motor Model.............................................

2.2.2.1 Parameter Calculation...............................8

2.2.2.2 Motor Losses..................................... 12

2.2.2.3 Heat Transfer Model and Power Ratings.................14

2.2.3 Pump Model.............................................. 17

2.2.3.1 Pump Mechanical Losses................................19

2.2.3.2 Pump Volumetric Losses................................20

2.3 Individual Component Model Validation.................................21

2.3.1 Motor Model Validation......................................21

2.3.2 Pump Model Validation......................................23

2.4 Integrated Model Validation ...................................... 24

2.4.1 Test Stand Apparatus .......................................25

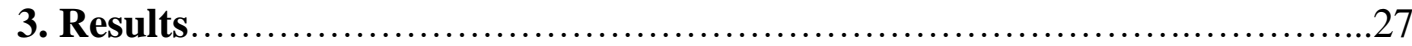

3.1 Integrated Model Validation Test Stand Results.....................27

3.2 System Design Guideline Development.................................34

3.2.1 Motor Sizing............................................... 34

3.2.2 Gearbox Selection............................................. 35

3.2.3 Motor Cooling.............................................. 39

3.2.4 Total System Design........................................43

3.2.5 Quasi-Steady-State Model...................................43

4. Discussion and Conclusion ................................................. 45

4.1 Test Stand Validation Discussion.................................45

4.1.1 Experimental vs. Model Predictions..............................45

4.1.2 Purpose of Model as a Tool........................................45

4.1.3 HAFO Power Supply Redesign.................................45

4.2 System Design Guidelines..............................................47

4.2.1 Design Guidelines........................................47

4.2.2 Limitations of Guidelines....................................49

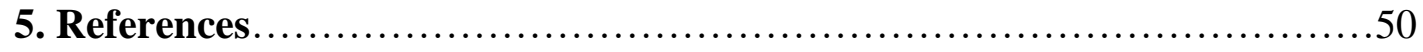




\section{INTRODUCTION}

The goal of this project was to develop guidelines and optimization techniques for the design of minimal-weight, wearable electro-hydraulic power supplies. A computational power supply model was created to aid in the component selection and design of a minimal-weight power supply. This study focused on small-scale, portable systems in the range of 50-350 W.

Hydraulic actuation systems have several advantages that make them suitable for wearable human-assistive devices. Hydraulics have force and power densities that are an order of magnitude higher than electric machines [1-3]. Another advantage of hydraulic systems is that the relatively heavy electro-hydraulic power supply can be worn on the user's back or waist, while the lightweight actuators can easily be located remotely using flexible hoses to route the high-pressure fluid. Another benefit of hydraulic systems is that they are shown to have high precision control, especially when compared to pneumatic systems [4].

There are several examples of exoskeletons that utilize the benefits of hydraulic power including Raytheon Sarcos's XOS2 and Lockheed Martin's Human Universal Load Carrier $[5,6]$.
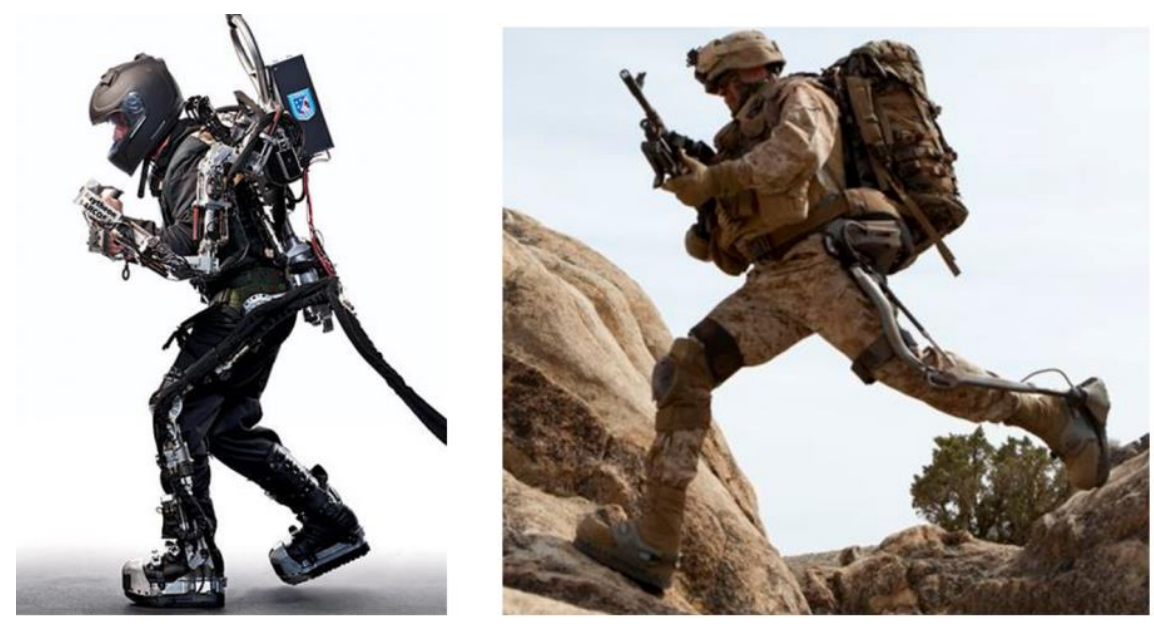

Figure 1. Raytheon XOS2 (left), Lockheed Martin HULC (right)

One issue with many of these types of systems is that they rely on tethered power systems, where the hydraulic power supply is located remotely and the fluid is routed to the wearable exoskeleton via hoses.

Other uses of hydraulic power include Boston Dynamic's BigDog, which uses an internal combustion engine to drive a hydraulic pump, providing high pressure fluid to the actuators on the legs. This machine's purpose was to carry heavy loads over large distances. However, this program was discontinued due to the high noise of the internal combustion engine [7]. 

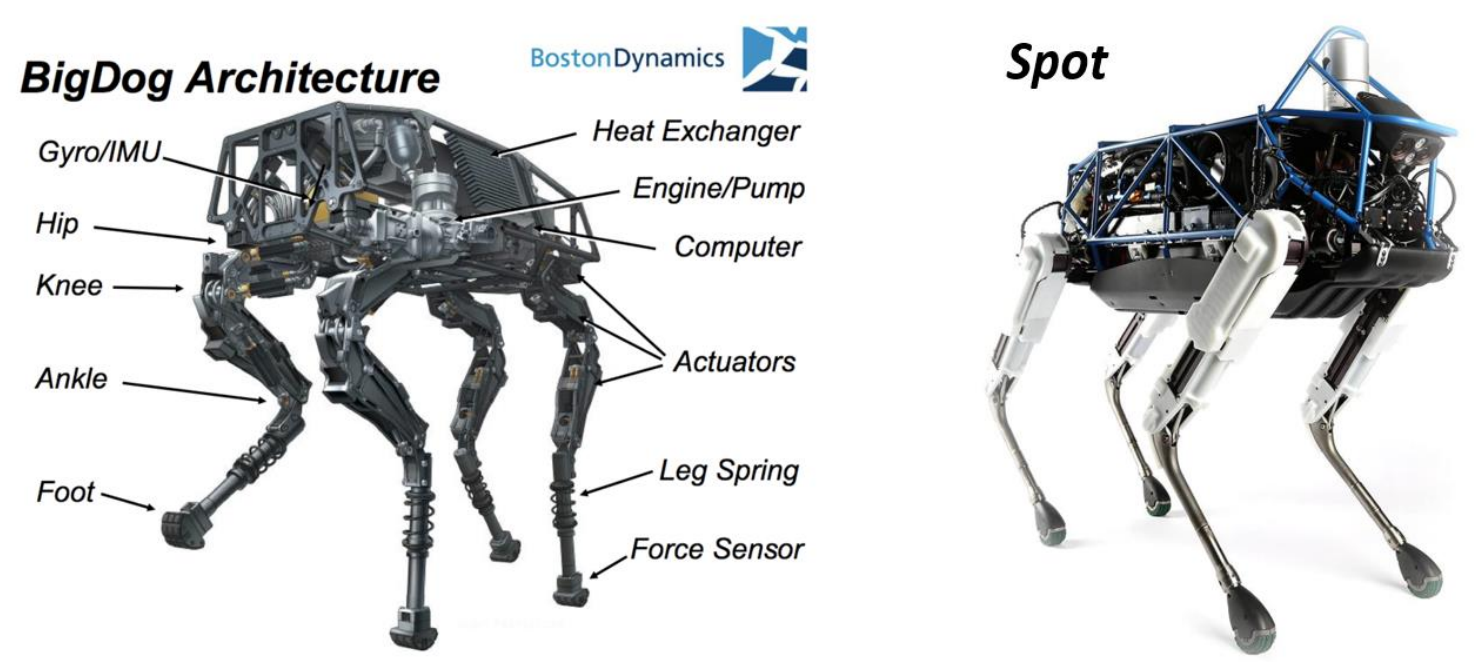

Figure 2. Boston Dynamic's BigDog (left), Spot (right)

The next generation of this project, Spot, was an electro-hydraulic machine that used a battery to supply power to an electric motor to drive a hydraulic pump [8]. However, this system could only carry $23 \mathrm{~kg}$ for a time of 45 minutes, and development was discontinued. As demonstrated by these projects, hydraulic systems are effective for providing high forces at several remote points away from the main power supply. However, the problem appears to be with the power supply. Internal combustion systems are light and powerful, but too noisy. Electric systems are quiet, but not energy-dense enough.

A critical factor for maintaining the evolution of devices such as exoskeletons used in military, medical, and industrial applications will be the development of the power supply [9]. This project focused on creating design tools and guidelines to aid in the design of an untethered, energy-dense systems that are also quiet and capable of being used in environments such as a hospital or indoor workplace.

Previous work at the University of Minnesota has explored the modeling of small-scale hydraulic systems. A conclusion from these studies found that hydraulic actuation systems around $100 \mathrm{~W}$ can be lighter than equivalent electromechanical systems [10,11].

Another study from a collaboration with MOOG hydraulics and the Italian Institute of Technology showed that hydraulics were the best solution in the construction of a hydraulically actuated quadraped robot, HyQ. This research team found that hydraulic were the best option for this application: "We chose the hydraulic solution for HyQ over the electric one, as it guarantees us higher performance and power and strength of the legs [12]."

However, these studies focused primarily on the actuator side of the systems, and did not look into optimization of the power supply. While the actuators have been shown to be lightweight and effective, especially in high force applications, the hydraulic power supply still remains the heaviest part of the system, and further work needs to be done to lower this weight.

Previous work in our lab also resulted in an untethered power supply for the hydraulic anklefoot orthosis shown in Figure 3 [13]. The portable power supply is worn on the user's lower back and the hydraulic actuators, located on the ankle, provide up to $90 \mathrm{Nm}$ of torque to the ankle. 


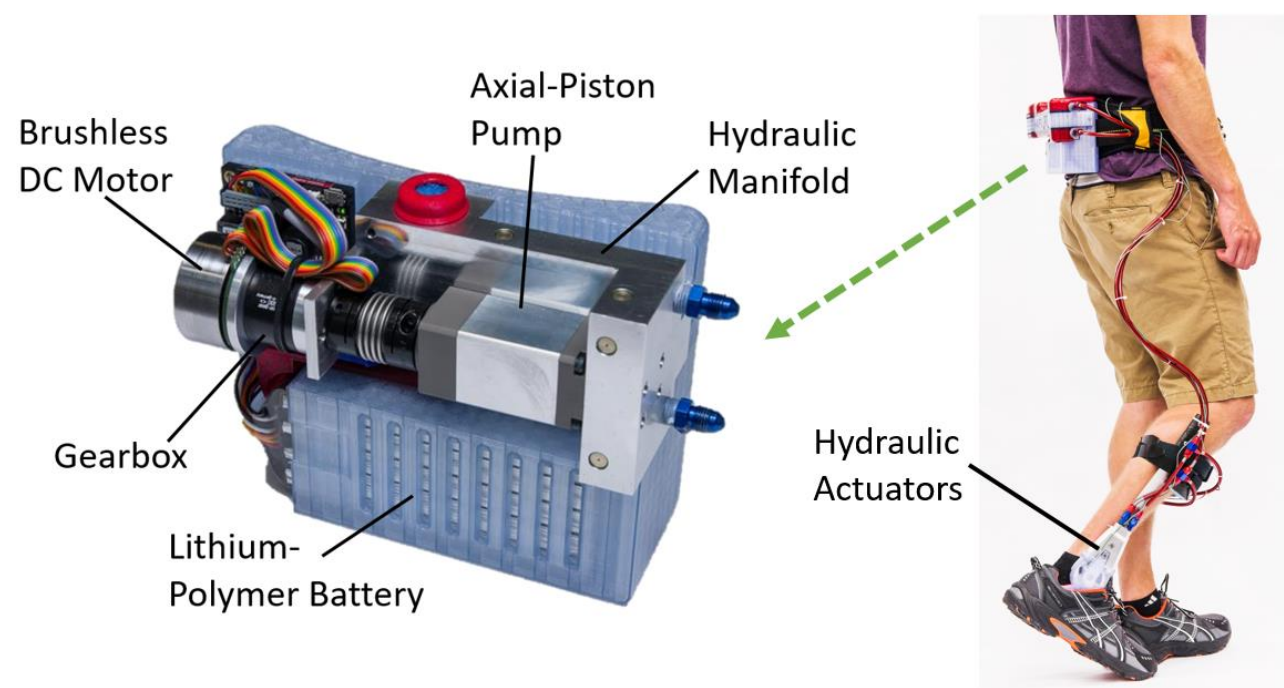

Figure 3. First generation power supply for hydraulic ankle-foot orthosis

The total weight of this $70 \mathrm{~W}$ power supply was $2.2 \mathrm{~kg}$ and it could provide up to $12 \mathrm{MPa}$ of pressure. The design of this power supply began with the definition of the maximum required pressure and flowrate. Based on these requirements, the smallest capable pump was selected. Then, the smallest size of electric motor that could meet the torque and speed requirements was chosen. Finally, a battery was selected that would be able to power the system for the desired runtime.

After analysis, the initial approach used to design this first-generation hydraulic power supply did not prove to be the most effective strategy for creating a minimal-weight system. The reason being that the battery weight needs to be considered, which is impacted by the motor and pump efficiencies. There are cases where heavier electric motors will operate more efficiently than lighter motors. Although the heavier motor adds more initial weight to the system, because it performs more efficiently this results in a lower battery weight, which may ultimately result in a lower overall system weight. Therefore, to explore design principles such as this, analytical models of the power supply components were created aid in component selection to minimize weight.

\section{METHODS}

The purpose of a hydraulic power supply is to supply fluid flow at a certain pressure and flowrate for a desired amount of time. While the desired flowrate and pressure may dynamically fluctuate for a given application, this study was limited to steady-state operation.

These power supplies could be used in applications ranging from wearable exoskeletons to hydraulic powered hand tools or autonomous robots used to carry heavy loads. The methods used in this study are shown in Figure 4.

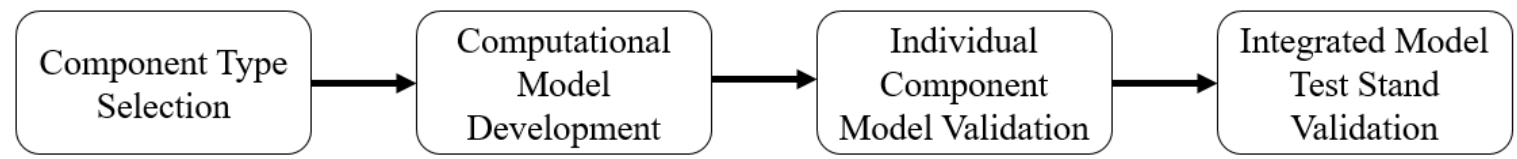

Figure 4. Project method outline 
The component type selection was done by considering factors such as operational efficiency, power density, and commercial availability. After the component types were selected, computational models were developed. These models were developed by first defining the geometry of the components and then using dynamic equations to define the operational performance. Once the computational models were developed, they were validated by comparing the model performance to commercially available components. Finally, a test stand was constructed to further validate the integrated model performance.

\subsection{Component Type Selection}

The wearable power supply must be quiet enough to be used in indoor applications. Therefore, it was determined that a battery-electric motor configuration is required to drive the hydraulic pump. The high-pressure fluid coming from the pump could be routed to a component such as a servo valve or directly to the actuators. Although there are various hydraulic circuit configurations that could be used to route the high-pressure fluid to the actuators, this project was limited to optimizing the parts of the system shown in Figure 5.

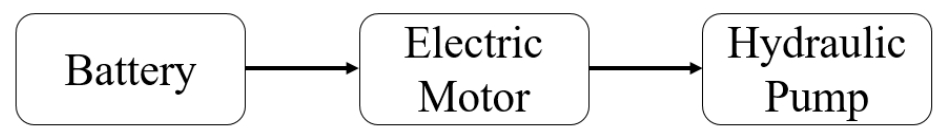

Figure 5. Power supply configuration

\subsubsection{Battery Selection}

The battery must have a high energy-density while maintaining reasonable stability for safety purposes. Additionally, the battery must be commonly available in a range of capacities depending on the energy needs of the intended application. Figure 6 shows the energy density of several common types of batteries.

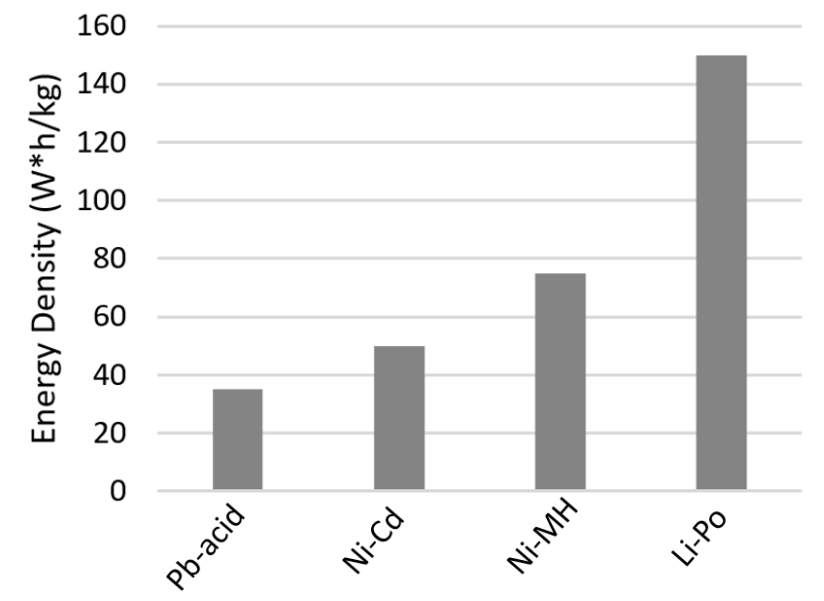

Figure 6. Energy densities of common battery types [14]

Among common battery types lithium-ion polymer (LiPo) have the highest energy densities. Lithium-ion polymer are a specific type of lithium-ion battery that utilize the exchange of lithiumions between electrodes and use a polymer gel electrolyte to separate the anode and cathode. These 
types of batteries are commercially available in a wide range of capacities and voltages. Therefore, lithium-polymer was chosen as a suitable battery for this application.

\subsubsection{Electric Motor Selection}

Since the untethered power system uses a DC battery supply, it was decided that DC motors would be chosen over AC motors. Also, DC motors are more common and readily available in the 50-350 $\mathrm{W}$ power range.

There are two types of DC motors, brushless and brushed. Brushed motors use small brushes connected to the rotating windings that alternate the current through the windings as they spin. Most brushless motors have fixed windings that require a motor controller to control the current to the windings which causes the permanent magnet rotor to spin.

Brushless DC motors have several advantages over brushed motors including higher efficiencies, better heat transfer properties, and generally higher power densities [15]. Table 1 compares brushless and brushed electric motors.

Table 1. Brushless vs. brushed electric motors [16]

\begin{tabular}{lll}
\hline Parameter & Brushless & Brushed \\
\hline Max. Efficiency & $85-90 \%$ & $75-80 \%$ \\
Thermal Cooling Properties & Higher & Lower \\
Cost & Higher & Lower \\
Control & Complex Motor Controller & Simple Voltage Controller \\
Noise & Lower & Higher \\
Lifespan & Higher & Lower \\
Rotor Inertia & Lower & Higher \\
Power/Weight Ratio & Higher & Lower \\
\hline
\end{tabular}

Given the advantages over other motor types, brushless DC motors were chosen for the power supply configuration.

\subsubsection{Pump Selection}

Piston pumps have the highest efficiency among all pump types [17]. Axial-piston pumps also retain relatively high efficiencies at low speeds when compared to other pump types such as gear pumps. The following plot shows data provided by Takako Industries comparing their line of small axial-piston pumps to a standard gear pump. 


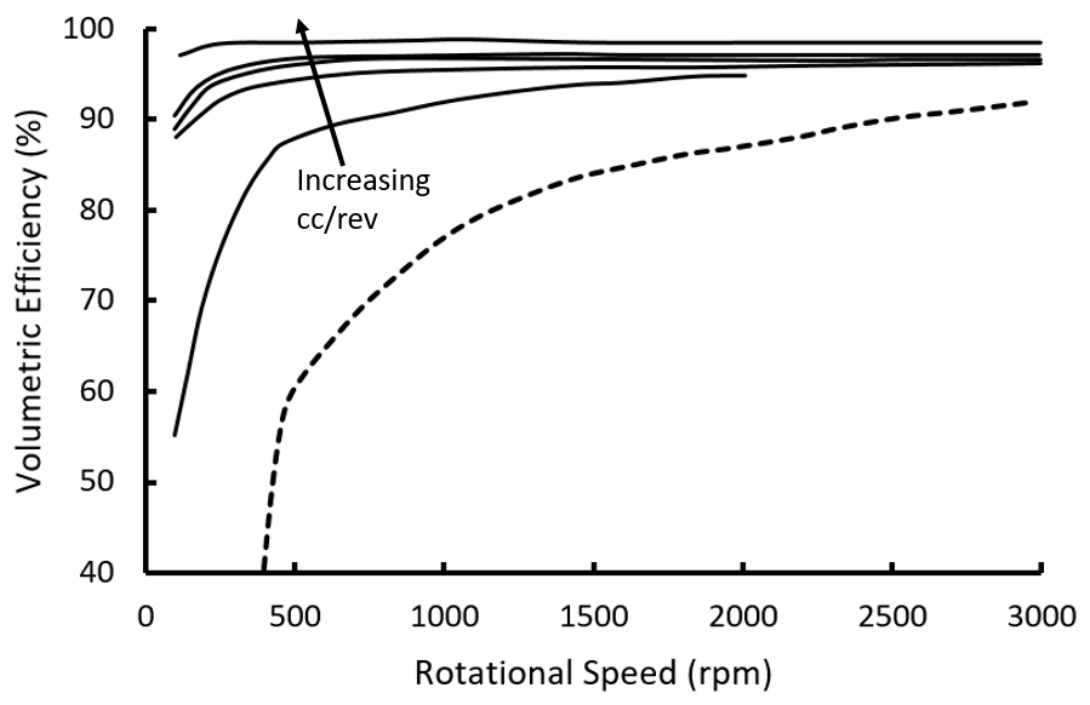

Figure 7. Volumetric efficiency of gear (dashed line) and axial-piston pumps ranging from $0.4-1.6 \mathrm{cc} / \mathrm{rev}$ (solid lines), $12 \mathrm{MPa}, \mathrm{VG} 32$ oil

As shown in Figure 7, the volumetric efficiency of the gear pump is significantly lower than all of the axial-piston pump models, especially at low speeds. This low efficiency would result in a larger motor required to drive the pump as well as a larger battery due to the low system efficiency. Although the weight of the pump may be lower than a piston pump, the overall system weight may be higher. As shown in previous research comparing hydraulic power systems with either piston pumps or vane pumps, the piston pump configuration resulted in a lower overall system weight [10]. Also, for hydraulic power supplies such as with the HAFO, the battery weight was several times higher than the pump weight, so the efficiency is likely a more important factor than weight. Therefore, axial-piston pumps were chosen as the pump of choice for this project. Gear and vane pump modeling may be considered in the future.

\subsection{Computational Model}

The goal was to create component models that could be easily adapted and sized. The modeling was done by first determining the defining characteristic equations for the motor, pump, and battery, and then by using computer software to run iterations of these equations for various combinations of component parameters. The equations that define component performance were developed and tested to ensure matching of performance to commercially available components. Once each component was validated, a combined system model consisting of the battery, motor, and pump was created to explore a range of design principles used to create a minimal-weight power supply.

\subsubsection{Battery Model}

The model for a lithium-ion battery was developed by obtaining the catalog data for the average energy density of a wide range of commercially available products, which was found to be about $148 \mathrm{Wh} / \mathrm{kg}$ [10]. Batteries have a small internal resistance. However, since this resistance is usually small, it was not accounted for in the battery model. Therefore, the weight of the battery was calculated directly from the average energy density of LiPo batteries. 


$$
W_{\text {battery }}=\frac{P_{\text {required }}}{148\left(\frac{W h}{k g}\right)}
$$

\subsubsection{Motor Model}

An electric motor can be modeled as shown in Figure 8, where $b$ is the viscous damping in the motor, $J$ is the rotor inertia, $T$ is the torque being applied externally to the motor shaft, and $k_{T} I$ is equivalent to the torque being produced by the motor.
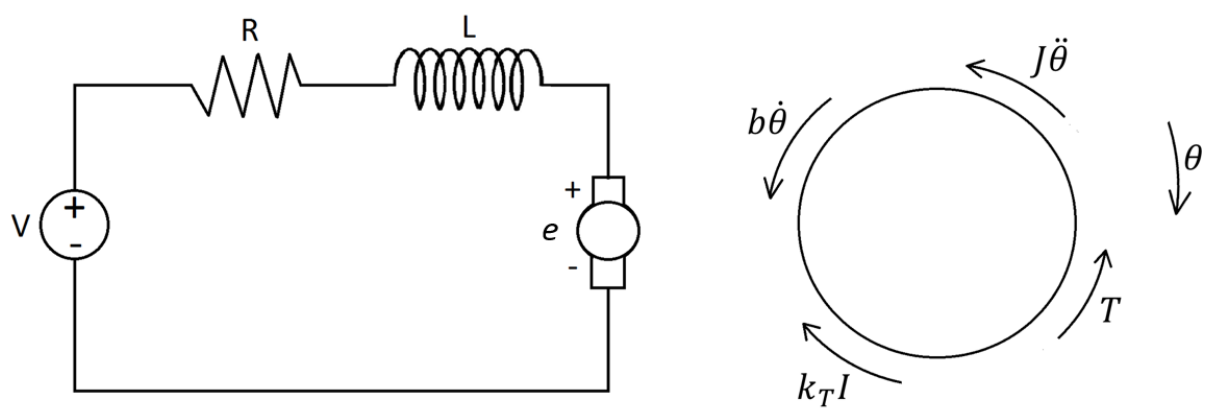

Figure 8. Motor modeling diagrams

The back EMF produced by the motor is proportional to the speed of the motor, where $k_{e}$ is a motor constant.

$$
V_{e m f}=k_{e} \dot{\theta}
$$

Using the Kirchhoff voltage law, the summation of the voltage around the electrical circuit must sum to zero.

$$
V=L \frac{d I}{d t}+R I+k_{e} \dot{\theta}
$$

Next, using the rotational motion diagram in Figure 8, the torques acting on the motor shaft must sum to zero, where $k_{t}$ is the motor torque constant.

$$
J \ddot{\theta}=k_{t} I-b \dot{\theta}-T
$$

This project only focused on steady-state analyses. Therefore, Equations 3 and 4 can be simplified to:

$$
\begin{gathered}
V=R I+k_{e} \dot{\theta} \\
T=k_{t} I-b \dot{\theta}
\end{gathered}
$$

Combining these two equations yields: 


$$
\begin{gathered}
I=\frac{T+b \dot{\theta}}{k_{T}} \\
V=\left(\frac{T+b \dot{\theta}}{k_{T}}\right) * R+k_{b} \dot{\theta}
\end{gathered}
$$

These two equations can be used to calculate the required current and voltage required to drive a motor at a desired speed and torque output. The efficiency for any operating torque and speed can then be calculated as,

$$
\eta_{\text {motor }}=\frac{P_{\text {out }}}{P_{\text {in }}}=\frac{T \dot{\theta}}{V I}=\frac{T \dot{\theta}}{\left(\frac{T+b \dot{\theta}}{k_{T}}\right) *\left[\left(\frac{T+b \dot{\theta}}{k_{T}}\right) R+* k_{b} \dot{\theta}\right]}
$$

Motor model parameters such as winding volume, magnet type and size, stator thickness, and rotor parameters were designed using approximate dimensions similar to commercially available DC motors. Motor performance parameters were derived based on this basic motor geometry.
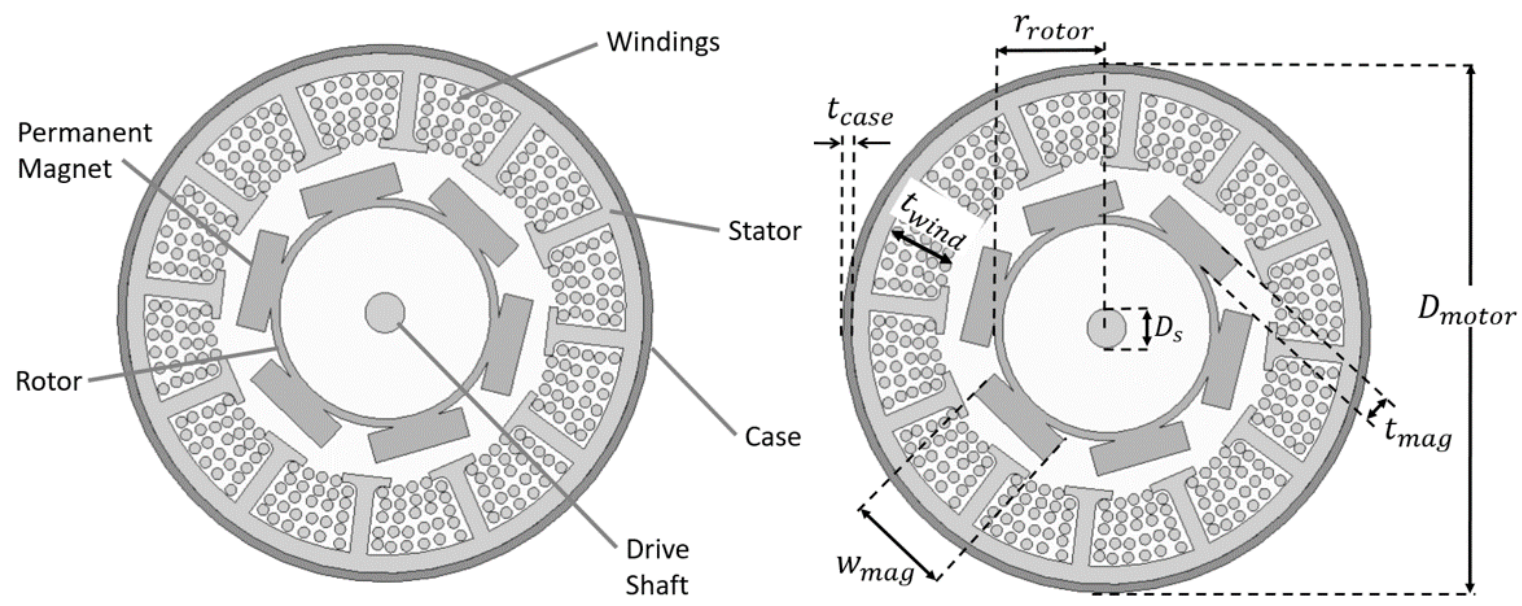

Figure 9. Motor model diagram with key dimensions

The figure above shows they key dimension parameters for the motor model. These parameters could be altered in the computer model. Additionally, each component could be scaled proportionally to be able to analyze a wide range of motor sizes of a particular type of construction. The weight of the motor was calculated by using the motor geometry to find the volume of each component and multiplying this by the density of the material. For example, to calculate the weight of the windings in a motor, the length of winding used was determined as the amount of wire that would fill the defined space of the winding. Then, using a packing factor of 0.8 , the volume of winding was used along with the density of copper to calculate the weight. This was done for all components of the motor, including the shaft, rotor, magnets, case, and stator.

\subsubsection{Motor Model Parameter Calculations}

The purpose of the motor model is to be able to construct any size motor in the range of 50-350 $\mathrm{W}$ and then calculate the performance characteristics of that motor. This was accomplished by 
defining the size of all components such as the magnet size, shaft diameter, and winding volume, as shown in Figure 9. Then, the model was designed to scale every component proportionally so that any size of motor could be defined.

The key motor parameters that define its performance are $R, k_{T}, k_{v}$, and, $b$.

Table 2. Motor performance parameters

\begin{tabular}{cc}
\hline $\begin{array}{c}\text { Motor Performance } \\
\text { Parameter }\end{array}$ & Description \\
\hline $\mathrm{R}$ & Winding/terminal resistance $(\mathrm{ohm})$ \\
$k_{t}$ & Torque constant $\left(\frac{\mathrm{Nm}}{\mathrm{A}}\right)$ \\
$k_{\mathrm{V}}$ & Speed constant $\left(\frac{\mathrm{rad} / \mathrm{sec}}{\mathrm{V}}\right)$ \\
$\mathrm{b}$ & Damping coefficient $(\mathrm{Nm} * \mathrm{sec})$ \\
\hline
\end{tabular}

The winding resistance $R$ is calculated using the following equation:

$$
R=\frac{\rho L}{A}
$$

Where $\rho$ is the resistivity of copper, around $1.68 * 10^{-8} \mathrm{ohm} * \mathrm{~m}$ at room temperature [18]. $L$ is the length of wire for one phase in $\mathrm{m}$ and $A$ is the cross-sectional area in $\mathrm{m}^{2}$. The diameter of the wire could also be adjusted. However, while the diameter of the winding changes the speed-torque characteristics of the motor, it does not significantly change the overall efficiency performance of the motor. At this point, the winding diameter was chosen to be $0.068 \mathrm{~mm}$, which gives the approximate speed-torque characteristics of the Maxon EC-i $48 \mathrm{~V}$ motors.

The next step in calculating the motor parameter $R$ was to determine the cross-sectional area of the winding wire, which can be done using the defined winding diameter:

$$
A=\frac{\pi * D^{2}}{4}
$$

The length of the winding can then be calculated using the key dimensions shown in Figure 9. This length can be calculated by finding the amount of wire that will fit inside of the specified volume for the windings:

$$
\begin{gathered}
L_{\text {total }}=\frac{V_{\text {windings }}}{A} * \text { Packing Factor } \\
V_{\text {windings }}=\frac{\pi *\left(D_{\text {motor }}-2 * T_{\text {case }}\right)}{4}-\frac{\pi *\left(D_{\text {motor }}-2 * T_{\text {case }}-2 * t_{\text {wind }}\right)}{4},
\end{gathered}
$$

It is common for small brushless motors to have 3 phases, therefore the winding resistance for each individual phase would be the total resistance divided by 3 . 


$$
L=\frac{L_{\text {total }}}{3}
$$

A packing factor of 0.8 was used for this calculation, which is an approximate packing factor for bundled wires. By using Equations 10-14, the winding resistance $R$ can be calculated for any size of motor constructed in the computer simulation.

The motor parameter $k_{T}$ is the torque-current proportionality constant. In the absence of any frictional damping the torque produced is proportional to the current supplied to the motor, $I$.

$$
T=k_{T} I
$$

To calculate the value of $k_{T}$, the Lorentz force equation was used.

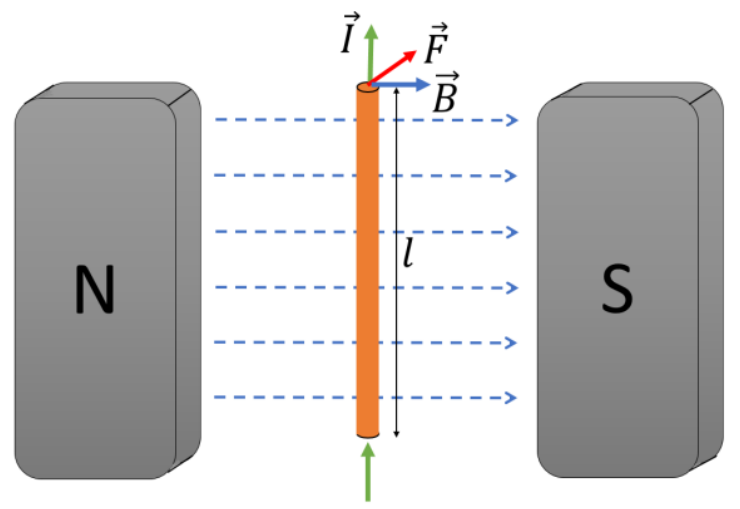

Figure 10. Lorentz force diagram

The force acting on the length of wire is,

$$
\vec{F}=\vec{I} L \times \vec{B}
$$

The wire length $L$ was calculated in Equation 14 above, where this is the winding length per each of the 3 phases.

The magnetic field strength was determined by the following equation, using neodymium magnets with a strength of $1.2 \mathrm{~T}$ [19].

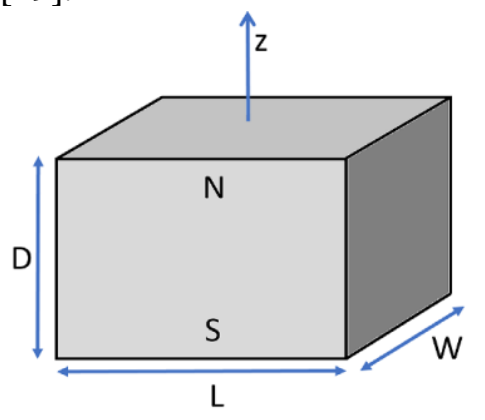

Figure 11. Block magnet dimensions 
The magnetic field strength $B$ at a distance along the z-axis is calculated as follows, where $B_{r}$ is the remanence field, a property of the neodymium field strength [20].

$$
\begin{aligned}
B=\frac{B_{r}}{\pi}[\arctan & \left(\frac{L W}{2 z \sqrt{4 z^{2}+L^{2}+W^{2}}}\right) \\
& \left.-\arctan \left(\frac{L W}{2(D+z) \sqrt{4(D+z)^{2}+L^{2}+W^{2}}}\right)\right]
\end{aligned}
$$

Figure 12 below shows the cross-section of one winding as well as the magnets connected to the motor rotor. As shown, current is running upward (out of the page) on the left side of the winding, and as the current loops around to the right side of the wire it travels downward (into the page). To produce a force that will drive the motor shaft clockwise the two magnets next to each other are flipped, where the north pole is near the windings on the left magnet, and the south pole is near the windings on the right magnet. As explained by the Lorentz force diagram of Figure 10, this will produce the forces directed to the right, as shown in Figure 12.

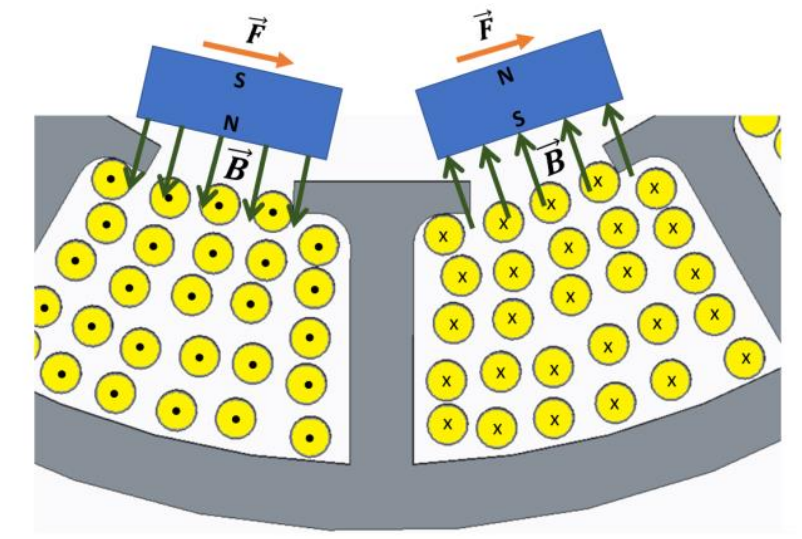

Figure 12. Torque production in DC brushless motor

The torque produced by the motor is equivalent to the Lorentz force generated by the magnetwinding interaction multiplied by the radius of the rotor. The motor parameter $k_{T}$ has units of Nm/A.

$$
T=F_{\text {Lorentz }} * r_{\text {rotor }}
$$

$\mathrm{k}_{t}$ is in units of $\mathrm{Nm} / \mathrm{A}$. The calculation of this parameter assumes that the magnet would be directly in front of the windings on average. Also, the switching of the current direction in the winding would be handled by the motor controller, which would alternate as magnets of alternating polarity pass by each side of one winding. This equation for calculating $k_{t}$ assumes that, on average, one total phase is active at a time. With these assumptions, this motor parameter can be estimated by.

$$
k_{t}=\frac{T}{I}=\frac{F_{\text {Lorentz }} * r_{\text {rotor }}}{I}=\frac{I * L * B * r_{\text {rotor }}}{I}=L * B * r_{\text {rotor }}
$$


The motor constant $k_{v}$ is equivalent to $1 / k_{t}$. Equations $20-21$ show how the units of $\mathrm{Nm} / \mathrm{A}$ are equivalent to $\mathrm{V} /(\mathrm{rad} / \mathrm{sec})$ :

$$
\begin{gathered}
k_{t}=\frac{1}{k_{v}}=k_{e} \\
1 V=1 \frac{\mathrm{kg} * \mathrm{~m}^{2}}{A * \mathrm{~s}^{3}} \\
1 \frac{\mathrm{N} * \mathrm{~m}}{A}=1 \frac{\mathrm{kg} * \mathrm{~m}^{2}}{A * \mathrm{~s}^{2}}=1 \frac{\mathrm{V}}{\mathrm{rad} / \mathrm{sec}}
\end{gathered}
$$

Equation 23 shows how $k_{t}$ is equivalent to $k_{e}$ using the electrical circuit model equations developed earlier:

$$
P_{\text {in }}=V * I=I^{2} * R+I * k_{e} \dot{\theta}
$$

The mechanical power out is,

$$
P_{\text {out }}=T * \dot{\theta}=k_{t} I * \dot{\theta}
$$

The input electrical power must be equivalent to the output power plus the winding losses.

$$
P_{\text {in }}=P_{\text {out }}+I^{2} R
$$

This relationship shown in Equation 25 holds true only if $k_{t}=k_{e}$, showing that these motor parameters are in fact equivalent.

The final motor performance characteristic, $b$, viscous damping will be outlined in the following section discussing motor losses.

\subsubsection{Motor Losses}

Primary losses in the motor include winding losses due to the resistance of the copper winding, mechanical losses such as bearing friction, and iron losses due to such phenomena as eddy currents [20]. The motor model incorporates these losses.

The two main types of losses in a brushless DC motor are known as the load and no-load losses. Load losses are dependent on the torque load on the motor and no-load losses are generally dependent on the speed of the motor. 


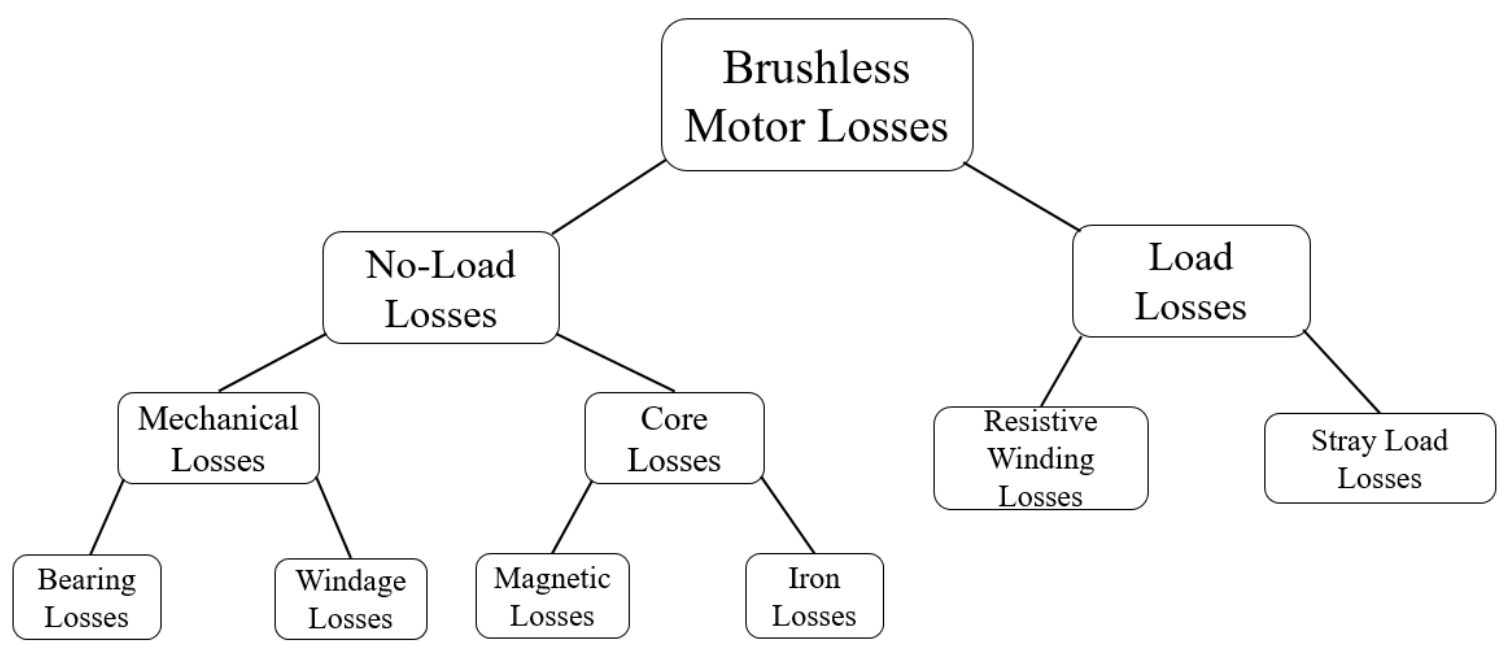

Figure 13. BLDC motor power loss overview

The dominant part of the load losses are the resistive winding losses.

$$
P_{w}=I^{2} R
$$

The no-load losses that contribute to the viscous damping coefficient $b$ are factors such as eddy current losses, bearing losses, and magnetic hysteresis losses. The following Equations 27-30 outline various no-load losses that contribute to the viscous damping parameter, $b$ [20]. Eddy currents are small circulating currents created when the magnetic flux changes through conductive core components of the motor as well as in the permanent magnets themselves. The power loss associated with the heating caused by these currents is,

$$
P_{c}=\frac{\pi^{2}}{6} V_{c} B^{2} f^{2} a^{2} \sigma
$$

where $V c$ is the volume of magnetic core in $\mathrm{m}^{3}, B$ is the peak flux density, $f$ is the frequency of magnetization, $\sigma$ is the electrical conductivity, and $a$ is the lamination thickness in $\mathrm{m}$.

The bearing losses in a motor can be represented by the following equations:

$$
\begin{array}{cc}
T_{V}=10^{-7} f_{0}\left(v_{0} n\right)^{2 / 3} D_{m}^{3} & v_{0} n \geq 2000 \\
T_{V}=160 * 10^{-7} f_{0} D_{m}^{3} & v_{0} n \leq 2000
\end{array}
$$

Where $T v$ is the torque losses in $\mathrm{Nm}, f_{0}$ is the bearing type factor, $V_{0}$ is the kinematic viscosity of lubricant in centistokes, $n$ is the bearing rotation speed in rpm, and $D m$ is the mean diameter of bearing in $\mathrm{m}$.

Magnetic hysteresis losses are caused by the change in magnetic field in a ferromagnetic material that causes the magnetic particles in the material to align and change directions, aligning with the changing magnetic field, thus causing friction and heat. The following equation represents these losses, 


$$
P_{h}=K_{h} V_{C} B^{n} f
$$

where $K_{h}$ is the hysteresis coefficient, $n$ is the Steinmetz coefficient, $f$ is the frequency of magnetization, $V_{c}$ is the volume of magnet in $\mathrm{m}^{3}$, and $B$ is the magnetic field strength.

These losses (Equations 27-29) can be summed to estimate the power losses due to the viscous damping present in the motor. However, there are several factors that would have to be estimated using these equations such as the hysteresis coefficient, bearing type factor, lamination thickness, etc. Therefore, to make an estimate of the viscous damping coefficient, $b$, these equations were not used directly. Instead, several viscous damping coefficients from commercially available motors from Micromo were compared as shown in Figure 14, and a best-fit line was used to extract an equation to estimate viscous damping as a function of the size of the motor.

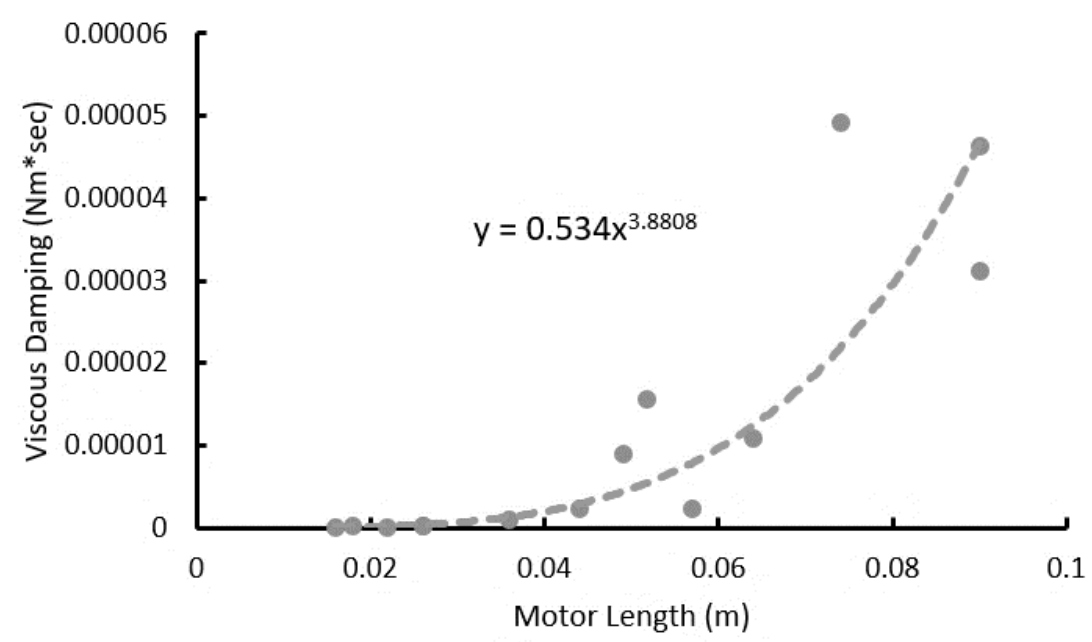

Figure 14. Viscous damping of motors (Micromo motors)

The viscous damping as a function of the motor height is as follows:

$$
b=0.534 h^{3.88}
$$

This equation was used in the motor model to determine the viscous damping coefficient for any size of motor. This form of equation was used since it provided the best fit, with an $\mathrm{R}^{2}$ value of 0.93 , which was higher than using exponential, linear, logarithmic, polynomial, or moving average fits.

Using these equations developed in the previous sections, motor performance coefficients of $k_{t}$, $k_{v}, R$, and $b$ could be calculated for any size motor in the range of 50-350 W.

\subsubsection{Heat Transfer Model and Power Ratings}

Motors are assigned a power rating at which they must be operated below to ensure overheating does not occur. The heat generated in a motor is due to the inefficiencies as previously outlined. Often, the motor windings and winding insulation material are the components that overheat first. For most Maxon motors, the maximum winding temperature is $155^{\circ} \mathrm{C}$. Therefore, in the motor model, a maximum winding temperature of $155^{\circ} \mathrm{C}$ was set, and the maximum power rating for a particular size motor was calculated by iteratively increasing the load applied to a motor until the 
winding temperature reached this maximum value. The diagram in Figure 15 shows the basics of heat production in a motor.

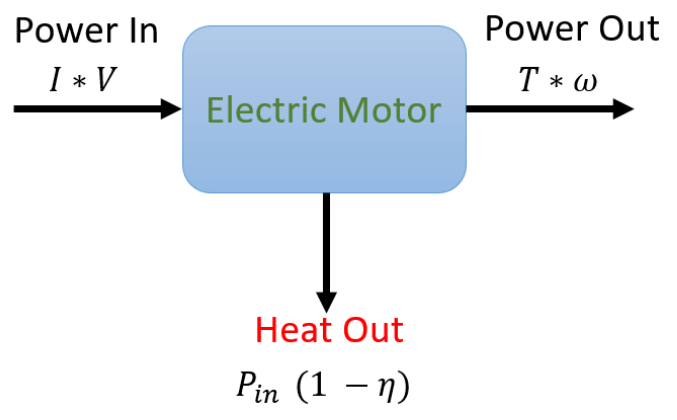

Figure 15. Heat production in an electric motor

It was assumed that all of the heat produced from inefficiencies originates from the windings and travels to the surrounding environment through the motor housing as shown in the heat-flow diagram in Figure 16.

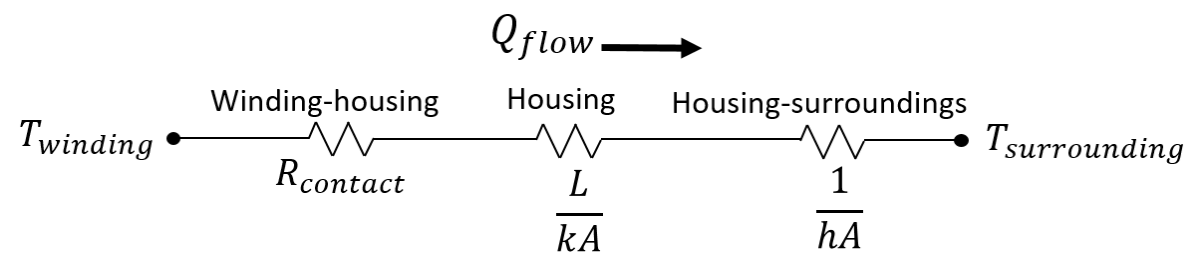

Figure 16. Electric motor heat transfer model

This set of thermal resistances are in series, so the total resistance is equal to the summation of each:

$$
R_{\text {total }}=R_{\text {contact }}+R_{\text {conduction }}+R_{\text {convection }}
$$

The contact resistance in a motor property that is a function of the winding diameter as well as winding insulation and construction techniques. Therefore, to estimate the contact resistance as a function of the motor size, the data in Figure 17 was taken from the data sheets of several Maxon motors: 


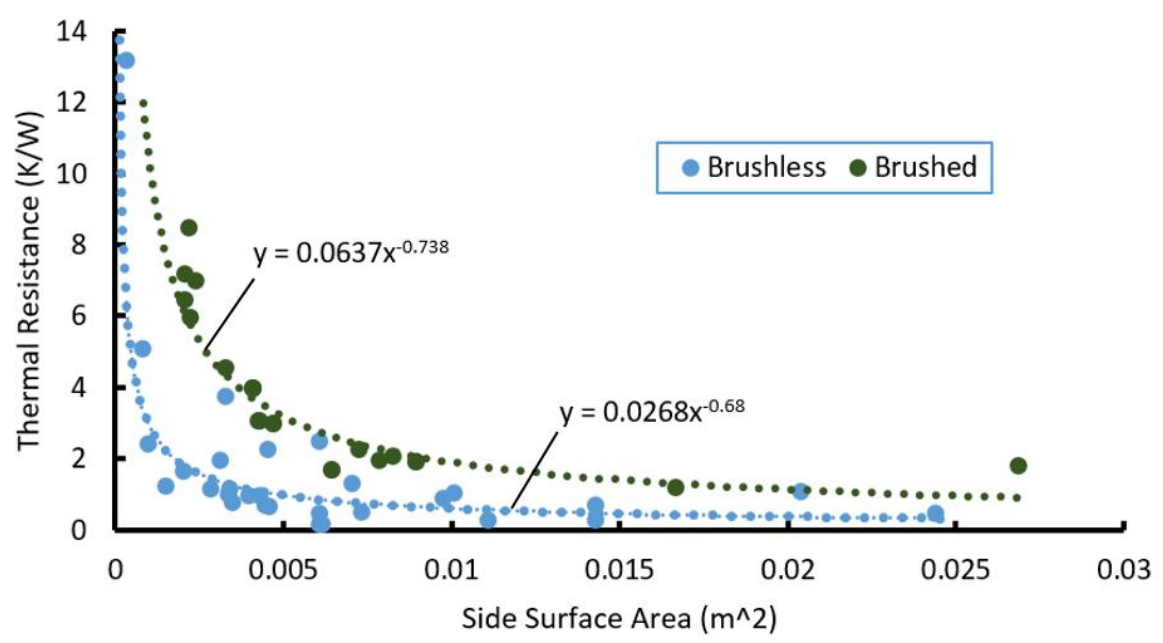

Figure 17. Winding-Case contact resistance as a function of motor surface area (Maxon motors)

From the data shown in the Figure 17 plot, a best-fit line was used to get the following equation relating motor surface area to contact resistance, this form of fit resulted in the highest $\mathrm{R}^{2}$ value when compared to all other forms of fit within Excel.

$$
R_{\text {contact }}=0.0268 * A^{-0.68}
$$

Also, as shown by Figure 17, the winding-case thermal resistance is lower for brushless versus brushed motors. This is because in brushed motors, the windings are in the center of the motor, whereas with brushless motors, the windings are in the outer region, just inside of the casing. This is what allows brushless motors to have higher power-densities than brushed motors.

The heat transfer model was developed primarily using standard heat transfer equations [21]. The equation for the conduction resistance is:

$$
R_{\text {conduction }}=\frac{L}{k A}
$$

where $L$ is the thickness of the motor case, $A$ is the total surface area of the case, and $k$ is the conduction coefficient for steel, $60 \mathrm{~W} / \mathrm{m} * \mathrm{~K}$ [21].

The equation for the convective heat transfer from the outer surface of the motor case is:

$$
R_{\text {convection }}=\frac{1}{h A}
$$

To get an approximation of the convective heat transfer coefficient, $h$, for natural convection, the following equations were used to approximate for laminar flow over a vertical plate. For a motor of height $0.15 \mathrm{~m}$ and a surface temperature of $100^{\circ} \mathrm{C}$ the Rayleigh number is:

$$
R a_{L}=\frac{g \beta\left(T_{s}-T_{\infty}\right) L^{3}}{\alpha v}=\frac{9.81 \frac{m}{s^{2}} * 0.00275 K^{-1} *(373-298) K *(0.08 m)^{3}}{\left(29.9 * 10^{-6} \frac{m^{2}}{s}\right) *\left(20.92 * 10^{-6} \frac{m}{s^{2}}\right)}=1.66 * 10^{6}
$$




$$
\begin{gathered}
\overline{N u_{L}}=0.68+\frac{0.670 R a_{L}^{\frac{1}{4}}}{\left[1+(0.492 / \mathrm{Pr})^{\frac{9}{16}}\right]^{\frac{4}{9}}}=0.68+\frac{0.670 *\left(1.66 * 10^{6}\right)_{L}^{\frac{1}{4}}}{\left[1+(0.492 / 0.700)^{\frac{9}{16}}\right]^{\frac{4}{9}}} \\
=19.1 \\
h=\frac{\overline{N u_{L}} * k}{L}=\frac{19.1 *\left(30 * 10^{-3}\right) \frac{W}{m * K}}{0.08 m}=7.2 \frac{W}{m^{2} * K}
\end{gathered}
$$

This is the approximate value used for the motor heat transfer model. Small changes to the setup conditions could affect this value such as the orientation of the motor being vertical or horizontal. So, this value may range from $5-15 \mathrm{~W} / \mathrm{m}^{\wedge} 2 * \mathrm{~K}$, depending on the exact setup of the motor and the environment it is operated in.

The total heat generated inside of the motor was assumed to be originating within or near the windings, so all the heat generated due to inefficiencies is assumed to flow from the windings to the external environment as outlined in Figure 16. Additionally, the winding resistance losses are often higher than the other no-load losses, so this approximation should be valid. The heat generated in the motor is:

$$
\dot{Q}=\left(1-\eta_{\text {motor }}\right) *(V * I)
$$

where $\dot{Q}$ is the rate of heat generated, $\eta$ is the overall motor efficiency, $V$ is the applied voltage and $I$ is the applied current. Next, to calculate the temperature of the windings Equations 40-41 were used.

$$
\begin{gathered}
\dot{Q}=\frac{\Delta T}{R_{\text {total }}}=\frac{T_{\text {winding }}-T_{\text {air }}}{R_{\text {total }}} \\
T_{\text {winding }}=\dot{Q} * R_{\text {total }}+T_{\text {air }}
\end{gathered}
$$

These heat transfer equations were used in the motor model to calculate the operational temperature of a motor's winding for a given torque and speed output. This allowed for the calculation of the maximum power ratings for a range of motor sizes.

\subsubsection{Pump Model}

The axial-piston pump model was adapted from an existing model by Jeong [22]. This model was modified to more closely model miniature axial-piston pumps, such as the Takako $0.4 \mathrm{cc} / \mathrm{rev}$ and Oildyne $0.17 \mathrm{cc} / \mathrm{rev}$ axial-piston pumps, which have simpler features compared to larger-scale pumps. Figure 18 shows the main pump components and key dimensions are defined in Table 3. 

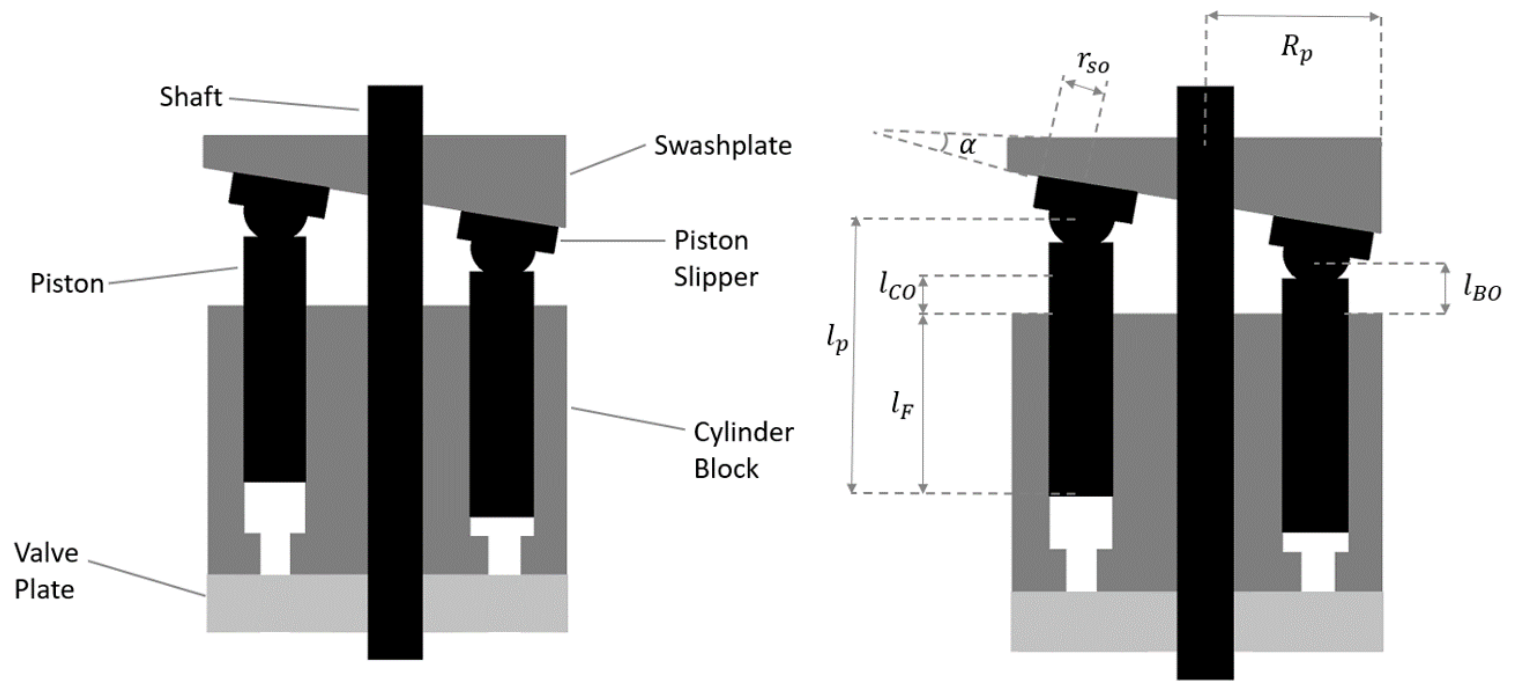

Figure 18. Axial-piston pump model dimensions

Table 3. Axial-piston pump key dimension parameters

\begin{tabular}{cl}
\hline$\alpha$ & swashplate angle \\
$d_{p}$ & piston diameter \\
$h_{p}$ & piston-cylinder wall gap \\
$h_{s}$ & slipper-swashplate gap \\
$h_{v}$ & valve plate-cylinder block gap \\
$l_{p}$ & piston length \\
$\mu$ & fluid dynamic viscosity \\
$P$ & pressure \\
$R_{p}$ & pitch radius \\
$w$ & shaft speed \\
$Z$ & number of pistons \\
$r_{s o}$ & radius of slipper \\
\hline
\end{tabular}

The area of one piston is: 


$$
A_{p}=\frac{\pi * d_{p}^{2}}{4}
$$

and the displacement that a single piston makes with one revolution of the pump is:

$$
V_{P \max }=\frac{A_{p} * R_{p} * \tan \alpha * \pi}{\sin \left(\frac{\pi}{2 z}\right)}
$$

Further dimensional calculations of the pump are shown in Appendix A.

The two types of losses in a hydraulic pump are mechanical and volumetric. The mechanical losses are due to friction caused by moving parts as well as viscous losses associated with the flowing fluid inside of the pump. Volumetric losses are due to leakage in the small gaps between moving components of the pump. The mechanical losses are usually more significant than volumetric losses. An outline of these losses is shown in Figure 19.

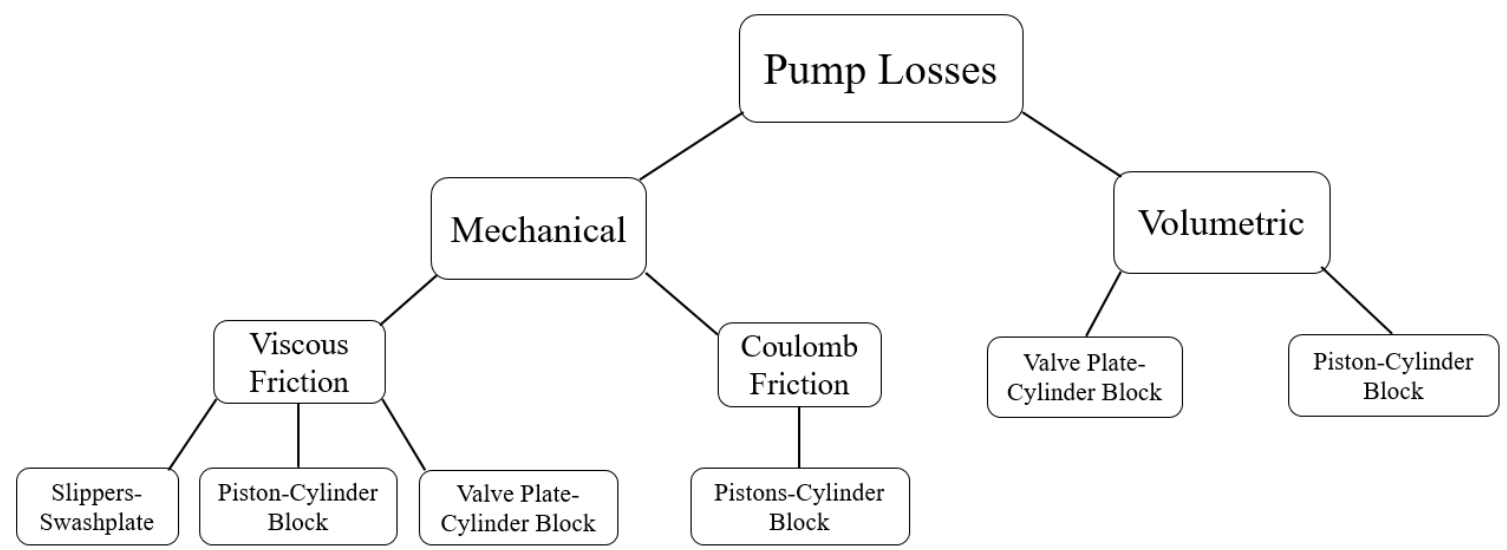

Figure 19. Axial-piston pump loss outline

\subsubsection{Pump Mechanical Losses}

The torque required to drive the pump without considering any friction losses can be written as

$$
T_{p p}=\frac{P * A_{p} * R_{p} * \tan \alpha * Z}{\pi}
$$

Viscous friction between the pistons and cylinder blocks causes an average torque loss as follows:

$$
\begin{gathered}
T_{\text {lup }}=\frac{\mu * \pi * d_{p} *\left(R_{p} * \tan \alpha\right)^{2} *\left(l_{F}+R_{p} * \tan \alpha\right) * w * Z}{2 * h_{p}} \\
+\frac{d_{p} * h_{p} * R_{p} * \tan \alpha * P * Z}{2}
\end{gathered}
$$

The torque loss due to Coulomb friction between the pistons and cylinder block is shown below:

$$
T_{l f p}=\left[\frac{B}{b}+\frac{A * b-a * B}{b * \sqrt{a^{2}-b^{2}}}\right] c * A_{p} * P * R_{p} * \tan \alpha * \frac{z}{\pi}
$$


Where $A, B, a$, and $b$ are defined as:

$$
\begin{gathered}
A=f_{p} * \tan \alpha *\left(l_{p}+l_{C O}-f_{p} * d_{p}\right) \\
B=f_{p} * \tan \alpha * l_{B O} \\
a=l_{p}-l_{C O}-f_{p} * \tan \alpha *\left(l_{p}+l_{C O}-f_{p} * d_{p}\right) \\
b=-\left(1+f_{p} * \tan \alpha\right) * l_{B O}
\end{gathered}
$$

The torque loss due to the viscous friction between the slippers and swashplate can be approximated with the following equation:

$$
T_{l s}=\frac{Z * \mu * w * R_{p} * \pi * r_{s o}^{2} * R_{p}}{h_{s}}
$$

The torque loss due to the viscous friction loss between the valve plate and cylinder block is as follows:

$$
T_{l v}=\frac{\mu * \pi * w *\left(r_{v 4}^{4}-r_{v 3}^{4}+r_{v 2}^{4}-r_{v 1}^{4}\right)}{2 * h_{v}}
$$

The mechanical efficiency is defined as follows:

$$
\eta_{m}=\frac{T_{p p}}{T_{p p}+T_{l u p}+T_{l f p}+T_{l s}+T_{l v}}
$$

\subsubsection{Pump Volumetric Losses}

The displacement per revolution of the pump with no leakage is as follows:

$$
Q_{v p}=w * A_{p} * R_{p} * \tan \alpha * \frac{z}{\pi}
$$

The leakage past the piston-cylinder block gap is:

$$
\begin{array}{r}
Q_{l p}=\frac{\pi * d_{p} * h_{p}^{3} * z * P}{24 * \mu * \sqrt{\left(l_{F}+R_{p} * \tan \alpha\right)^{2}-\left(R_{p} * \tan \alpha\right)^{2}}} \\
+\frac{d_{p} * h_{p} * w * R_{p} * \tan \alpha * z}{2}
\end{array}
$$

The leakage between the gap between the valve plate and cylinder block is:

$$
Q_{l v}=\frac{h_{v}^{3} * \lambda_{v} * Z * P}{24 * \mu * l_{v}}+\frac{h_{v} *\left(b_{v 1}+b_{v 2}\right) * R_{p} * w * Z}{4}
$$

The volumetric efficiency is as follows: 


$$
\eta_{v}=\frac{Q_{v p}-Q_{l p}-Q_{l v}}{Q_{v p}}
$$

The overall pump efficiency can be calculated by combining the mechanical and volumetric efficiencies:

$$
\eta=\eta_{v} * \eta_{m}
$$

The pump model was designed to be able to scale in size. In addition to overall size, individual component parameters such as the swashplate angle and piston dimensions could be varied. As with the motor model, the weight of the pump model was calculated by using the component dimensions to calculate the volume, and then multiplying the volume by the density of the material of that part.

\subsection{Component Model Validation}

\subsubsection{Motor Model Validation}

The brushless DC motor model was validated by comparing its output to catalog data for commercially available motors. A motor's power rating is the maximum power that a motor can operate at continuously without overheating, as shown by Figure 20 right. Figure 20 left shows the peak efficiency for a range of motor sizes compared to commercially available motors.
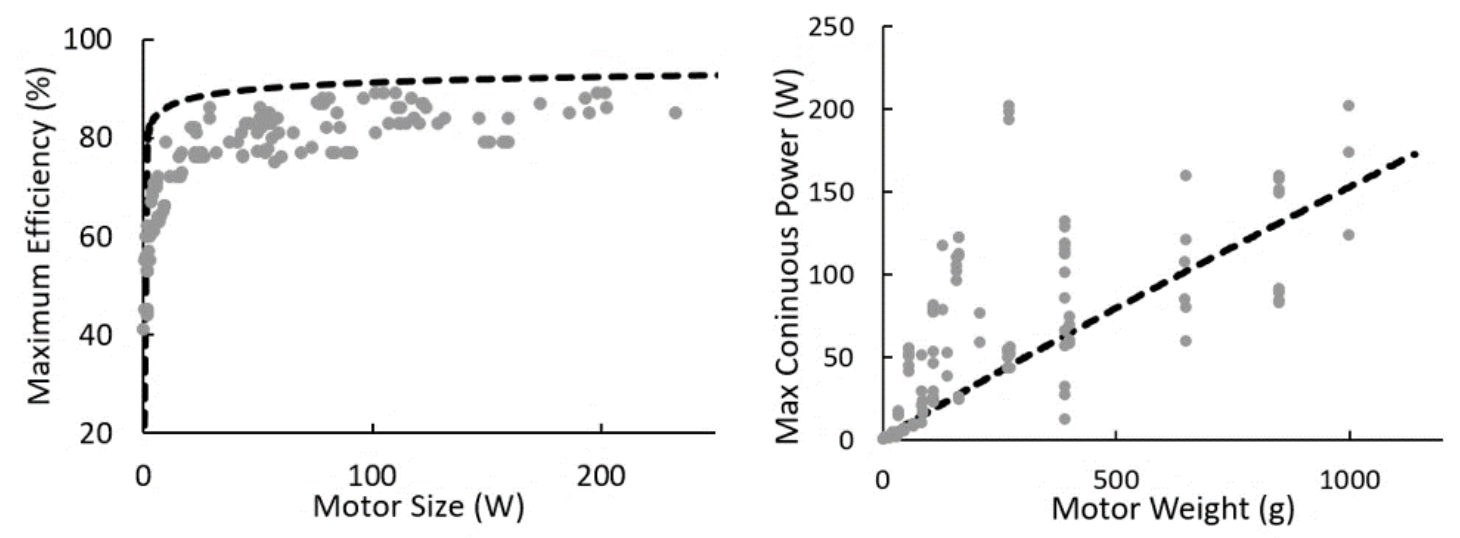

Figure 20. Motor model validation, data points from Maxon and Micromo catalog data, dashed line from model output

The motor model approximated the catalog data. The model's power-weight ratio prediction is about in the middle of the Maxon and Micromo motors. The maximum efficiency of the motor model is near the upper range of the catalog data.

The motor model was also validated by comparing the maximum operation ranges of the computational model to three of the Maxon EC-i motors: 70, 100, and $180 \mathrm{~W}$. The model data for this comparison was created by first determining the weight of the motor in the model that was rated for maximum power outputs of each 70,100 , and $180 \mathrm{~W}$. Then at each given torque, the motor model was operated at a higher and higher voltage (or speed) until the simulated temperature of the windings reached a maximum of $155^{\circ} \mathrm{C}$. Any operating condition underneath the curve 
would be allowable as a continuous operating condition. Any continuous operation outside of this curve would result in overheating of the motor.

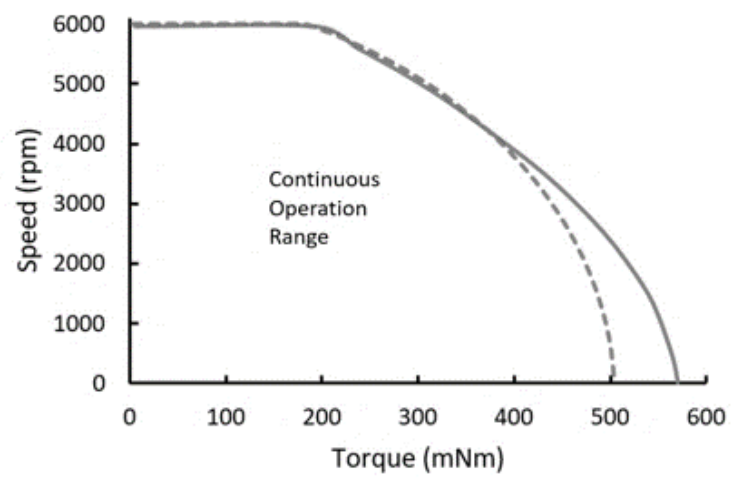

(a)

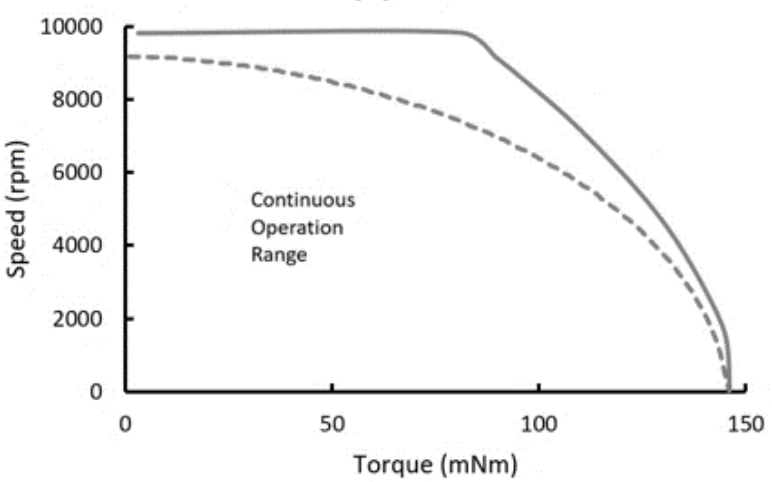

(c)

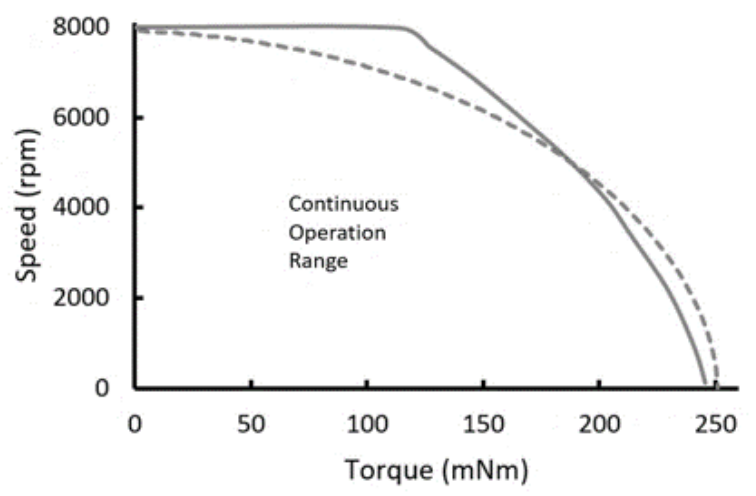

(b)

Figure 21. Continuous operation range limits, Maxon EC-i $70 \mathrm{~W}$ (a), $100 \mathrm{~W}$ (b), and $180 \mathrm{~W}$ (c) motors, model data (dashed lines), Maxon catalog data (solid lines)

The computational motor model was compared to the Maxon EC-i $100 \mathrm{~W}, 48 \mathrm{~V}$ motor's speedtorque characteristics. A $100 \mathrm{~W}$ sized motor was built with the model, and then the winding diameter was adjusted until similar motor characteristics as the Maxon motor were achieved, approximately $0.68 \mathrm{~mm}$. The plot in Figure 22 shows both the catalog data for the Maxon motor's speed torque characteristics as well as the motor model characteristics at 3 different applied voltages. 


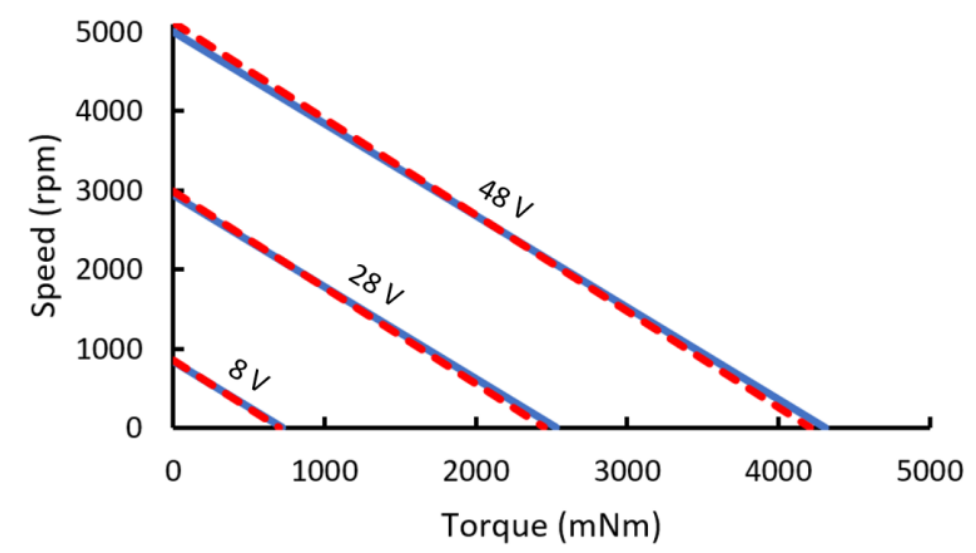

Figure 22. Maxon EC-i $100 \mathrm{~W}$ motor, catalog spec. performance (solid line), model data (dashed line)

Also, the motor parameters of $k_{t}, k_{b}$, and $R$ and weight were compared to ensure the model was producing reasonable results. The following table compares the motor performance parameters of the model to the EC-i $100 \mathrm{~W}$ motor. As in Figure 22, the winding diameter of the model was chosen to be $0.68 \mathrm{~mm}$, which resulted in close matching of motor parameters.

Table 4. Motor model validation, performance parameter comparison

\begin{tabular}{ccc}
\hline $\begin{array}{c}\text { Motor Performance } \\
\text { Parameter }\end{array}$ & Maxon Motor & Model \\
\hline $\mathrm{R}(\mathrm{ohm})$ & 1.01 & 0.94 \\
$k_{t}\left(\frac{\mathrm{Nm}}{\mathrm{A}}\right)$ & 0.091 & 0.092 \\
$k_{\mathrm{v}}\left(\frac{\mathrm{rad} / \mathrm{sec}}{\mathrm{V}}\right)$ & 10.99 & 10.87 \\
Weight $(\mathrm{g})$ & 390 & 532 \\
\hline
\end{tabular}

The weight of the model is higher than the Maxon motor. However, as shown by Figure 20, the model power-weight ratio was in the middle of the commercial motors, and the Maxon EC-i $100 \mathrm{~W}$ motor has a higher than average power-weight ratio.

\subsubsection{Pump Model Validation}

There are only a few commercially available axial-piston pumps in the size range considered in this project. Therefore, unlike the motor model validation, where many commercial motors were compared, the pump model was validated by comparing its performance to three pumps, the Takako miniature axial-piston pumps $(0.4,0.8$, and $1.6 \mathrm{cc} / \mathrm{rev})$. Figure 23 shows the mechanical and volumetric efficiencies as well as the required input torque for the $0.4-1.6 \mathrm{cc} / \mathrm{rev}$ pump driven at a constant $200 \mathrm{rad} / \mathrm{sec}$ speed and varying pressures with VG32 oil. Most of the dimensions for the three Takako pumps were measured and input to the pump model, and the output of this model compared to the catalog data for each pump is shown in Figure 23. The measured dimensions are listed in Appendix B. 


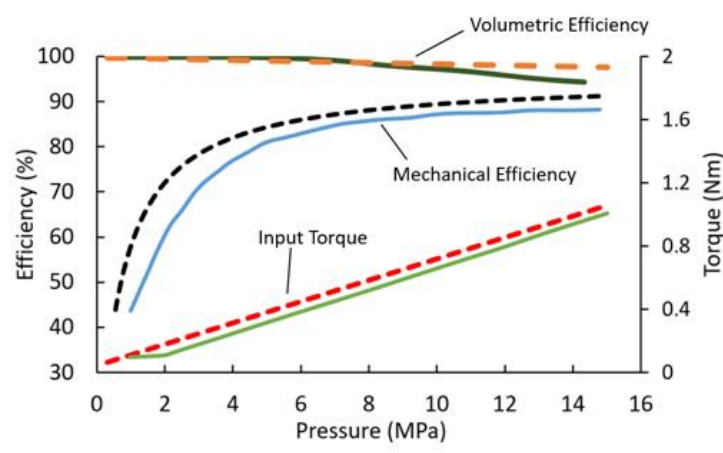

(a)

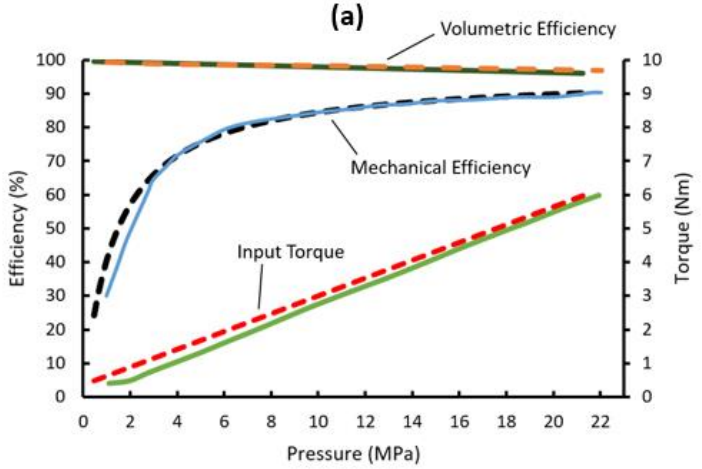

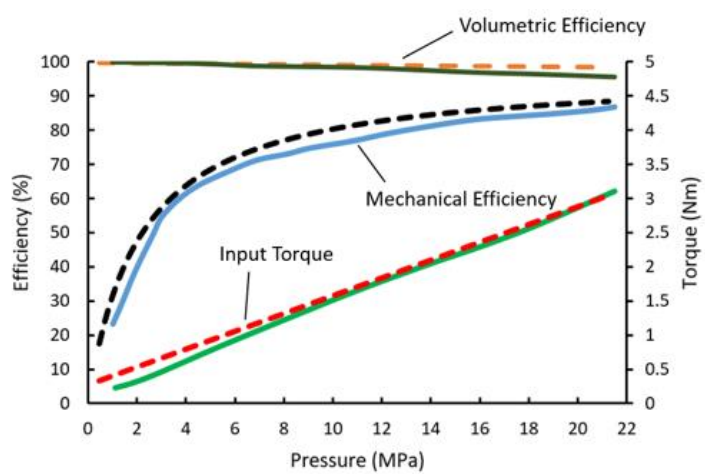

(b)

(c)

Figure 23. Takako pump validation, model data (dashed lines), measured data from Takako catalog (solid lines), $0.4 \mathrm{cc} / \mathrm{rev}(\mathrm{a}), 0.8 \mathrm{cc} / \mathrm{rev}$ (b), $1.6 \mathrm{cc} / \mathrm{rev}$ (c)

The component parameters that could not be measured were the three clearance gaps including the piston-cylinder block gap, slipper-swashplate gap, and valve plate-cylinder block gap. Values for these clearance gaps were known to be between 1 and 10 microns. The model was run and compared to the Takako catalog data. Iterations were made to the clearance gap values until the volumetric efficiency approximately matched the catalog data. The clearance gaps were assumed to be the same for all three gaps and these values were determined to be 4 microns for the 0.4 and $0.8 \mathrm{cc} / \mathrm{rev}$ and 6 microns for the $1.6 \mathrm{cc} / \mathrm{rev}$ pump.

The energy density and efficiency of hydraulics tend to increase with pressure [23-24]. Therefore, most of the analyses performed using this model were for pressures exceeding $3 \mathrm{MPa}$ since it was assumed that that the potential applications would utilize high pressures, such as with the ankle-foot orthosis, which required a maximum peak pressure of $12 \mathrm{MPa}$.

After each component model was validated, a combined system model was created. This combined model was used to explore a range of component parameters to aid in the development of guidelines and principles related to the overall design of a portable hydraulic power supply.

\subsection{Test Stand Validation}

A test stand was constructed to validate the performance of the total system model and to demonstrate how the computer model can be used to aid in the component selection process for the design of a low-weight, wearable power supply. 


\subsubsection{Test Stand Apparatus}

The test stand consisted of a brushless DC motor directly coupled to an axial-piston pump. Figure 24 shows a CAD rendering of the setup.

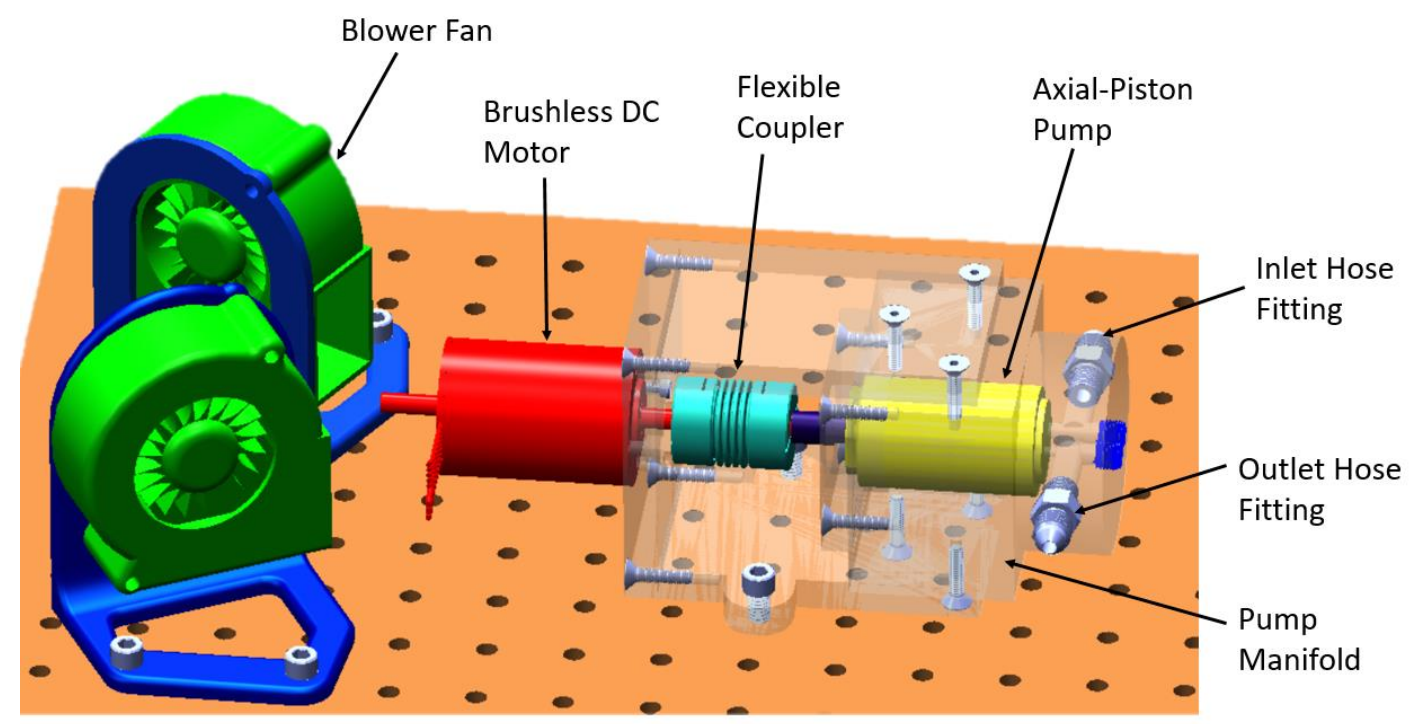

Figure 24. Test stand set-up

The design of the test stand allowed for a range of pump and motor sizes to be interchanged. The motors used were Maxon EC-i brushless DC motors, with power ratings of 70, 100, and 180 W. The pumps used were Parker-Oildyne 3-piston cartridge axial-piston pumps with varying swashplate angles of $5.23^{\circ}, 7.65^{\circ}, 10.05^{\circ}(0.17,0.25,0.33 \mathrm{cc} / \mathrm{rev})$. Figure 25 illustrates the 9 possible power supply combinations that could be analyzed in the test stand.

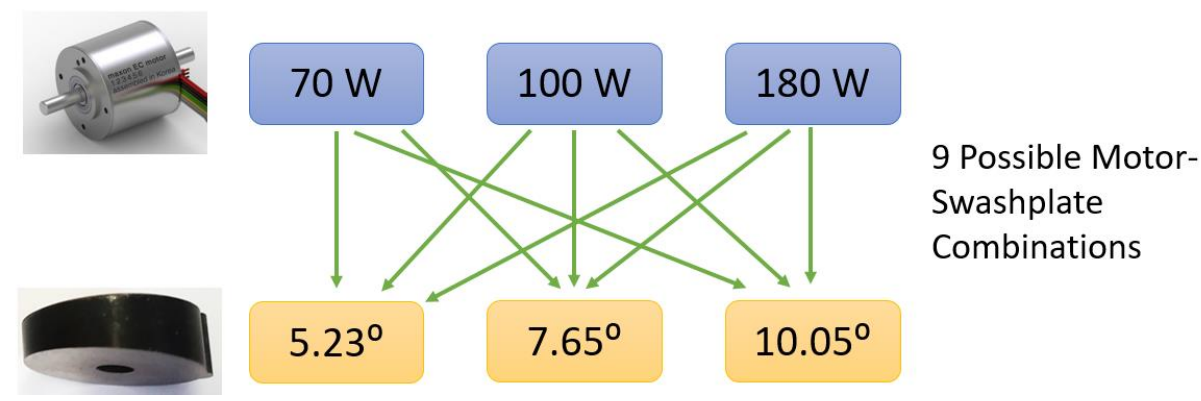

Figure 25. Possible combinations for power supply setup

Figure 27 below shows the inner components of the Oildyne, 3-piston pumps used. The 3 models with varying swashplate angles were identical except for the different swashplate angles. 

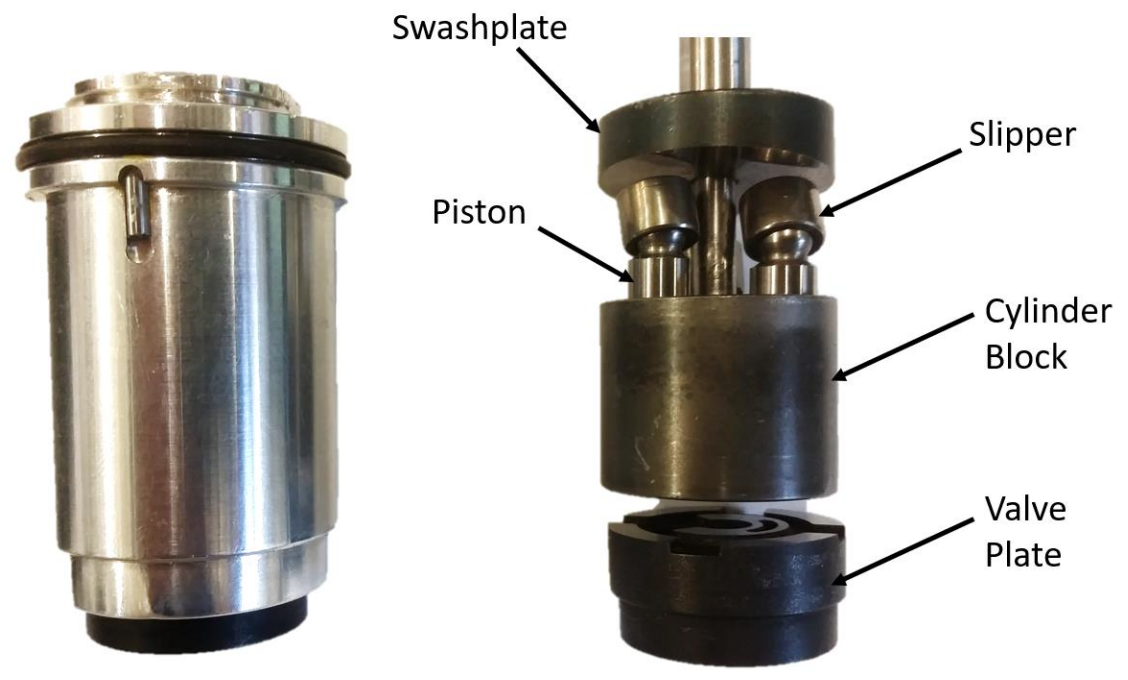

Figure 27. Oildyne cartridge, 3-piston, axial-piston pump

A DC power supply was used to provide power to a Maxon ESCON 50/4 motor controller. This power supply provided a constant $48.2 \mathrm{~V}$ at a load $10 \mathrm{~A}$.

A needle valve was used to regulate the pressure of the system. The Maxon motor controller has a closed loop speed control function that was used to regulate a desired motor speed and thus a desired flowrate. The needle valve was tightened to a particular position at a given motor speed until the desired load pressure was reached. The hydraulic circuit for this setup is below in Figure 28.

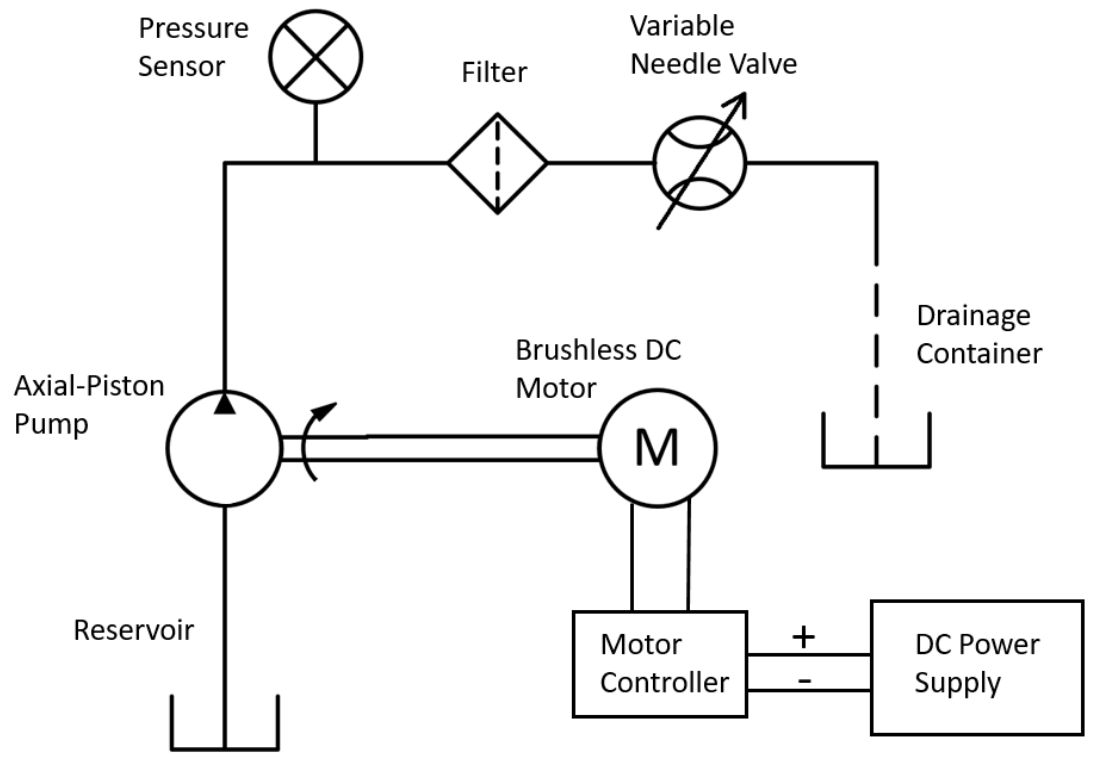

Figure 28. Test stand hydraulic circuit + electric motor circuit

The voltage and current coming from the DC power supply were measured to determine the power input to the system. 


$$
P_{\text {in }}=V * I
$$

The output power was calculated by measuring the output pressure with a pressure transducer (Omega 0-2000 psi), and the output flowrate was determined by using the motor model to find the required rotational speed of the pump and using the closed-loop speed control on the motor controller to set the desired speed.

$$
\begin{gathered}
P_{\text {out }}=P * Q \\
\eta_{\text {total }}=\frac{P_{\text {out }}}{P_{\text {in }}}=\frac{V I}{P Q}
\end{gathered}
$$

The weight of the battery required to run the system for the designed runtime was calculated as follows:

$$
W_{\text {battery }}=\frac{P_{\text {in }} * \text { run time }(\text { hrs. })}{148 \mathrm{Wh} / \mathrm{kg}}
$$

Then, the total weight of the system was calculated by summing the motor, pump, and modelbased battery weight.

$$
W_{\text {total }}=W_{\text {pump }}+W_{\text {motor }}+W_{\text {battery }}
$$

The simulation was used to determine what combination of motor size and pump swashplate angle would result in the lowest system weight for various pressure, flowrate, and runtime conditions.

\section{RESULTS}

\subsection{Integrated Model Validation Test Stand Results}

Figures 29-36 show the simulation and experimental results of the overall system weight for a range of motor sizes and swashplate angles. Appendix D shows the data collected from the experiments. The plots shown for the experimental results are created with these 9 data points, and a linear interpolation and averaging function in MATLAB was used to smooth out the plots. Each figure demonstrates a different operating pressure, flowrate, and runtime. 

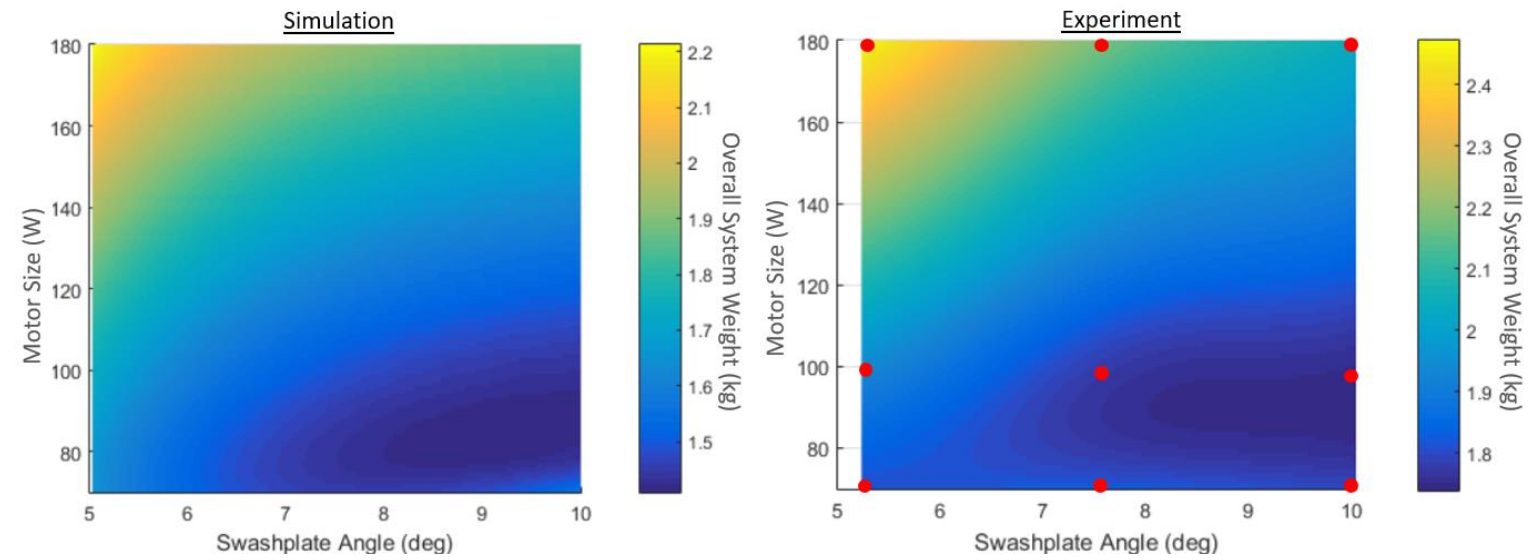

Figure 29. $3.5 \mathrm{MPa}, 10 \mathrm{cc} / \mathrm{sec}, 2 \mathrm{hr}$ runtime, 9 red dots show 9 motor-swashplate combinations
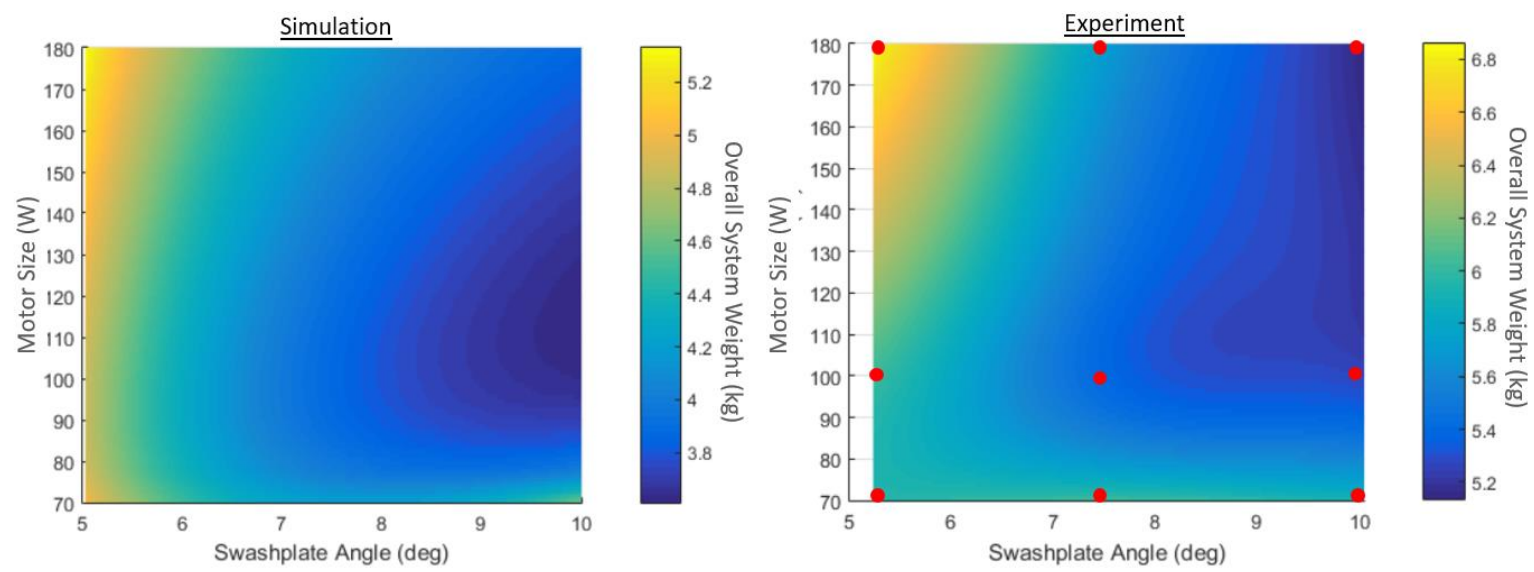

Figure 30. 3.5 MPa, $10 \mathrm{cc} / \mathrm{sec}, 8 \mathrm{hr}$ runtime
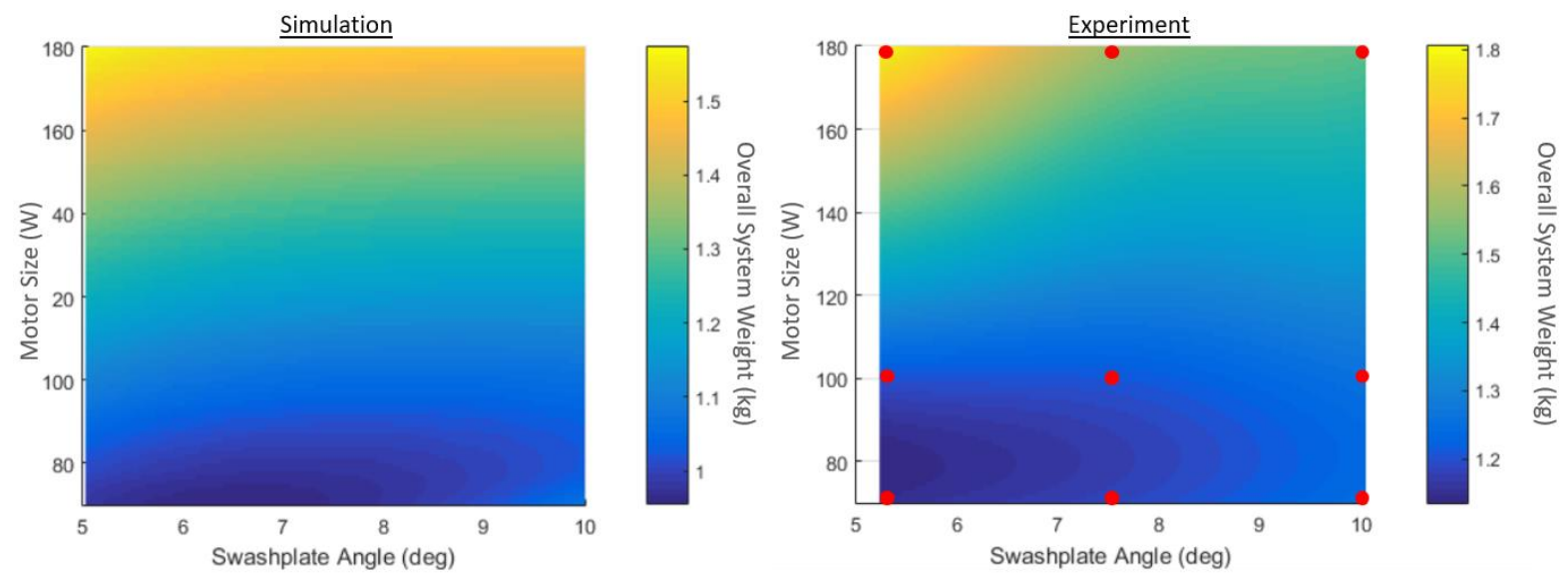

Figure 31. 3.5 MPa, $5 \mathrm{cc} / \mathrm{sec}, 2 \mathrm{hr}$ runtime 

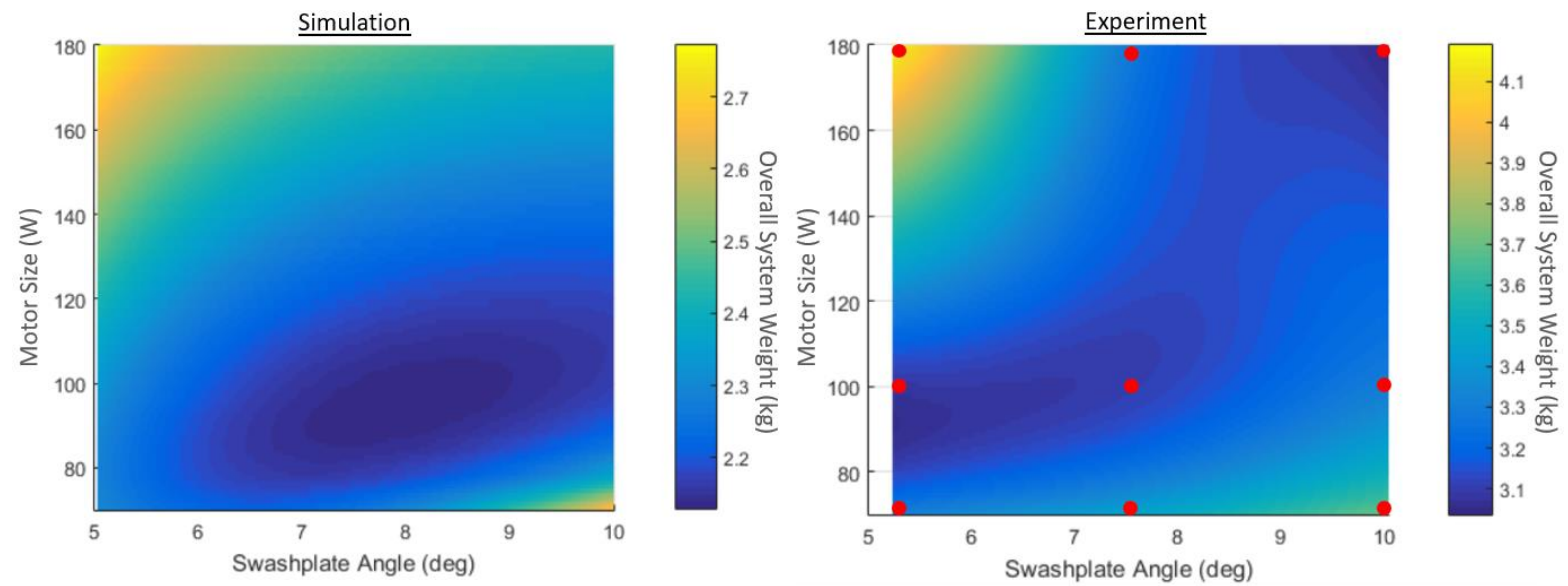

Figure 32. $3.5 \mathrm{MPa}, 5 \mathrm{cc} / \mathrm{sec}, 8 \mathrm{hr}$ runtime
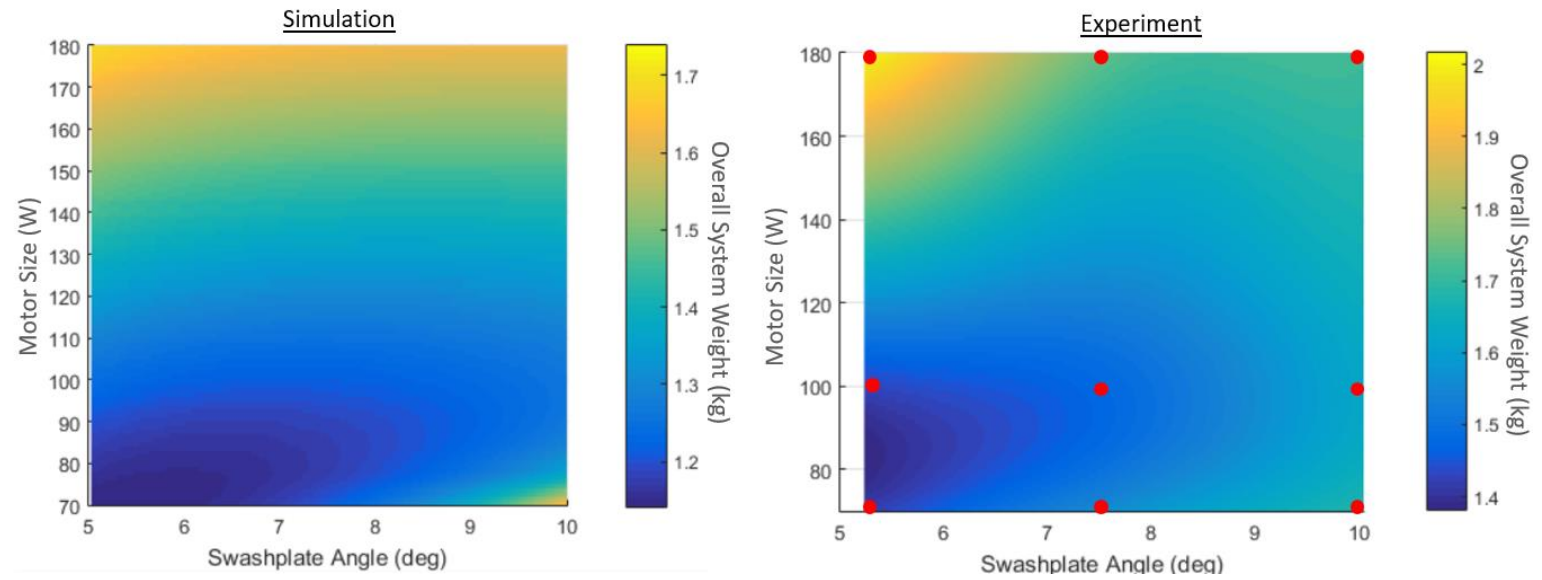

Figure 33. $5 \mathrm{MPa}, 5 \mathrm{cc} / \mathrm{sec}, 2 \mathrm{hr}$ runtime
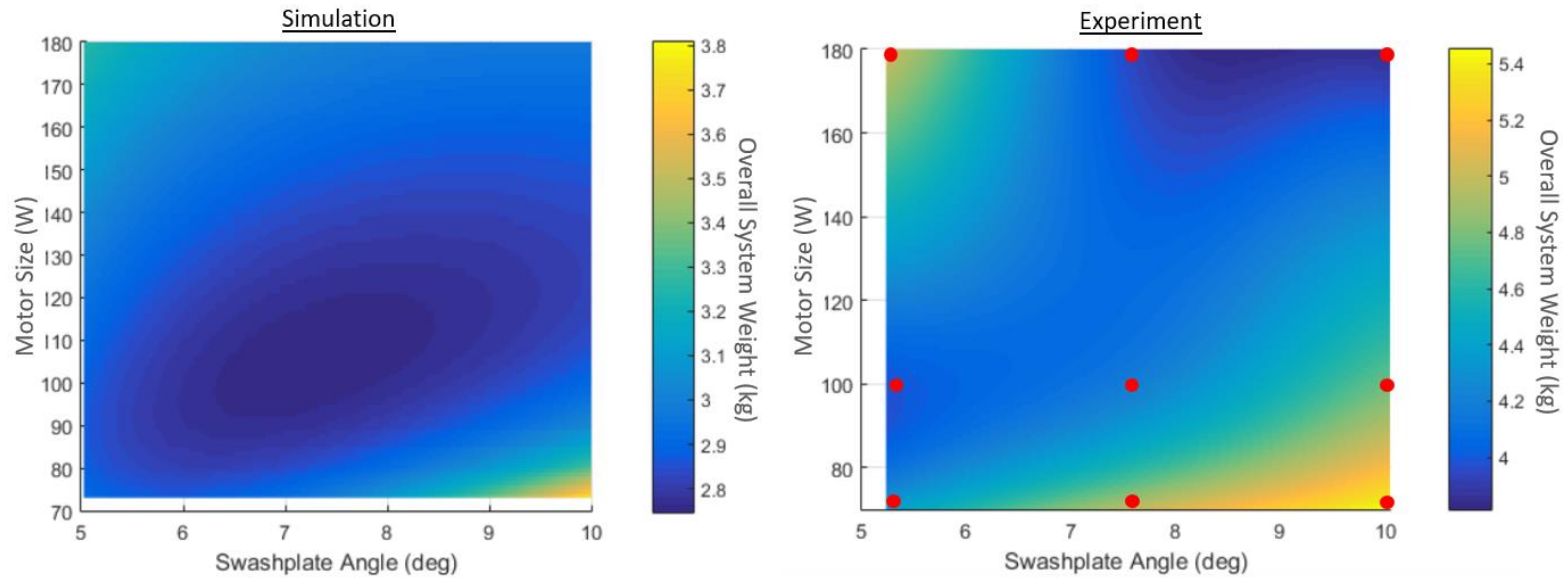

Figure 34. $5 \mathrm{MPa}, 5 \mathrm{cc} / \mathrm{sec}, 8 \mathrm{hr}$ runtime 

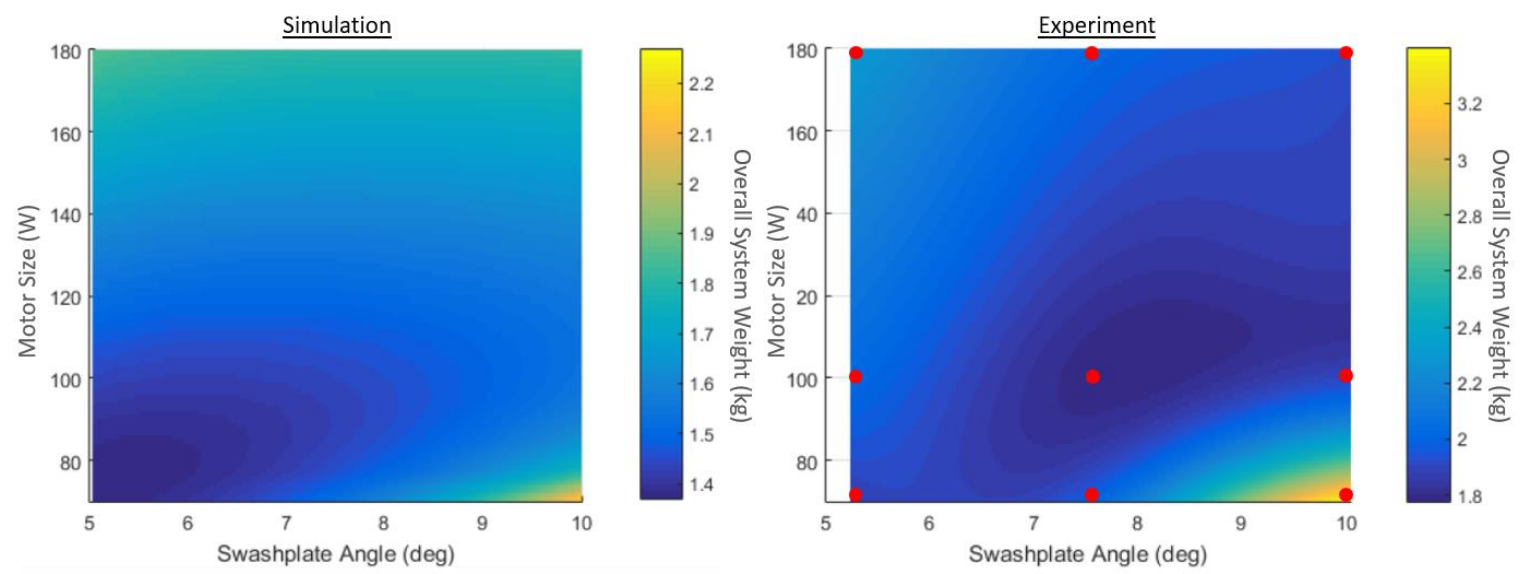

Figure 35. $7 \mathrm{MPa}, 5 \mathrm{cc} / \mathrm{sec}, 2 \mathrm{hr}$ runtime
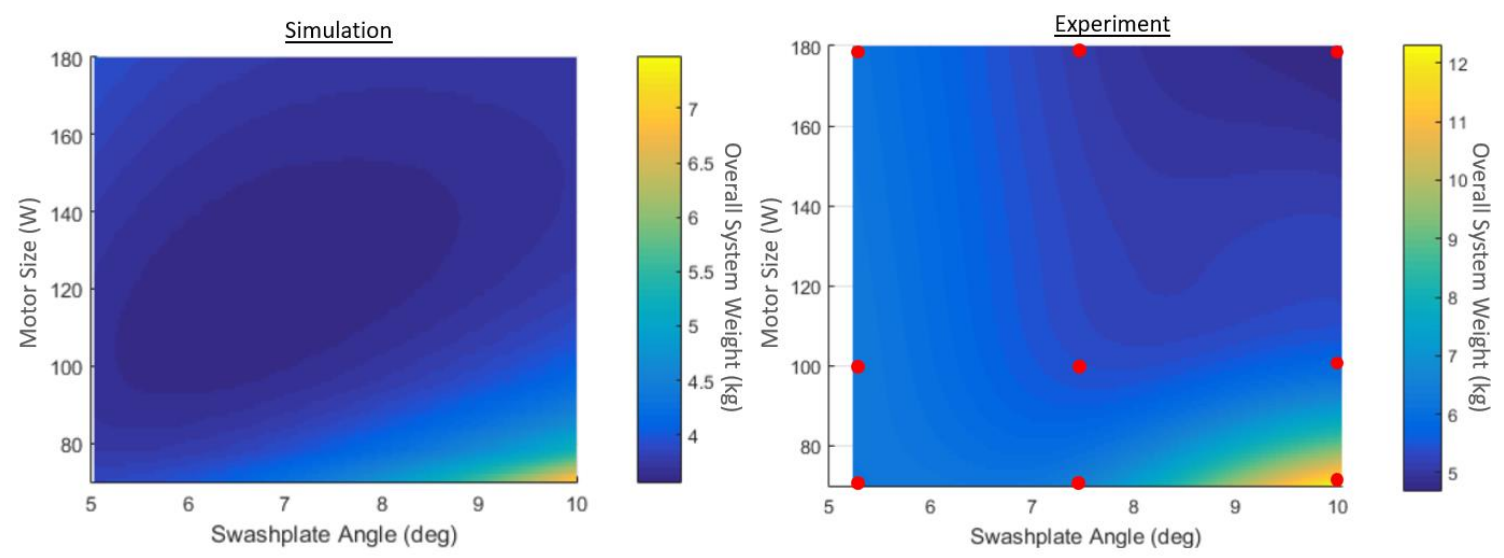

Figure 36. $7 \mathrm{MPa}, 5 \mathrm{cc} / \mathrm{sec}, 8 \mathrm{hr}$ runtime

As shown by the plots, the experimental results match the overall trends of the simulation. The approximate regions of minimal system weight as well as the high system weight regions are similar.

While the overall trends of high and low systems weight matched between the model and experimental results, the model system weights were consistently lower than the experimental weights. There are four main factors that likely contribute to this discrepancy. These factors are likely due to additional inefficiencies that were not accounted for in the model. First, the electric motor efficiency in the model was shown to be on the high end of the commercially available motors, so the experimental motor was likely running at a higher efficiency than the model predicted. Second, the Oildyne cartridge piston pumps have simpler designs than the Takako pumps which likely resulted in lower operational efficiencies in the test stand. The Oildyne pumps do not have ball bearings to center the rotational members inside of the outer case, which may result in binding between the cylinder block and case if there are small misalignments in the pump-motor shaft coupling. Third, the model did not account for any fluid friction losses outside of the pump. The test-stand had additional hose fittings and hoses that would result in pressure losses. For the $10 \mathrm{cc} / \mathrm{sec}$ flowrate, the pressure loss was calculated to be about $0.3 \mathrm{MPa}$ in the length of hose used, which would result in decreased system efficiency in the test-stand setup. Fourth, the model assumed that the motor controller operated at the peak data sheet efficiency of 95\%, however, 
depending on the operating conditions this efficiency may have been lower. Also, volumetric losses due to fluid compressibility were considered. At a pressure of $12 \mathrm{MPa}$, the change in volume of hydraulic oil was found to be only $0.8 \%$, meaning that the effect of fluid compressibility likely did not have a significant impact on the performance of the test stand compared to the model.

The model was modified to reflect these inefficiencies not accounted for. A decrease in overall efficiency of $35 \%$ was incorporated into the model. This value of $35 \%$ was selected by considering the addition of the efficiencies as described, and this value was manually adjusted until this fixed value was found to produce a good match between the simulation and experimental weights. The results of this modification are shown in Figures 37-44.
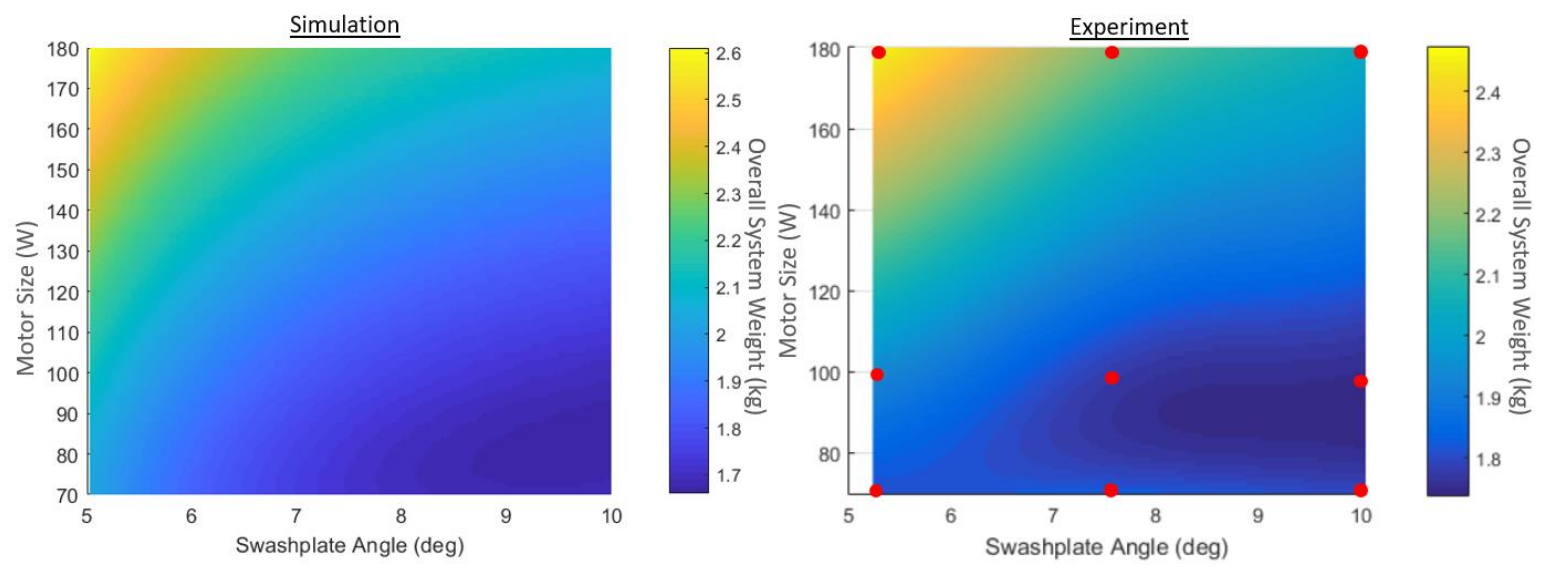

Figure 37. 3.5 MPa, $10 \mathrm{cc} / \mathrm{sec}, 2 \mathrm{hr}$ runtime, $35 \%$ additional inefficiency in model
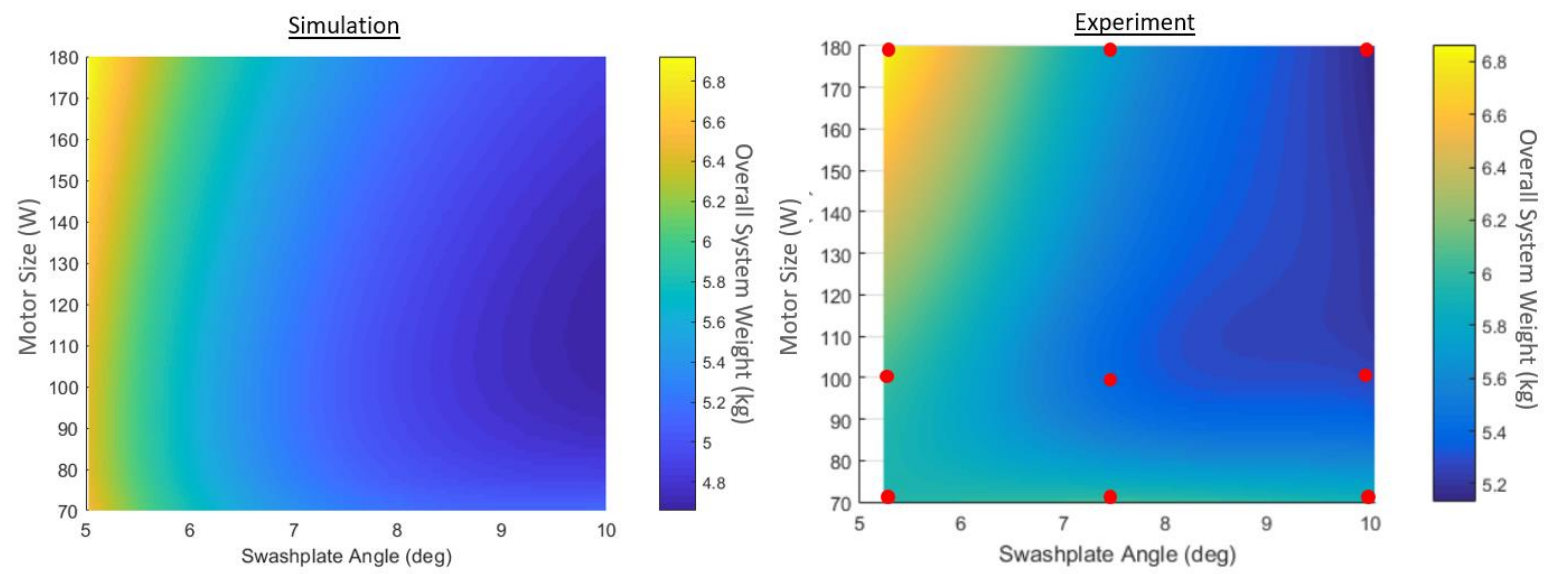

Figure 38. $3.5 \mathrm{MPa}, 10 \mathrm{cc} / \mathrm{sec}, 8 \mathrm{hr}$ runtime, $35 \%$ additional inefficiency in model 

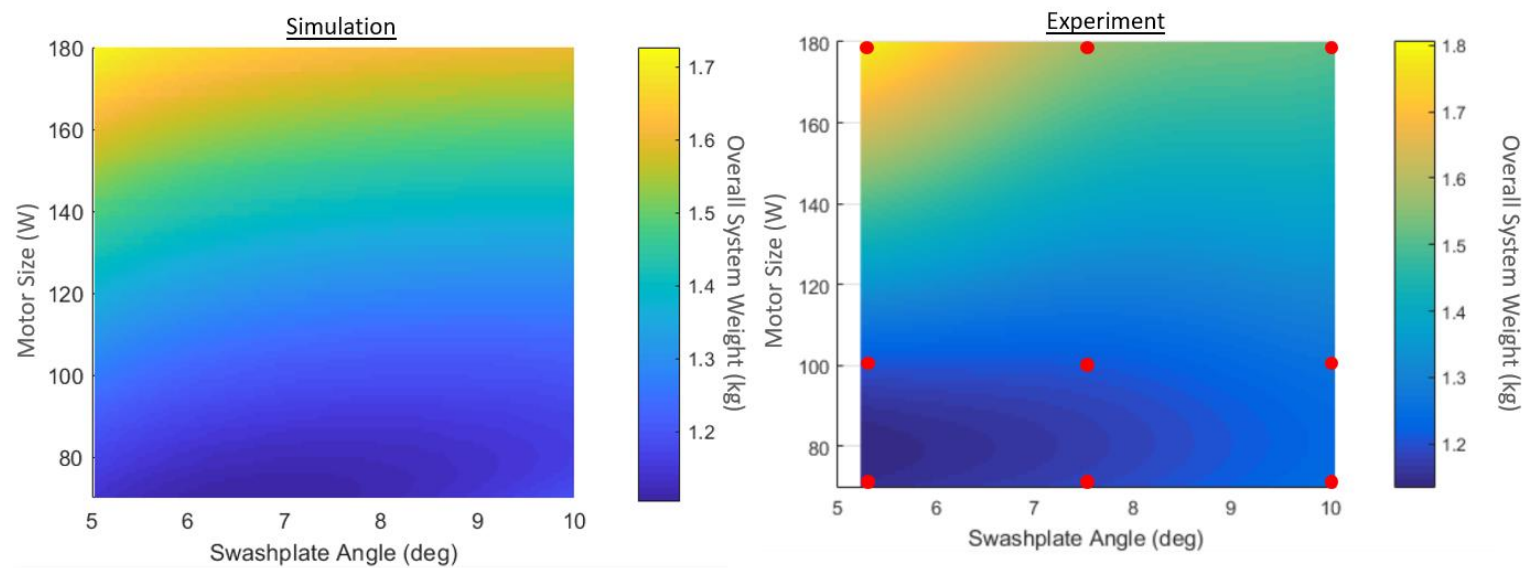

Figure 39. $3.5 \mathrm{MPa}, 5 \mathrm{cc} / \mathrm{sec}, 2 \mathrm{hr}$ runtime, $35 \%$ additional inefficiency in model
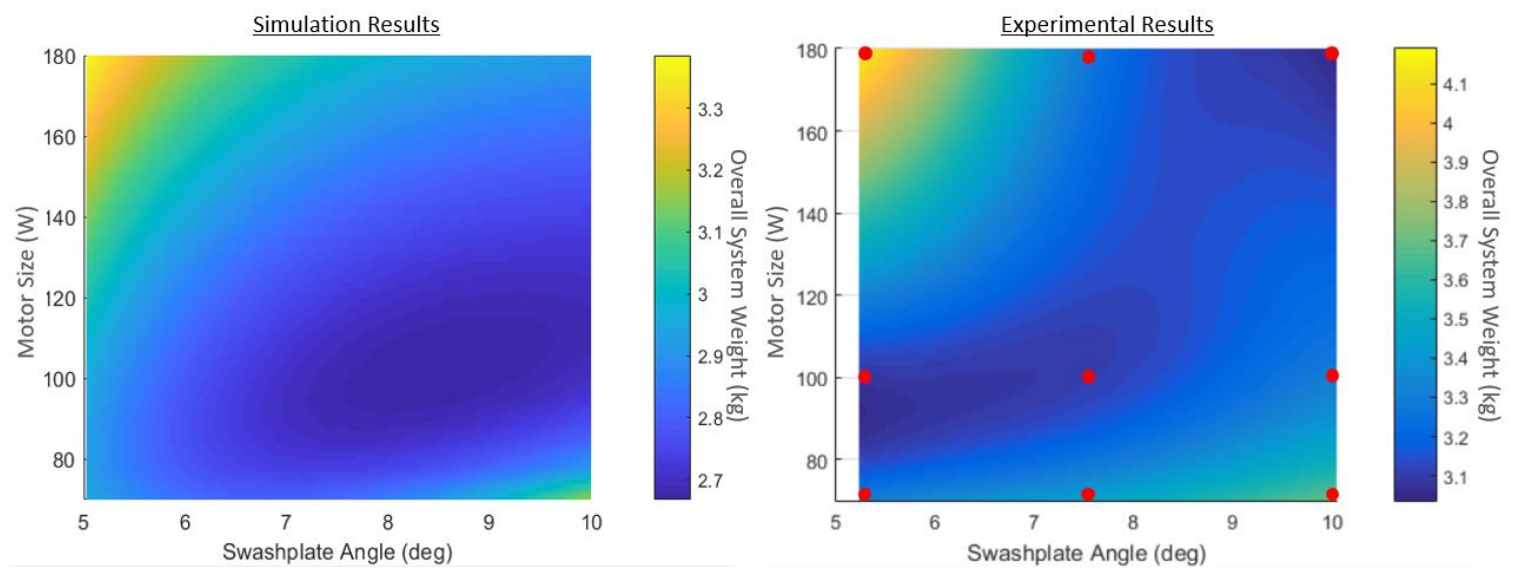

Figure 40. 3.5 MPa, $5 \mathrm{cc} / \mathrm{sec}, 8 \mathrm{hr}$ runtime, $35 \%$ additional inefficiency in model
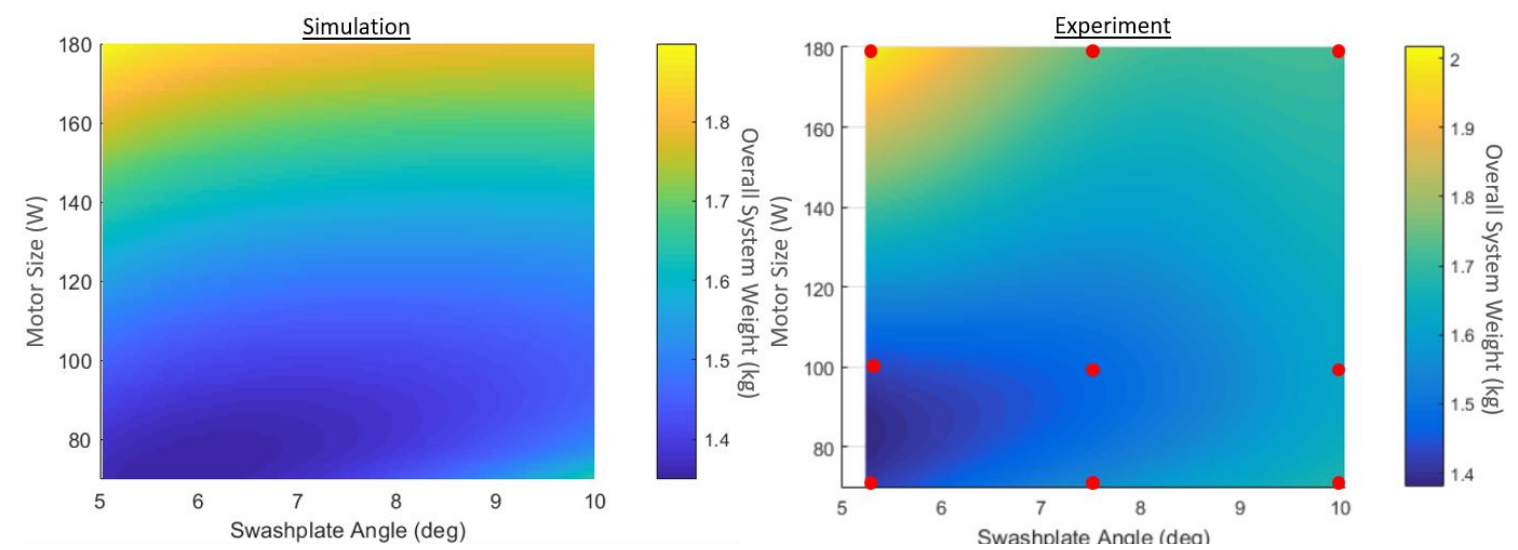

Figure 41. $5 \mathrm{MPa}, 5 \mathrm{cc} / \mathrm{sec}, 2 \mathrm{hr}$ runtime, $35 \%$ additional inefficiency in model 

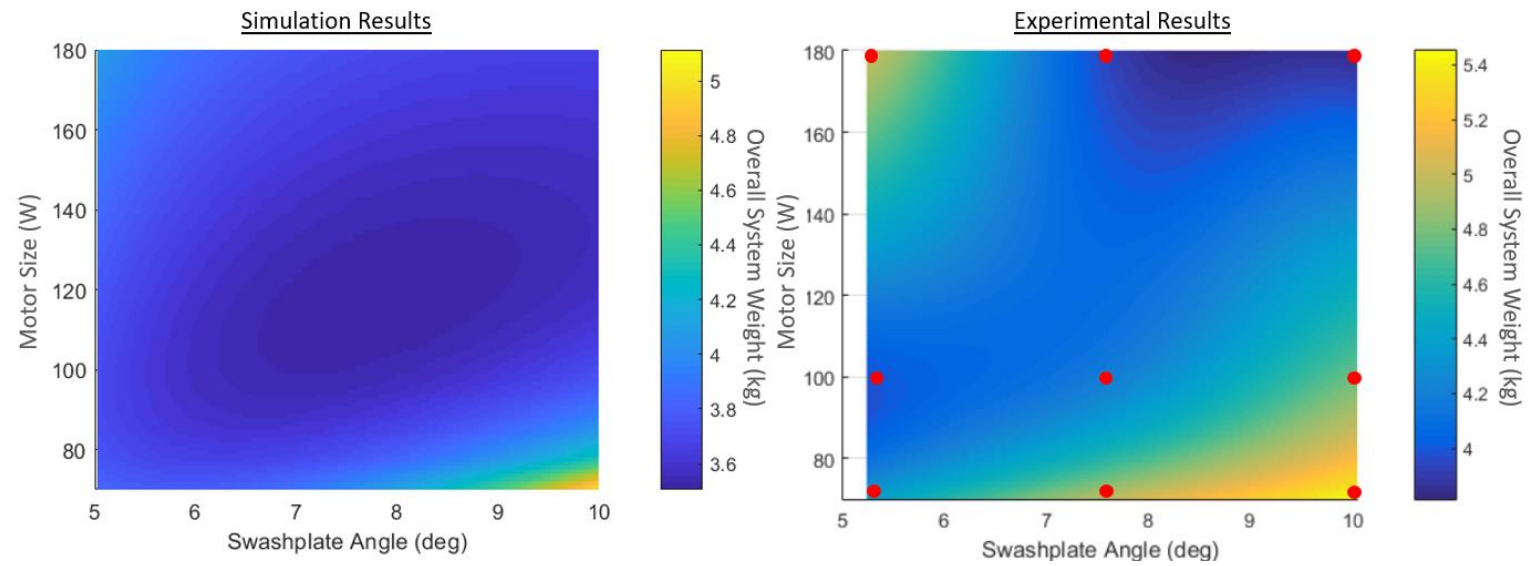

Figure 42. $5 \mathrm{MPa}, 5 \mathrm{cc} / \mathrm{sec}, 8 \mathrm{hr}$ runtime, $35 \%$ additional inefficiency in model
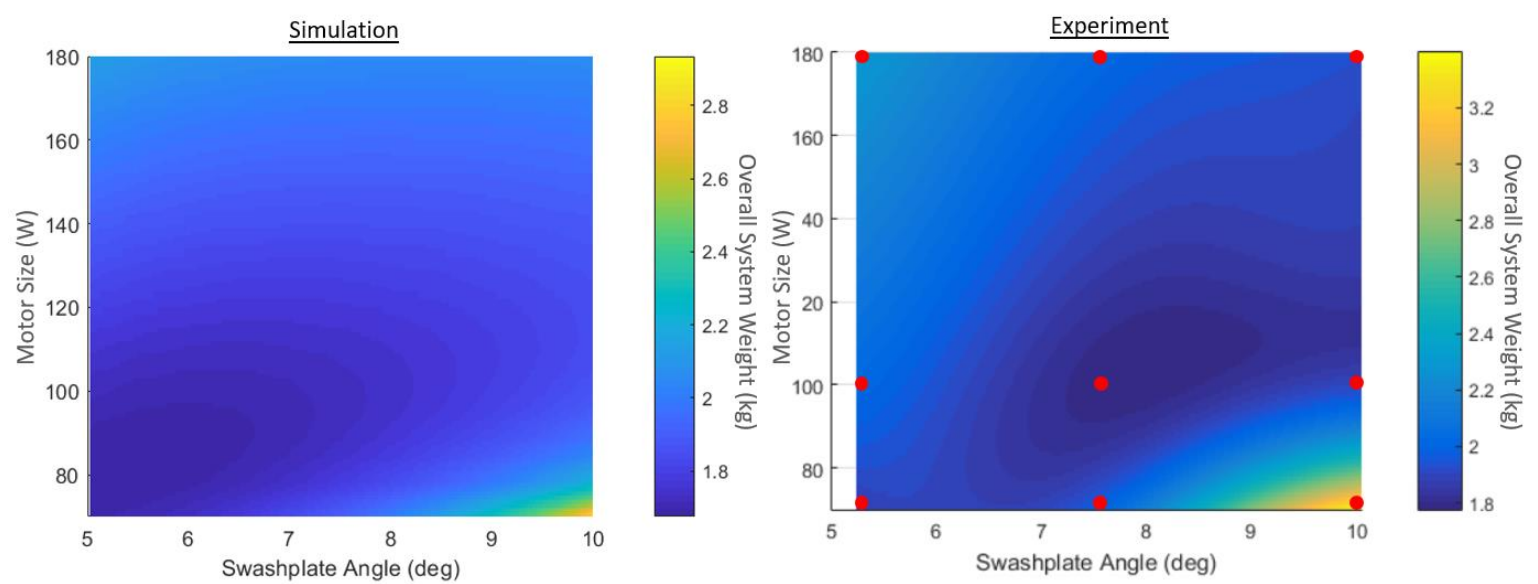

Figure 43. $7 \mathrm{MPa}, 5 \mathrm{cc} / \mathrm{sec}, 2 \mathrm{hr}$ runtime, $35 \%$ additional inefficiency in model
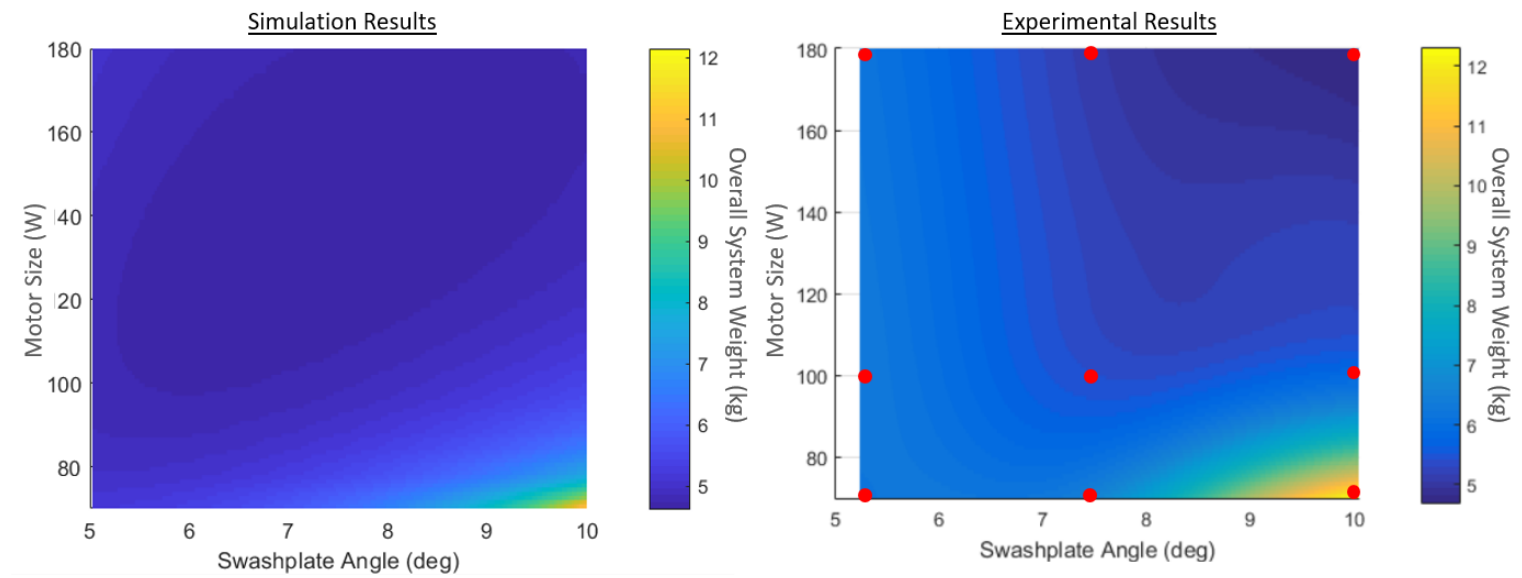

Figure 44. $7 \mathrm{MPa}, 5 \mathrm{cc} / \mathrm{sec}, 8 \mathrm{hr}$ runtime, $35 \%$ additional inefficiency in model 


\subsection{System Design Guideline Development}

\subsubsection{Motor Sizing}

The motor model was used explore methods of motor sizing. A case study was done using the motor model, where motors (Maxon EC-i, $70 \mathrm{~W}$ (240 g), $100 \mathrm{~W}(390 \mathrm{~g})$, and $180 \mathrm{~W}(820 \mathrm{~g})$ ) were compared at several steady-state operating points. The total system mass, including the motor and battery were compared for the system running at constant $200 \mathrm{rad} / \mathrm{sec}, 2$ hour runtime, and various torques (Figure 45).

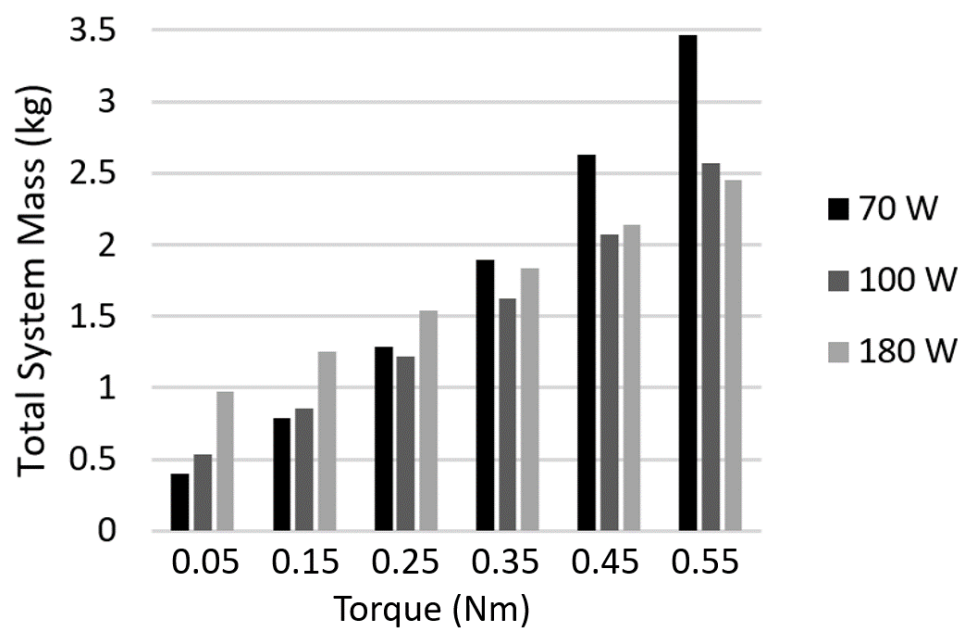

Figure 45. Motor + battery mass for various steady-state torque conditions

The $70 \mathrm{~W}$ motor results in the lowest system weight at the low torque conditions. However, at the higher torque conditions, it is the heavier $180 \mathrm{~W}$ motor that produces the lowest system weight. This is because at the higher torque conditions, the larger motor operates more efficiently. Although the larger motor adds more weight on its own, the higher operating efficiency results in a lower battery weight, and thus a lower overall system weight. The plot in Figure 46 below, was created to observe the motor model efficiency for varying sizes of motors at steady-state operation of 100 $\mathrm{rad} / \mathrm{sec}$ and various steady-state torques. 


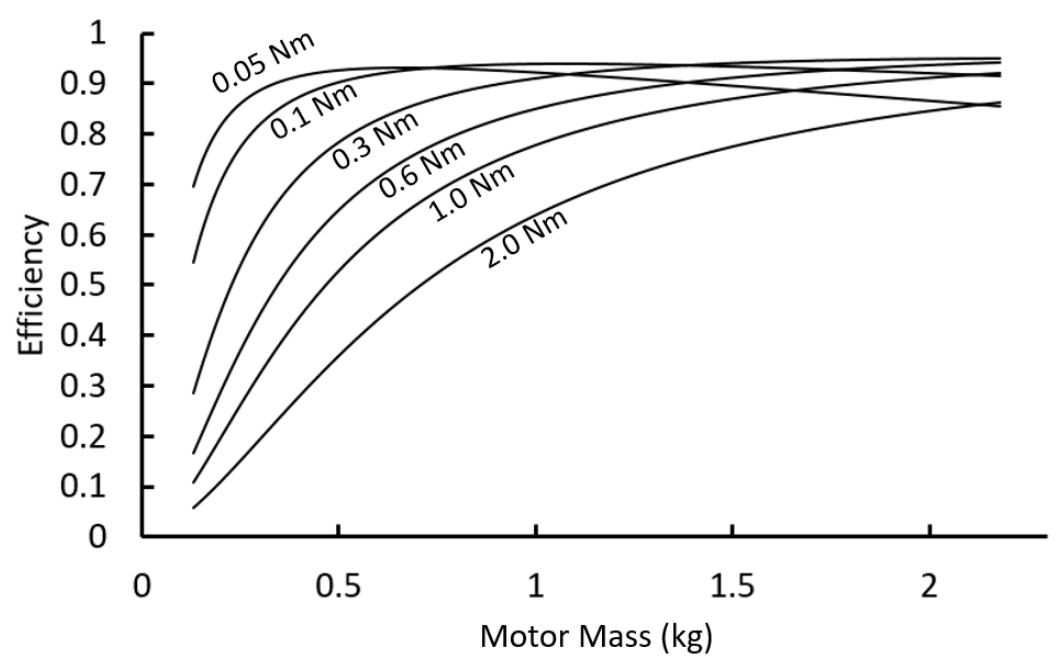

Figure 46. Electric motor efficiency is higher for larger motors, $100 \mathrm{rad} / \mathrm{sec}$, varying torques

Figure 46 shows that in general, larger motors operate at higher efficiencies. This is especially true for high torques.

Next, the motor model was used to explore how the desired runtime affects motor sizing. Figure 47 shows the results from a case study where a fixed pump size was used and the motor size was iterated to find what size would produce the lowest system weight. A $0.17 \mathrm{cc} / \mathrm{rev}$ pump was used and specified to output $5 \mathrm{cc} / \mathrm{sec}$ at $5 \mathrm{MPa}$
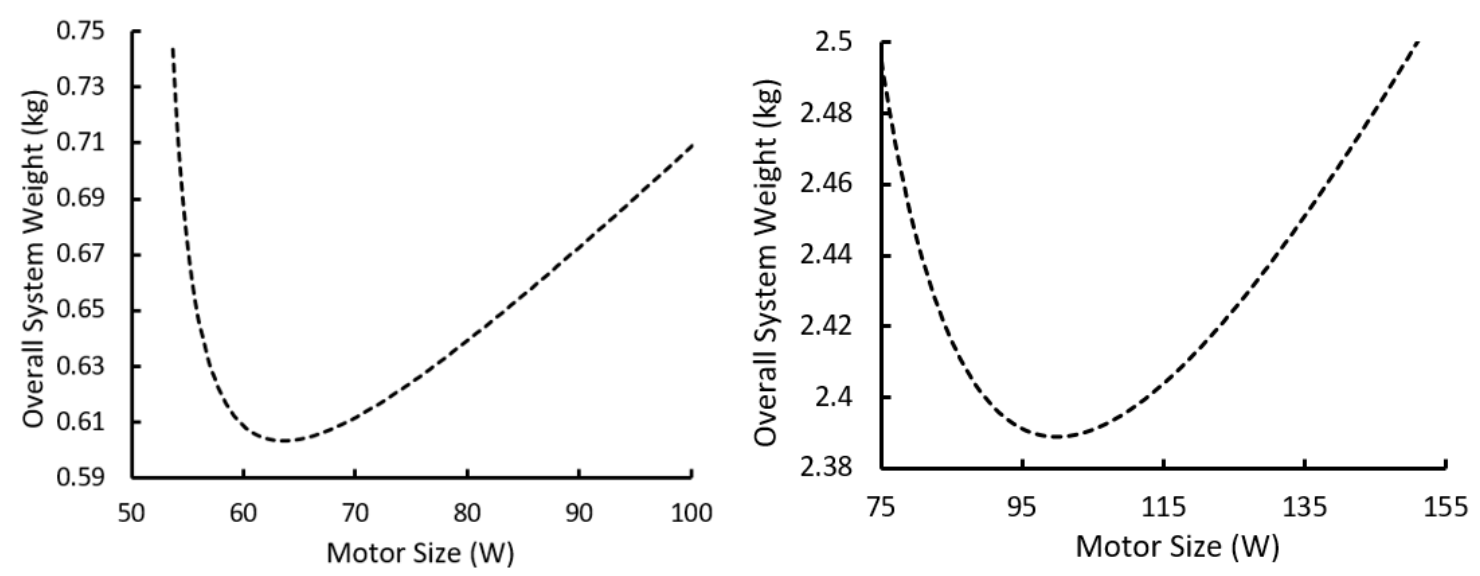

Figure 47. Motor selection, $0.5 \mathrm{hr}$. runtime (left), $8 \mathrm{hr}$. runtime (right)

Figure 47 shows how there is one motor size that produces a minimal system weight. These plots also show how the motor size for a minimal-weight system is affected by the desired system runtime, with all other design requirements held the same. The motor size that results in a minimal system weight for the 0.5 hour case is around $62 \mathrm{~W}$, while it is $100 \mathrm{~W}$ for the 8 hour runtime case.

\subsubsection{Gearbox Elimination}

The speed and torque characteristics of electric motors do not match well to pumps because electric motors are generally designed to operate at higher speeds and lower torques than pumps. Two options to correct for this mismatch are to add a gearbox or to modify the pump characteristics 
to result in a lower displacement per revolution. The displacement of an axial-piston pump can be reduced by simply making the overall pump smaller or by reducing the piston bore. Another option to lower the displacement is to reduce the swashplate angle. The swashplate angle is easy to modify, and was chosen as the means to modify the torque characteristics of the pump. The torque required to operate a pump without friction losses was defined previously by Equation 44:

$$
T_{p}=\frac{P * A_{p} * R_{p} * \tan \alpha * Z}{\pi}
$$

This equation shows that for a given pressure $P$, the torque required to drive the pump is proportional to the swashplate angle $\alpha$. The displacement per revolution of the pump also depends on the swashplate angle, as defined previously in Equation 43:

$$
V_{p}=\frac{A_{p} * R_{p} * \tan \alpha * \pi}{\sin \left(\frac{\pi}{2 z}\right)}
$$

Equation 43 shows that the displacement per revolution also increases as swashplate angle increases. Therefore, the swashplate angle can be decreased to better match the speed-torque characteristics of the motor. Decreasing the swashplate angle will decrease the displacement per revolution of the pump, thus reducing the torque required to produce a desired pressure. Figure 48 shows the effect on efficiency of operating a small pump at steady-state conditions with various fixed swashplate angles. The pump model was used with input dimensions similar to that of the Oildyne $0.17 \mathrm{cc} / \mathrm{rev}$ cartridge-piston pump (CP500), with 3 pistons, each $7 \mathrm{~mm}$ in diameter.
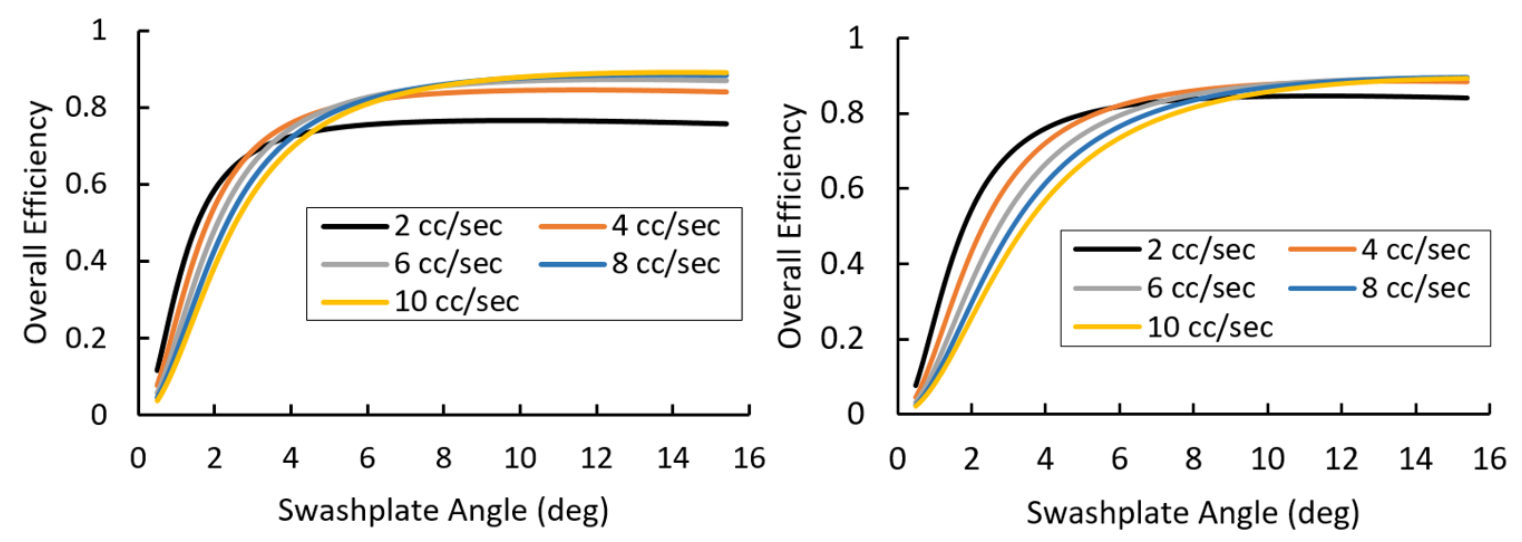

Figure 48. Pump efficiency model for $0.17 \mathrm{cc} / \mathrm{rev}$ pump, operated at $14 \mathrm{MPa}$ (left) and $7 \mathrm{MPa}$ (right)

The data in Figure 48 shows that there is a swashplate angle limit around 5 degrees below which the pump efficiency dramatically decreases. This is because at low swashplate angles the displacement of the pump is small, and the pump must be driven at high speeds to produce the desired flowrate. At high speeds, the viscous losses impact the efficiency. Figure 49 shows the viscous losses for a similar pump at operating conditions of $14 \mathrm{MPa}$ and $8 \mathrm{cc} / \mathrm{sec}$ flowrate. As shown, the viscous losses are significantly higher for low swashplate angles since the pump must be driven at very high speeds to produce the $8 \mathrm{cc} / \mathrm{sec}$ flowrate. 


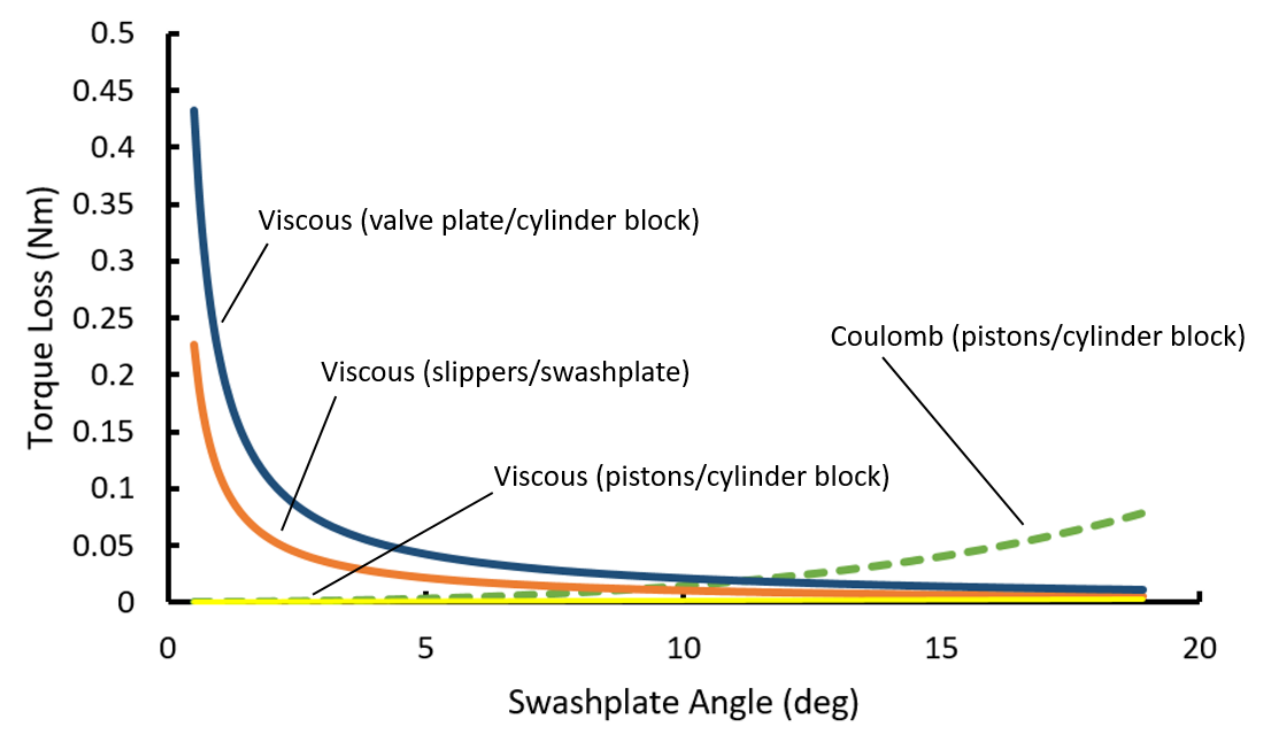

Figure 49. Breakdown of torque losses in $0.17 \mathrm{cc} / \mathrm{rev}$ axial-piston pump operated at $14 \mathrm{MPa}, 8$ $\mathrm{cc} / \mathrm{sec}$, torque loss is difference in required torque to drive pump versus required torque with no friction losses

A reduction in the piston diameter would accomplish the same task as reducing the swashplate angle. Referring to Equations 43-44, a piston diameter reduction would decrease the torque and decrease the flowrate per revolution of the pump. As with the swashplate angle decrease, a piston diameter decrease would require the pump to be driven at a higher speed to produce a certain flowrate. A similar trend occurs with viscous losses beginning to dominate as smaller and smaller piston diameters are used. This trend is seen with all types of pumps, regardless of geometry, because as the pump displacement per revolution is decreased to reduce torque requirements, the pump must be driven at higher speeds, resulting in increased viscous losses.

If the swashplate angle of a small axial-piston pump is reduced to around 5 degrees to better match the speed-torque characteristics of an electric motor, it is necessary to determine what range of torques are required by the electric motor for various operating pressures.
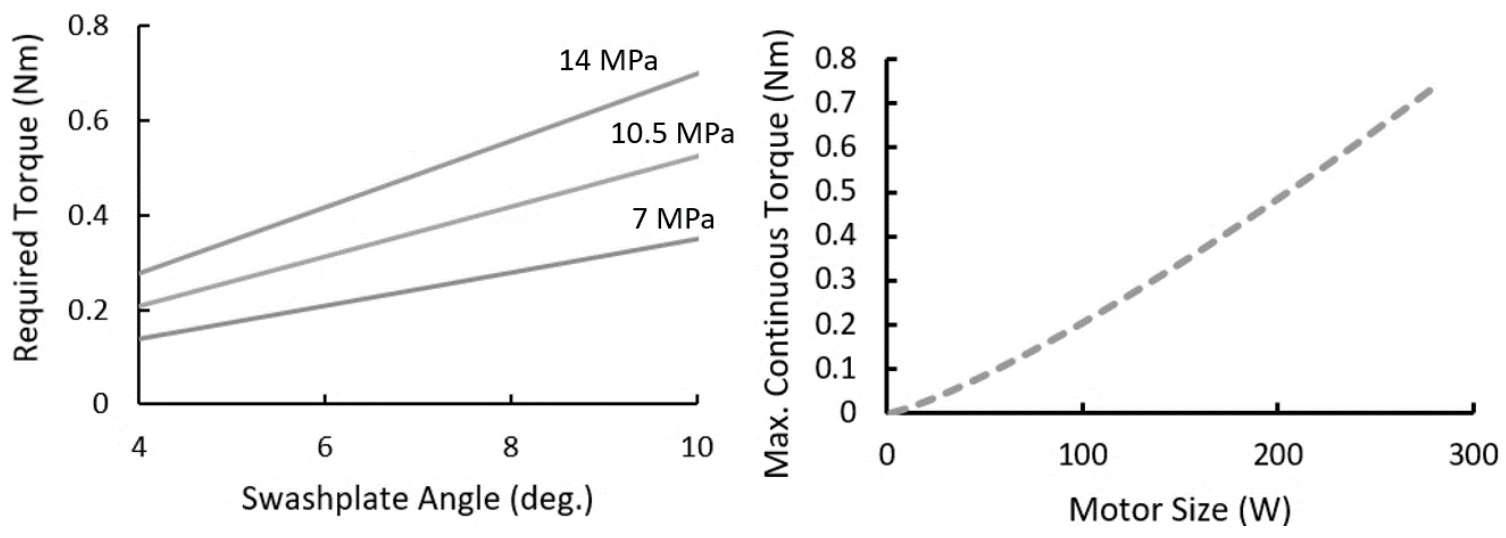

Figure 50. Motor torque to drive pump (left), maximum continuous motor torque for various motor sizes (right) 
The left plot in Figure 50 shows that for a 3-piston, $7 \mathrm{~mm}$ piston diameter pump, the torque required to output $14 \mathrm{MPa}$ is in the range of $0.4-0.6 \mathrm{Nm}$ for swashplate angles in the range of 5-8 deg. Shown by the plot on the right, motors above $150 \mathrm{~W}$ could produce this torque. Therefore, a gearbox could be eliminated and the electric motor could be directly coupled to the pump, thus eliminating both the added weight of the gearbox itself as well as the added weight of the battery due to the inefficiencies of the gearbox, which would often be below $80 \%$.

Another aspect to consider is that a gearbox can allow a motor to operate more efficiently, which would reduce the battery weight. Figure 51 shows a case that uses a fixed $150 \mathrm{~W}$ size motor driving a fixed $0.17 \mathrm{cc} / \mathrm{rev}$ axial-piston pump for a 2 hour runtime at $10 \mathrm{cc} / \mathrm{sec}$. The overall system weight was calculated for various gear reduction ratios applied to the motor-pump connection for pressures of 5 and $15 \mathrm{MPa}$.
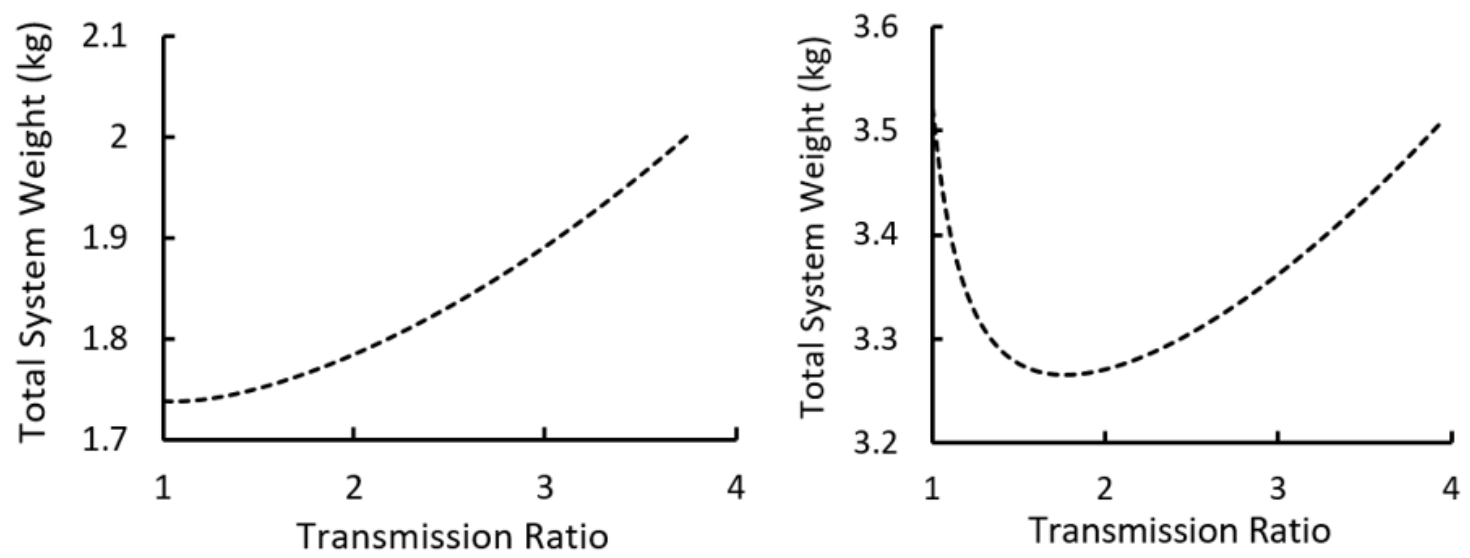

Figure 51. Gear reduction exploration effect on system weight, $5 \mathrm{MPa}$ (left), 15 $\mathrm{MPa}$ (right), assuming ideal gearbox with no weight or efficiency losses

For lower pressures, adding a gear reduction does not lower the overall system weight. However, as shown in Figure 51, at higher pressures a gear reduction ratio allows the fixed motor to operate at a higher efficiency, thus resulting in a lower battery weight and a lower overall system weight.

A gearbox configuration was considered for 9 different operating pressures and flowrates. The weight reductions, shown in Table 5, are equivalent to the amount of battery weight saved due to the optimized gear reduction allowing the motor to operate more efficiently.

Table 5. Optimized gearbox battery weight savings for various operating conditions, assuming ideal, massless gearbox, $2 \mathrm{hr}$ runtime, $0.17 \mathrm{cc} / \mathrm{rev}$ pump, $150 \mathrm{~W}$ motor

\begin{tabular}{|c|c|c|c|}
\hline & $5 \mathrm{cc} / \mathrm{sec}$ & $10 \mathrm{cc} / \mathrm{sec}$ & $15 \mathrm{cc} / \mathrm{sec}$ \\
\hline $5 \mathrm{MPa}$ & $4 \mathrm{~g}$ & $1 \mathrm{~g}$ & $0 \mathrm{~g}$ \\
\hline $10 \mathrm{MPa}$ & $46 \mathrm{~g}$ & $36 \mathrm{~g}$ & $31 \mathrm{~g}$ \\
\hline $15 \mathrm{MPa}$ & $219 \mathrm{~g}$ & $259 \mathrm{~g}$ & $354 \mathrm{~g}$ \\
\hline
\end{tabular}


Table 5 shows that only the high pressure, $15 \mathrm{MPa}$ cases benefited from the addition of a gear reduction to allow the motor to operate more efficiently, thus lowering the battery weight. However, this analysis did not consider the weight or the efficiency of the gearbox, which would result in additional battery weight. A small gearbox may be around $150 \mathrm{~g}$ itself. For the three $15 \mathrm{MPa}$ cases, if the gearbox operated at an $80 \%$ efficiency, it would add 307, 617, and $968 \mathrm{~g}$ of battery weight to the 5,10 , and $15 \mathrm{cc} / \mathrm{sec}$ cases, thus outweighing the reduction in battery weight due to the increase in motor efficiency. This demonstrates that a gearbox will ultimately add additional weight to the system

\subsubsection{Motor Cooling}

Another weight reduction method that was explored was the idea of using active cooling systems to allow the use of a smaller, lighter motor. The primary limit on maximum motor power operation is ensuring that overheating does not occur. With active cooling, a smaller motor can be used without overheating. Figure 52 shows the maximum power rating for a range of motor sizes in several cooling conditions. As the cooling convection coefficient is increased the maximum continuous power a motor can operate at also increases.

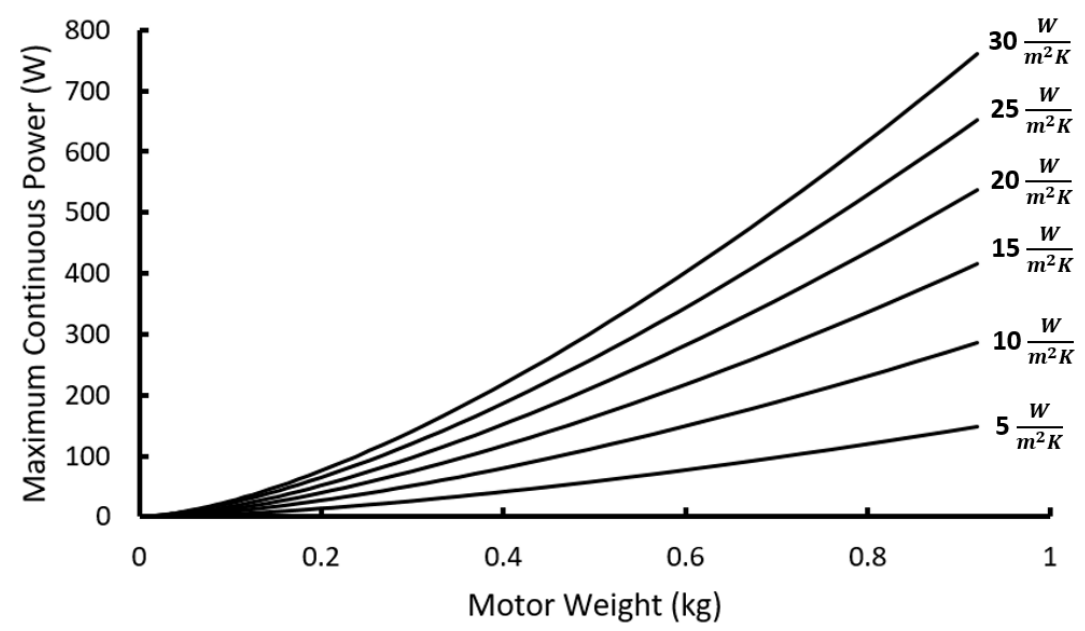

Figure 52: Active cooling effect on maximum motor power rating for various convection cooling coefficients, results from thermal motor model

While a smaller motor would reduce motor weight, there are several tradeoffs that must be considered. As demonstrated by the motor sizing exploration, although a smaller motor is lighter, it is often less efficient than a larger motor, thus resulting in more battery weight. This tradeoff was explored for various operating conditions to assess the potential weight savings. Figure 53 shows the motor size that results in a minimal system weight for various system runtimes. This was done for the same conditions as shown in Figure 47, where a fixed $0.17 \mathrm{cc} / \mathrm{rev}$ pump was used and operation conditions of $5 \mathrm{MPa}$ and $5 \mathrm{cc} / \mathrm{sec}$ were specified. This study demonstrated that the motor size required to produce a minimum system weight for the given conditions was $62 \mathrm{~W}$ and $100 \mathrm{~W}$ for runtimes of 0.5 and 8 hours. Figure 53 below shows the motor size that results in a minimum system weight for a range of desired run times, with all other setup conditions held constant. 


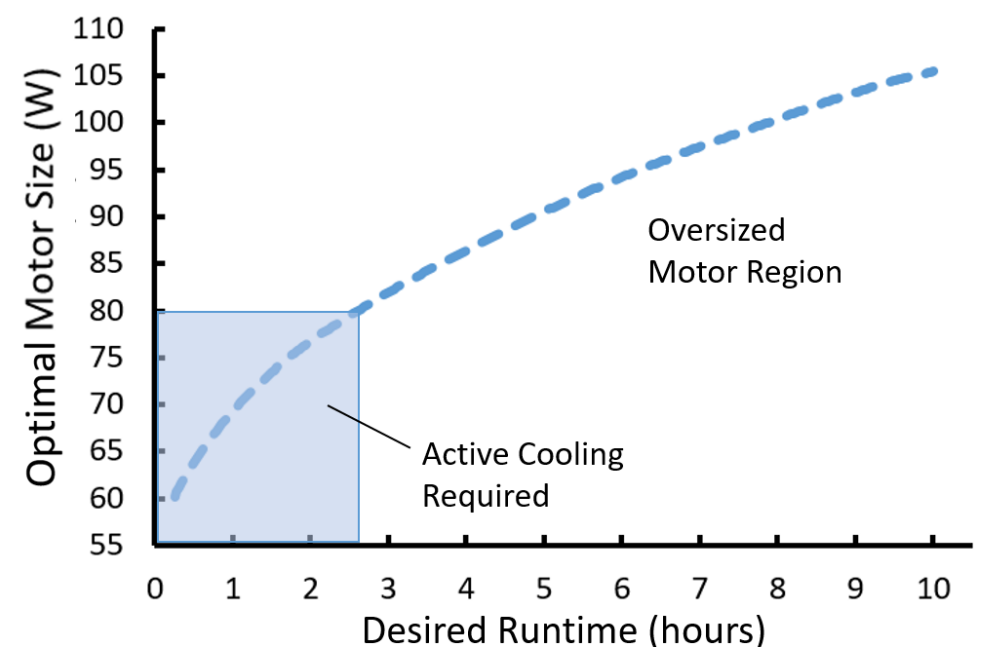

Figure 53. Optimal motor size selection is dependent on runtime, $5 \mathrm{MPa}, 5 \mathrm{cc} / \mathrm{sec}$, weight of active cooling systems not considered

This shows that as the desired runtime is increased, the motor size that results in a minimum system weight also increases. This is because at longer runtimes, the battery weight dominates overall system weight, so using a heavier, more efficient motor is optimal for minimizing system weight. Using the motor model, it was determined that the minimum possible motor size that could drive the pump at continuous conditions of $5 \mathrm{MPa}$ and $5 \mathrm{cc} / \mathrm{sec}$ was $81 \mathrm{~W}$ to ensure overheating did not occur. This means that for the runtimes under 2.5 hours, where the optimally-sized motor is below $81 \mathrm{~W}$, active cooling is required to allow the motor to run without overheating. For designed runtimes above 2.5 hours, active cooling would not be required, and oversized motors would produce lower overall system weights.

For active cooling it is useful to determine what the approximate weight savings would be if a cooling system was implemented to allow undersized motors to operate. Figure 54 shows the case for a 0.5 hour runtime, showing the overall system weight using a range of motor sizes. The $46 \mathrm{~g}$ difference is the total system weight difference between using active cooling to be able to use the weight-optimum, undersized $62 \mathrm{~W}$ motor versus using the minimum $81 \mathrm{~W}$ motor without cooling.

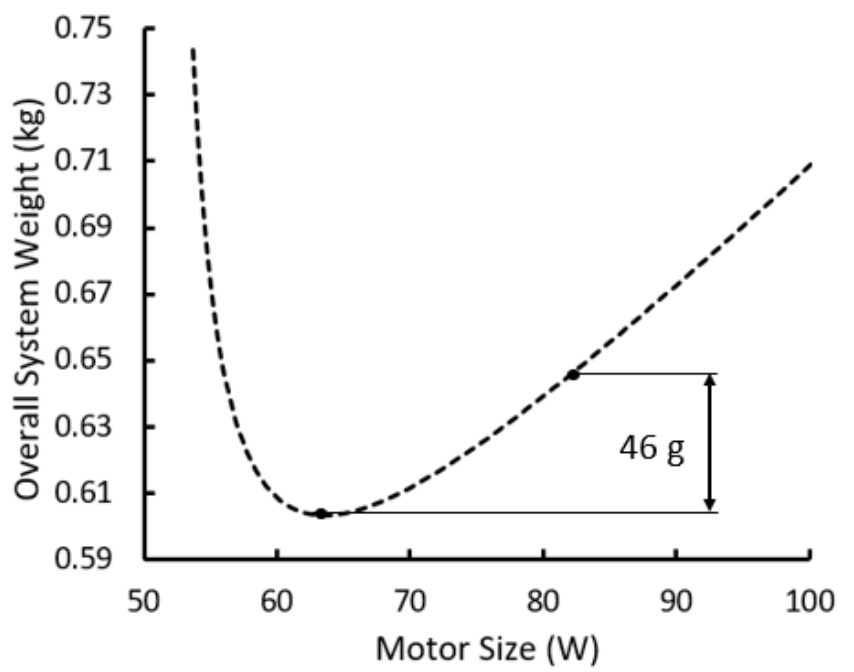

Figure 54. 0.5 hr. runtime, system weight difference between using 
an actively-cooled $62 \mathrm{~W}$ motor compared to using a non-cooled $81 \mathrm{~W}$ motor

This $46 \mathrm{~g}$ savings does not consider the weight added by the cooling system, which would likely be more than $46 \mathrm{~g}$. Additionally, several operating pressures, flowrates, and runtimes were modelled to determine the weight savings of using undersized motors with active cooling systems for short design runtimes. Most cases showed that using a zero-weight cooling system could reduce overall system weight for design runtimes under about 3 hours.
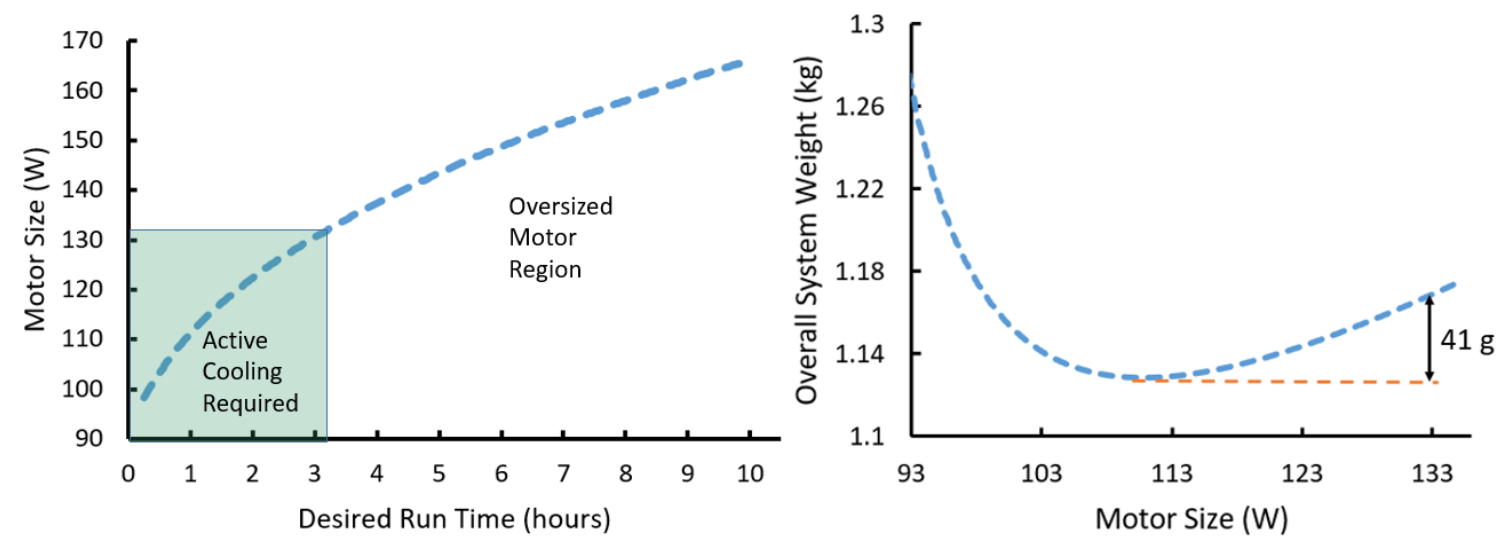

Figure 55. Left: $10 \mathrm{MPa}, 5 \mathrm{cc} / \mathrm{sec}, 133 \mathrm{~W}$ minimum motor without active cooling;

Right: 1 hr runtime, comparing ideal sized motor vs. minimum motor without active cooling

These cases resulted in weight savings in the range of 40-130 $\mathrm{g}$ when using an undersized motor versus the minimum sized motor without active cooling for short runtimes around 0.5-1.0 hours (Appendix C). Again, this analysis did not include the weight of an active cooling system. A practical cooling system might include a small fan as well as additional battery weight needed to power the fan. For example, a small blower fan (Fugetek $12 \mathrm{~V}$ fan) weighs about $80 \mathrm{~g}$. The power consumption is $6 \mathrm{~W}$, which for a 1 hour runtime would translate to about $40 \mathrm{~g}$ of battery weight. So, adding a basic cooling system such as this may add somewhere around $120 \mathrm{~g}$ to the system. Therefore, an active cooling system does not reduce overall system weight, especially for long system runtimes.

Shown in Figure 55, as the designed runtime for a system is increased, the weight of the battery becomes dominant in the overall system weight, and therefore larger, more efficient, electric motors result in lower overall system weights. However, also shown in Figure 56, the energy density of the batteries used has an impact on optimal motor selection for a minimized system weight. The plot shows the optimal motor size for a range of design runtimes. 


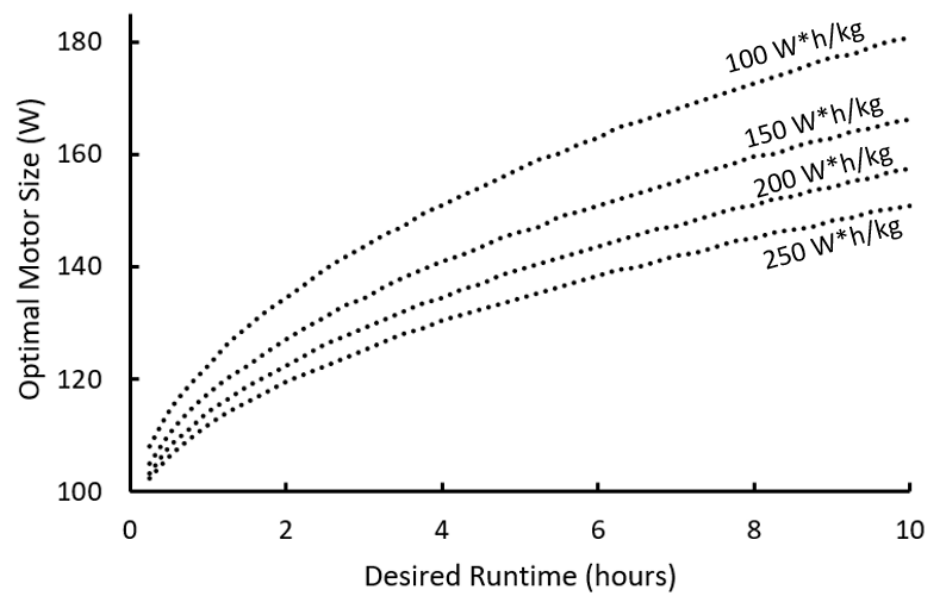

Figure 56: Effect of battery energy density on system design motor size selection for $10 \mathrm{MPa}, 5 \mathrm{cc} / \mathrm{sec}$, and a $0.17 \mathrm{cc} / \mathrm{rev}$ pump

As the energy density of the battery goes down, the weight of the battery becomes an even higher percent of the overall system weight. This means that for lower battery energy densities it is more important to select larger motors that operate more efficiently than for cases where the battery energy density is high.

Another area where a cooling system might potentially reduce overall weight comes from the resistivity of copper being temperature dependent. As the motor is cooled, the resistivity of the copper windings is reduced, making the electric motor more efficient, thus resulting in a lower battery weight. Figure 57 demonstrates the effect of actively cooling an $80 \mathrm{~W}$ motor driving a 0.17 cc/rev pump at $5 \mathrm{MPa}$ and various flowrates.

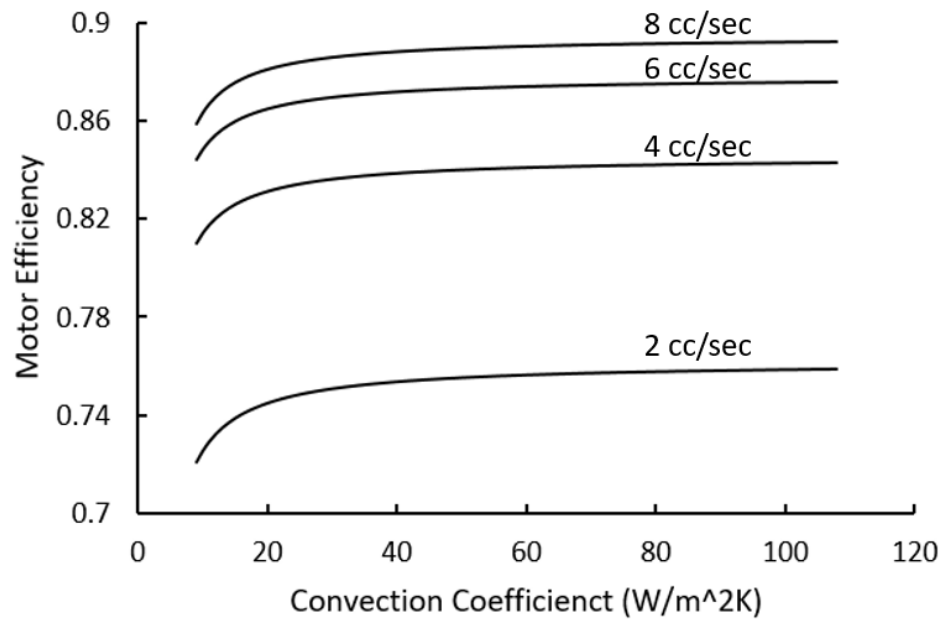

Figure 57. Copper winding loss effect on motor efficiency due to copper temperature dependence

The results show that the temperature difference of the windings due to using active cooling does not have a significant impact on the overall efficiency of the motor. A maximum increase in efficiency of about $3 \%$ was observed. 


\subsubsection{Total System Design}

A combined system model was used to aid in the design of a complete minimal-weight system. The inputs to the model were desired pressure, flowrate, and runtime. The program was designed to iterate through several combinations of motor size, pump size, and pump swashplate angle. The resulting output was the motor size, piston size, and swashplate angle that resulted in the lowest overall system weight. Parameters such as the number of pistons was fixed to three. Figure 58 shows an output from the program with desired $10 \mathrm{MPa}$ pressure, $10 \mathrm{cc} / \mathrm{sec}$ flowrate, 2 hour runtime, and a $150 \mathrm{~W}$ motor. The program output in Figure 58 is only for a $150 \mathrm{~W}$, but for the entire analysis several similar plots were produced for varying motor sizes.

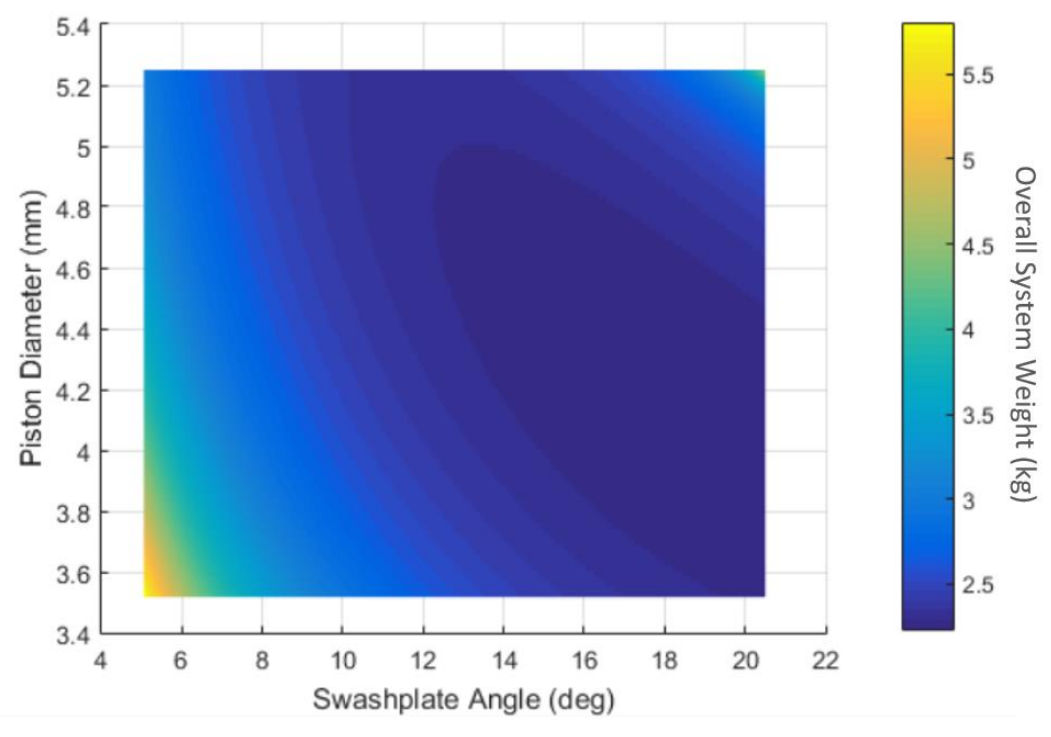

Figure 58. Weight optimization using fixed $150 \mathrm{~W}$ motor, variable pump, and desired $10 \mathrm{cc} / \mathrm{sec}, 10 \mathrm{MPa}, 2 \mathrm{hr}$ runtime

The results for the minimal-weight configuration are a pump size with three pistons, $4 \mathrm{~mm}$ in diameter, a $19^{\circ}$ swashplate angle, and $0.11 \mathrm{cc} / \mathrm{rev}$ displacement, a $93 \mathrm{~W}$ motor, and overall system weight of $2.01 \mathrm{~kg}$. As shown by Figure 58, near the lower left corner of the plot, the pump displacement is low, with both small pistons as well as low swashplate angles. As shown in Figure 48 , as the displacement of the pump is reduced to small values, viscous losses become large, resulting in high systems weight. This combined system model could be used in the design of power supply with a range of desired flowrates, pressures, and runtimes defined by the user.

While the total system model outputs a combination of pump and motor parameters that results in a minimal system weight, Figure 58 shows that there is a wide range of pump parameters close to the optimal solution that results in a system weight close to the optimal design weight. Therefore, the combined system model could be used to either design a minimal-weight system with custom parts or it could be used to aid in the selection of commercially available components that are close to the optimal components determined by the model.

\subsubsection{Quasi-Steady-State Model}

The previously described analyses were limited steady-state operating conditions for fixed operating pressures and flowrates. However, in a real-world application it is likely that the operating conditions would vary throughout a cycle. The model was adapted to calculate system 
weight for a sequence of operating pressures and flowrates. To demonstrate this, Figure 59 shows a 9 seconds cyclical operation with three steady-state operating conditions. This analysis still does not account for dynamic motor and pump operations, but the steady-state analysis should be adequate for cycles with relatively low dynamic shifting. These pressures and flowrates were chosen to be in a similar range to that of the hydraulic-ankle foot orthosis requirements.

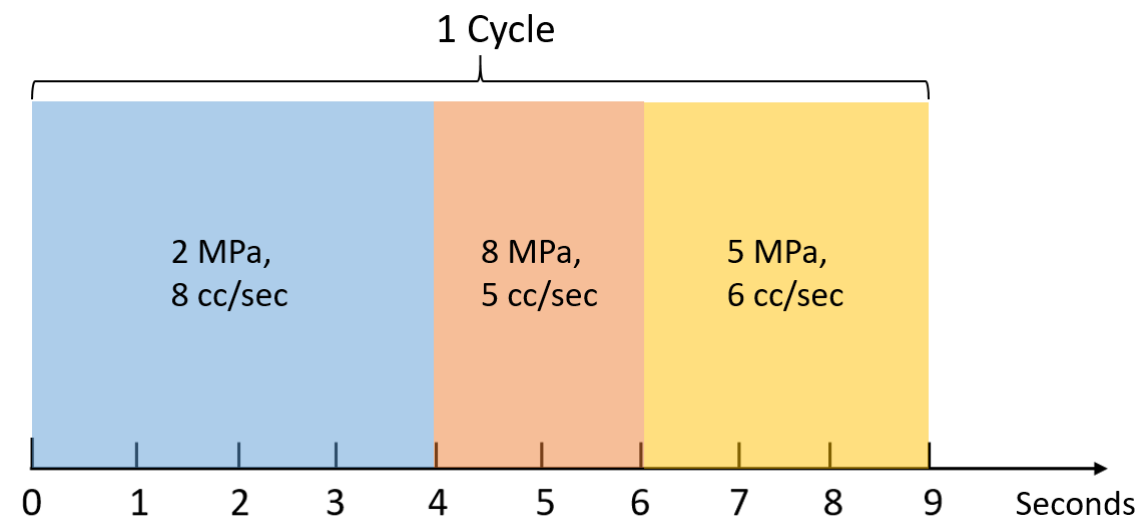

Figure 59. Quasi-steady-state, cyclical operation

The model was used to determine the overall system weight for various motor powers and swashplate angles for a run time of 4.5 hours (1800 cycles).

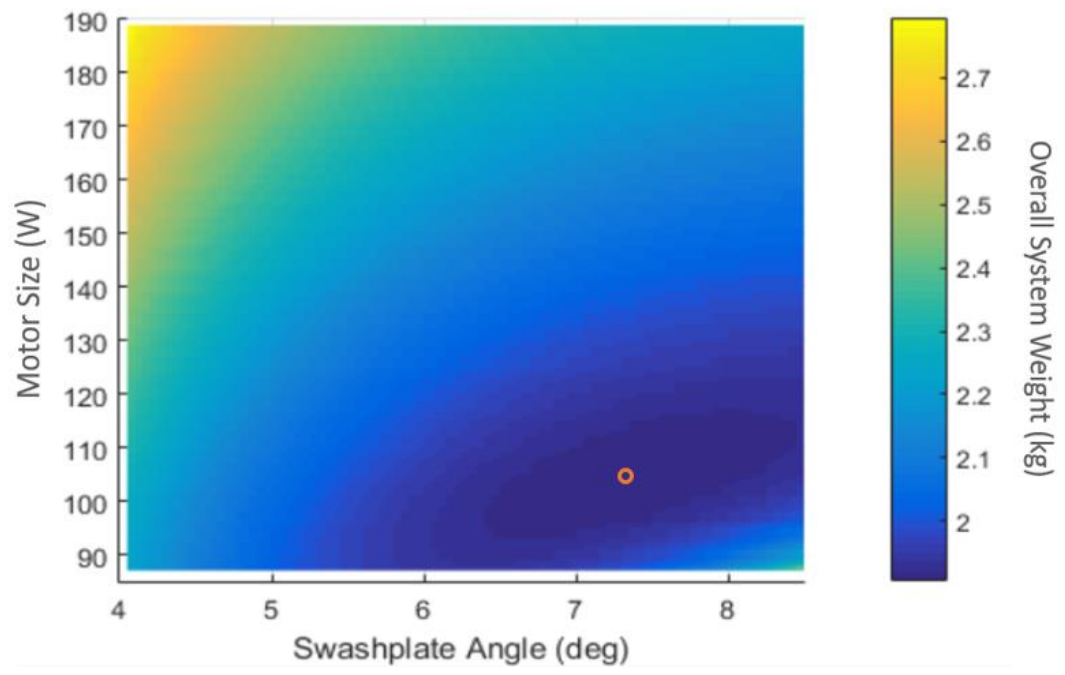

Figure 60. Quasi-steady-state system analysis results

A swashplate angle of $7.2^{\circ}$ and a motor size of $108 \mathrm{~W}$ results in the lowest system weight, 1.95 $\mathrm{kg}$, for this set of operating conditions. Other applications that require a cyclical mode of operation could be broken into even smaller sections for analysis. However, this method of analysis has limitations since it does not account for dynamic operation, which may be significant for applications with high levels of variability in operation pressure and flowrate. 


\section{Discussion and Conclusion}

\subsection{Test Stand Validation Discussion}

\subsubsection{Experimental vs. Model Predictions}

The test stand results showed somewhat higher overall system weights than the simulation predictions. As discussed, the likely reason for this mismatch was due to inefficiencies that were unaccounted for in the simulation. After the $35 \%$ additional inefficiencies were added to the model, the simulation results matched well to the experimental results.

\subsubsection{Purpose of Model as a Tool}

The purpose of this computational model is for it to be used as a tool for finding approximate combinations of component parameters that will result in a low system weight. As shown by the plots of the experimental results, the minimal-weight combination of motor and pump size is usually surrounded by a relatively large area of low system weight combinations, only a small amount higher than the minimum. Therefore, the simulation can be used to find an approximate combination of pump and motor size that will result in a low system weight, and it is not critical to have an exact motor and pump size combination to result in a low system weight. This simulation tool is especially useful for avoiding combinations of pump and motor size that results in an exceptionally high system weight. As shown by the plots in Figures 37-44, there are certain regions of the plots that result in exceptionally high system weights. For example, Figure 38 with the 3.5 $\mathrm{MPa}, 10 \mathrm{cc} / \mathrm{sec}$, and $8 \mathrm{hr}$ runtime shows that the $5.23^{\circ}$ and $7.76^{\circ}$ pump sizes should be avoided for all motor combinations, and the $10.05^{\circ}$ pump would result in a low system weight for all combinations of motor sizes, especially the 100 and $180 \mathrm{~W}$ motors. The simulation versus the experimental results showed that while the areas of minimum system weight generally matched, there were some discrepancies. However, the areas of exceptionally high system weight seemed to be a very close match for every pressure, flowrate, and runtime tested. This shows that the model is especially useful for avoiding these poor designs.

\subsubsection{HAFO Power Supply Redesign}

The validated model can be used for applications such as redesigning the power supply for the hydraulic ankle-foot orthosis. The HAFO power supply consisted of a 3.7 transmission ratio gearbox. The HAFO power supply used a Takako $0.4 \mathrm{cc} / \mathrm{rev}$ pump with a swashplate angle of 13.2 degrees, and the original $627 \mathrm{~g}$ battery was calculated to allow the system to run for 45 minutes at steady-state conditions of $3.97 \mathrm{MPa}$ and $10.3 \mathrm{cc} / \mathrm{sec}$, which was calculated by finding the average pressure and flowrate requirements for one walking cycle. The plots in Figure 62 show the minimalweight designs for a 45 and 120 minute runtime. 


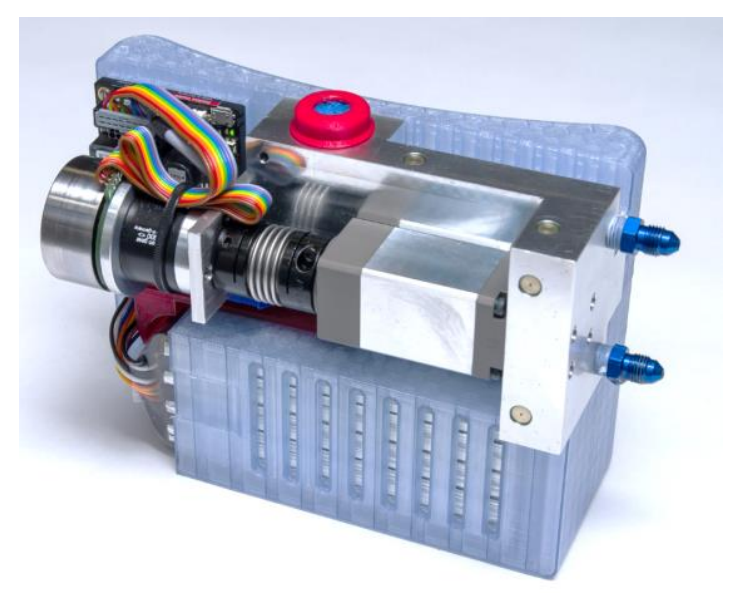

Figure 61. Hydraulic ankle-foot orthosis power supply
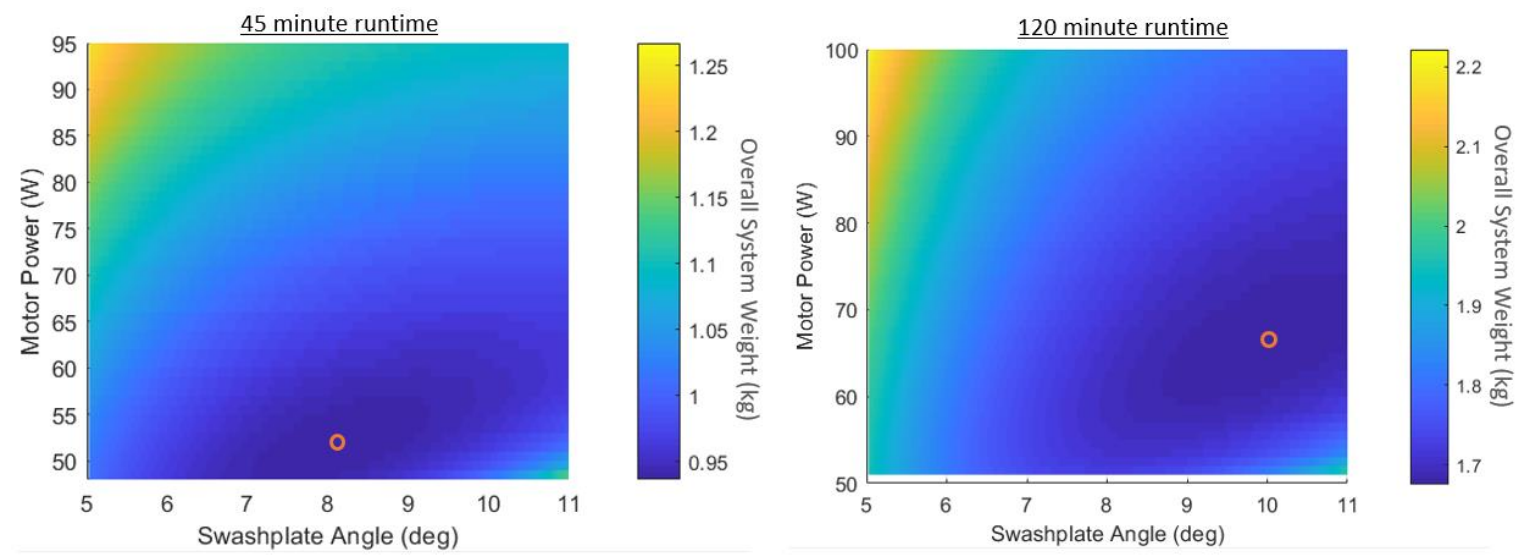

Figure 62. HAFO power supply design using computation model to explore design parameters of motor size and pump swashplate angle

For the 45 minute runtime, a 8.0 degree swashplate angle and a $51 \mathrm{~W}$ motor results in the lowest system weight. For the 120 minute runtime, a 9.9 degree swashplate angle and a $67 \mathrm{~W}$ motor results in the lowest system weight. Table 6 below shows the weight comparison between the model design and the original HAFO power supply.

Table 6. Weight comparison of original HAFO power supply to computational model design

\begin{tabular}{|c|c|c|c|c|}
\hline \multirow[b]{3}{*}{ Component } & \multicolumn{4}{|c|}{ Mass (g) } \\
\hline & \multicolumn{2}{|c|}{45 min. runtime } & \multicolumn{2}{|c|}{$120 \mathrm{~min}$. runtime } \\
\hline & HAFO Power Supply & HPS Model Design & HAFO Power Supply & HPS Model Design \\
\hline Motor & 140 & 213 & 140 & 288 \\
\hline Gearbox & 110 & 0 & 110 & 0 \\
\hline Pump & 251 & 251 & 251 & 251 \\
\hline Battery & 627 & 472 & 1672 & 1136 \\
\hline Total & 1128 & 936 & 2173 & 1675 \\
\hline
\end{tabular}

These results show that for the 45 minute runtime, the original power supply is $192 \mathrm{~g}$ heavier, and for the 120 minute runtime the original power supply is $498 \mathrm{~g}$ heavier. This shows that the original power supply design is sufficient for a 45 minute runtime. However, this original design 
performs poorly for longer runtimes, as with the 120 runtime case. For the 120 minute runtime it would be beneficial to reduce the pump swashplate angle from 13.2 to 8.0 degrees, and use a $51 \mathrm{~W}$ motor directly driving the pump.

\subsection{System Design Guidelines Discussion}

\subsubsection{Design Guidelines}

There are four main guidelines that were developed after analyzing the results of section 4.2 Design Guideline Development:

1. The smallest electric motor that can provide the required torque and speed may not result in minimum system weight.

As shown previously, it is often best to select an oversized motor. As shown in Figure 46, larger electric motors generally operate more efficiently than smaller motors, especially at high torques. The reason is because the majority of DC electric motor losses come from winding $I^{2} \mathrm{R}$ losses [20]. This can be shown by examining the equations that govern torque production in an electric motor,

$$
\begin{gathered}
T=k_{t} * I \\
F=I L x B \\
R=\frac{\rho L}{A} \\
P_{w}=I^{2} R
\end{gathered}
$$

To see how these equations demonstrate the described trend, assume two motors, one smaller with winding length $\mathrm{L}$, and one larger motor with winding length $2 \mathrm{~L}$. Both have equivalent wire diameters and identical magnetic field strength $B$. To produce an equivalent force with both motors, from Equation 65, the larger motor will need half the current since it has twice the length of wire. From Equation 66, the resistance of the winding for the larger motor will be twice that of the smaller. Then, using Equation 67 for the larger motor, the power loss will be half of the smaller motor. Although the resistance is twice that of the smaller motor, the current is half that of the smaller motor, thus resulting in half the power loss. Although this analysis does not consider viscous losses, it demonstrates why larger motors operate more efficiently, especially at higher torques.

Also, it was shown that the optimal motor size is dependent on design runtime, and as the design runtime increases the optimal motor size also increases. This is because as the desired runtime of the system becomes longer, the weight of the battery dominates the overall system weight. Thus, the operating efficiency of the motor becomes more important than the weight of the motor itself.

These case studies demonstrate that it is often best to select an oversized motor, since larger motors often operate more efficiently, which reduces battery weight and therefore overall system weight. Also, selecting larger motors helps to ensure that overheating will not occur in the case of unforeseen heating conditions in real-world applications. 
2. The gearbox between the electric motor and pump should be eliminated to reduce system weight.

As demonstrated by the case study shown in Table 5, the addition of a gearbox could allow the motor to operate more efficiently and save battery weight in this manner. However, when considering the additional weight added by both the gearbox itself and the additional battery weight due to the gearbox inefficiencies, it was determined that adding a gearbox would ultimately add weight to the system.

To directly drive the pump with an electric motor, the pump needs have sufficiently low displacements. For motors in the 100-300 W range, the displacement of the pump must be around $0.2 \mathrm{cc} / \mathrm{rev}$ or lower to allow pressures up to $14 \mathrm{MPa}$ to be generated There are very few commercially available axial-piston pumps with such a small displacement. So, it would be beneficial to develop designs for new pumps with even lower displacements than current available pumps. This would allow for these motors to be directly coupled to the pumps, thus eliminating the additional weight associated with a gearbox.

To best match the motor to the pump in a direct-drive configuration, another area to consider is varying the motor construction. The motor model that was developed is the most common type of BLDC motor design with an internal rotor. However, there is a less common design known as an outer rotor design, where the windings are fixed in the center of the motor and the rotor with the permanent magnets attached is external to this.
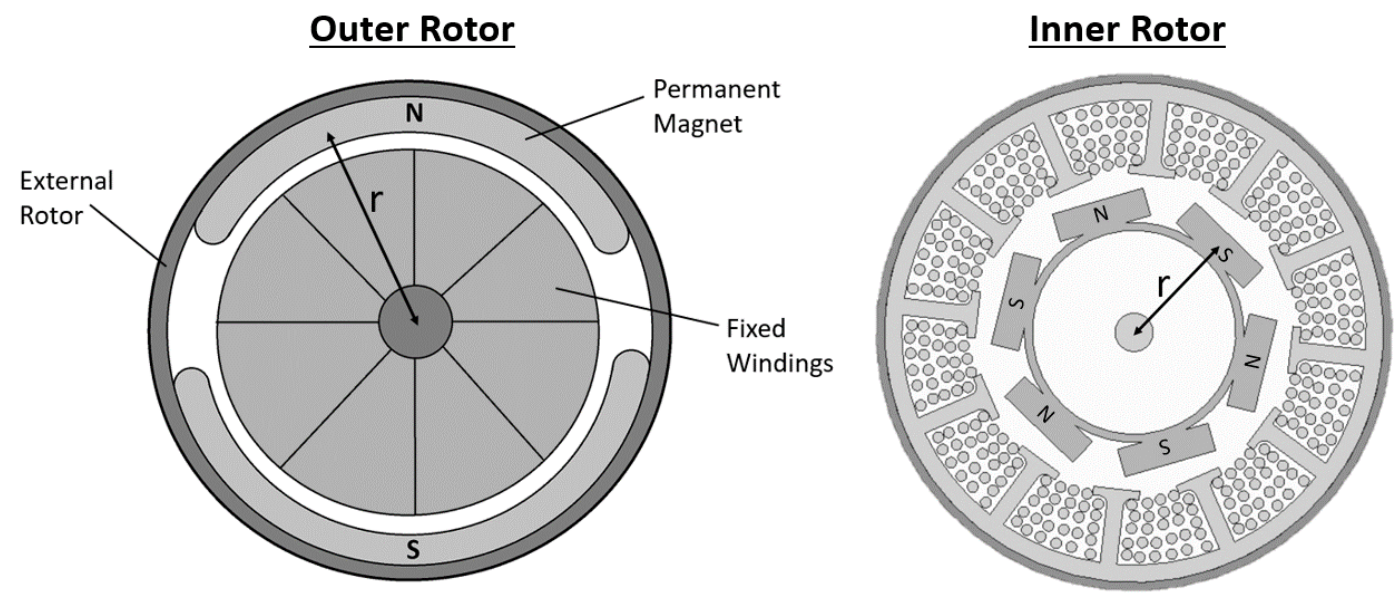

Figure 63. Outer and inner rotor BLDC motor designs

As shown in Figure 63 above, the radius of the acting force for the outer rotor design is greater than for the inner rotor. This allows the outer rotor design to be able to produce higher torques at lower speeds than the inner rotor design. This essentially creates the same effect as a gearbox by reducing the speed and increasing the torque, which allows for a better matching of motor to pump performance. Although these types of motors may be better suited to an application for small hydraulic power supplies, the availability of these types of motors is limited compared to conventional designs. 
3. Active cooling of the motor does not reduce system weight.

Active cooling can allow undersized motors to be used for a certain application, which reduces the motor weight in the system. However, it was shown that for several designs, this did not reduce system weight. Using an undersized motor actually increased the overall system weight in many cases. This is again due to the fact that larger motors often operate more efficiently. Although an undersized motor may reduce the motor weight, because the smaller motor if less efficient, it will add additional battery weight to the system. Therefore, active cooling should not be used in an attempt to reduce overall system weight. However, in real-world applications of such power supplies, cooling systems may still be of potential use to ensure that the motor does not overheat in the case of variations in natural convection cooling conditions. Also, for systems designed for very short runtimes under 30 minutes, it may be effective to use active cooling and an undersized motor since the battery weight is not a significant amount of the overall system weight at these runtimes, and it is therefore not as important to use a more efficient, heavier motor.

4. Iterative modeling is necessary to determine the various range of component parameters necessary to result in a minimal-weight system

As shown by the analyses performed in this study, there are several factors that contribute to the selection of individual components. Additionally, the selection of one component influences the operational efficiency of the other components in the system. Therefore, while it is useful to have basic guidelines to aid in the selection of components, the best was to design a system is to use the computational model to iterate through a wide range of design possibilities.

\subsubsection{Limitations of Guidelines}

The system design guidelines can be used aid in the design of a lightweight hydraulic power supply. One limitation of these guidelines is that the analyses for this project were all done for steady-state operation. While the quasi-steady-state model addressed this matter, the quasi-steadystate model assumes that dynamic operating effects are negligible. For systems that have a high degree of dynamic changes in pressure and flowrate requirements throughout a cycle, it may be the case that the models developed would not be accurate. Therefore, the model developed should be used for systems that have low levels of dynamic changes in pressure and flowrate.

Although the steady-state limitation on the models may not translate perfectly to a dynamically changing system, many of the design guidelines would likely still apply. For example, even with dynamic changes in motor speed and direction, the fact that larger motors will generally operate more efficiently than small motors still applies, and therefore the guideline are a good place to start when designing small-scale power supplies. 


\section{References}

[1] Akers, A., Gassman, M., and Smith, R., Hydraulic Power System Analysis. Taylor \& Francis, 2006.

[2] Durfee, W., and Sun, Z., Fluid Power System Dynamics. Center for Compact and Efficient Fluid Power, 2009.

[3] Hunt, T.M., The Hydraulic Handbook. Elsevier, 1996.

[4] Gilbertson, M., Beekman, D., Mohanty, B., Hashemi, S., Lee, S., Van de Ven, J. D., \& Kowalewski, T. M. (2016, October). Force Analysis and Modelling of Soft Actuators for Catheter Robots. In ASME 2016 Dynamic Systems and Control Conference (pp. V002T25A005-V002T25A005). American Society of Mechanical Engineers of Physical Medicine \& Rehabilitation, 71(2), pp. 112-115.

[5] Shields, Guy; Kovalsky, Corrine (27 September 2010). "Raytheon Unveils Lighter, Faster, Stronger Second Generation Exoskeleton Robotic Suit". Raytheon. Retrieved 9 July 2016.

[6] (June 2011) “Lockheed Martin's HULC Robotic Exoskeleton Enters Biomechanical Testing at U.S. Army Natick Soldier Systems Center” available at: lockheedmartin.com, Retrieved 10 October 2016

[7] www.bostondynamics.com/bigdog, 2017 Boston Dynamics

[8] www.bostondynamics.com/spot, 2017 Boston Dynamics

[9] National Research Council. 2004. Meeting the Energy Needs of Future Warriors. Washington, DC: The National Academies Press. doi:https://doi.org/10.17226/11065.

[10] Jicheng, Xia, 2015, "Modeling and Analysis of Small-Scale Hydraulic Systems" PhD. Thesis, University of Minnesota, Minneapolis, MN

[11] Neubauer, Brett, 2017, "Principles of Small-Scale Hydraulic Systems for HumanAssistive Machines" PhD Thesis, University of Minnesota, Minneapolis

[12] "New Quadruped Robot Takes Big Strides Toward Saving Lives" Moog Industrial Newsletter Issue 38, October 2015

[13] Neubauer, B., Nath, J., and Durfee, W., 2014. "Design of a portable hydraulic ankle-foot orthosis”. In Engineering in Medicine and Biology Society (EMBC), 2014 36th Annual 
International Conference of the IEEE. IEEE, 2014, pp. 1182-1185.

[14] Rahn, Christopher D. Battery Systems Engineering. Hoboken: Wiley, 2013.

[15] Toliyat, Hamid A., and Gerald B. Kliman, eds. Handbook of electric motors. Vol. 120. CRC press, 2004

[16] Yedamale P., Microchip Technology In., "Brushless DC (BLDC) Motor Fundamentals" AN885

[17] Wilson, W. E., 1950. Positive-displacement pumps and fluid motors. Pitman, London.

[18] Metallic Materials Specification Handbook, Fourth Ed., Robert B. Ross, Chapman \& Hall, London, 1992

[19] Juha Pyrhönen; Tapani Jokinen; Valéria Hrabovcová (2009). Design of Rotating Electrical Machines. John Wiley and Sons. p. 232. ISBN 0-470-69516-1.

[20] Tong, Wei., Mechanical Design of Electric Motors. CRC press, 2014

[21] Bergman, T., Lavine, A., Incropera, F., DeWitt, D., Fundamentals of Heat and Mass Transfer $7^{\text {th }}$ Edition, John Wiley and Sons, April 2011

[22] Jeong, H., 2007. "A novel performance model given by the physical dimensions of hydraulic axial piston motors: model derivation”. Journal of Mechanical Science and Technology, 21(1), pp. 83-97.

[23] Xia, J., \& Durfee, W. K., 2014. Experimentally validated Models of O-ring seals for tiny hydraulic cylinders. In ASME/BATH 2014 Symposium on Fluid Power and Motion Control, FPMC 2014 Web Portal ASME (American Society Of Mechanical Engineers). DOI: 10.1115/FPMC2014-7825

[24] Hashemi, S., \& Durfee, W., 2017. Low-Friction, Long- Stroke Rolling Diaphragm Cylinder for Passive Hydraulic Rehabilitation Robots. In press, ASME Journal of Medical Devices 


\section{$\underline{\text { Appendix }}$}

\section{A: Pump Dimensions}

The distance between the ball joint on the piston and the top of the cylinder block while the piston is at bottom dead center is as follows:

$$
l_{B O}=R_{p} * \tan \alpha
$$

This displacement per piston can also be defined as follows:

$$
V_{P \max }=A_{p} *\left(l_{p}-l_{B O}-l_{F}\right)
$$

The length of the piston inside of the cylinder block at top dead center is as follows:

$$
l_{F}=l_{p}-l_{B O}-\frac{\pi * R_{p} * \tan \alpha}{\sin \left(\frac{\pi}{2 z}\right)}
$$

The length that the piston travels from top dead center to bottom dead center is:

$$
l_{C O}=l_{p}-l_{F}-l_{B O}
$$

The radius of the slipper pad is estimated to be as follows:

$$
r_{s o}=\frac{5}{4} * d_{p}
$$

The diagram below shows the key dimensions of the valve plate.

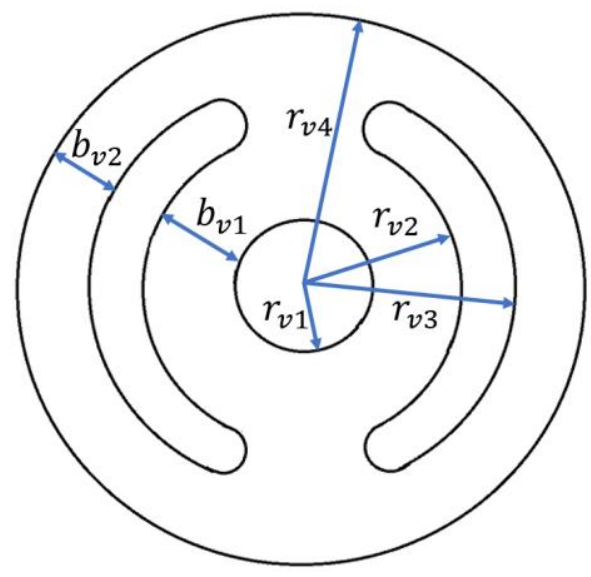


Figure 57: Key valve plate dimensions

The following equations can be used to approximate the valve plate dimensions:

$$
\begin{gathered}
\lambda_{v}=0.4 * d_{p} \\
b_{v 1}=0.15 * d_{p} \\
b_{v 1}=b_{v 2} \\
l_{v}=\frac{b_{v 1} * b_{v 2}}{b_{v 1}+b_{v 2}} \\
s=2 *\left[R_{p} * \sin \left(\frac{180}{z}\right)-\frac{d_{p}}{2}\right] \\
r_{v 4}=R_{p}+s+\frac{d_{p}}{2} \\
r_{v 1}=R_{p}-s-\frac{d_{p}}{2} \\
r_{v 3}=r_{v 4}-b_{v 2} \\
r_{v 2}=r_{v 1}-b_{v 1}
\end{gathered}
$$

\begin{tabular}{|c|c|c|c|c|c|}
\hline & & & $0.4 \mathrm{cc} / \mathrm{rev}$ & $0.8 \mathrm{cc} / \mathrm{rev}$ & $1.6 \mathrm{cc} / \mathrm{rev}$ \\
\hline Component & Symbol (MATLAB Code) & Unit & Value & Value & Value \\
\hline Piston Diameter & Dp & $\mathrm{m}$ & 0.00448 & 0.00598 & 0.00695 \\
\hline Pitch Radius & $\mathrm{Rp}$ & $\mathrm{m}$ & 0.0078 & 0.013 & 0.0165 \\
\hline Piston Length & Lp & $\mathrm{m}$ & 0.0096 & 0.012 & 0.015 \\
\hline Number of Pistons & $\mathrm{z}$ & \# & 7 & 7 & 7 \\
\hline Swashplate Angle & alpha & angle & 13.2 & 8.85 & 10.3 \\
\hline Piston-Cylinder Gap & $\mathrm{Hp}$ & $\mathrm{m}$ & 0.000004 & 0.000004 & 0.000006 \\
\hline Slipper-Swashplate Gap & $\mathrm{Hs}$ & $\mathrm{m}$ & 0.000004 & 0.000004 & 0.000006 \\
\hline Valve Plate-Cylinder Gap & $\mathrm{Hv}$ & $\mathrm{m}$ & 0.000004 & 0.000004 & 0.000006 \\
\hline Barrel Diameter & Dc & $\mathrm{m}$ & 0.023 & 0.03 & 0.038 \\
\hline Shaft Diameter & Ds & $\mathrm{m}$ & 0.0059 & 0.0059 & 0.0084 \\
\hline Depth of Cylinder Holes & Ls & $\mathrm{m}$ & 0.0118 & 0.0142 & 0.0179 \\
\hline Height of Cylinder & $\mathrm{Lb}$ & $\mathrm{m}$ & 0.0145 & 0.0167 & 0.0207 \\
\hline Valve Plate Thickness & Vt & $\mathrm{m}$ & 0.004 & 0.0041 & 0.0051 \\
\hline Swashplate Thickness & St & $\mathrm{m}$ & 0.004 & 0.004 & 0.004 \\
\hline Fluid Viscosity & $\mathrm{mu}$ & $\mathrm{Pa}^{*} \mathrm{~s}$ & 0.027 & 0.027 & 0.027 \\
\hline Overall Friction Factor & $\mathrm{Fp}$ & - & 0.085 & 0.085 & 0.085 \\
\hline
\end{tabular}

\section{B: Takako Pump Dimensions}




\section{C: Motor Cooling}

- Minimum motor size: $181 \mathrm{~W}$
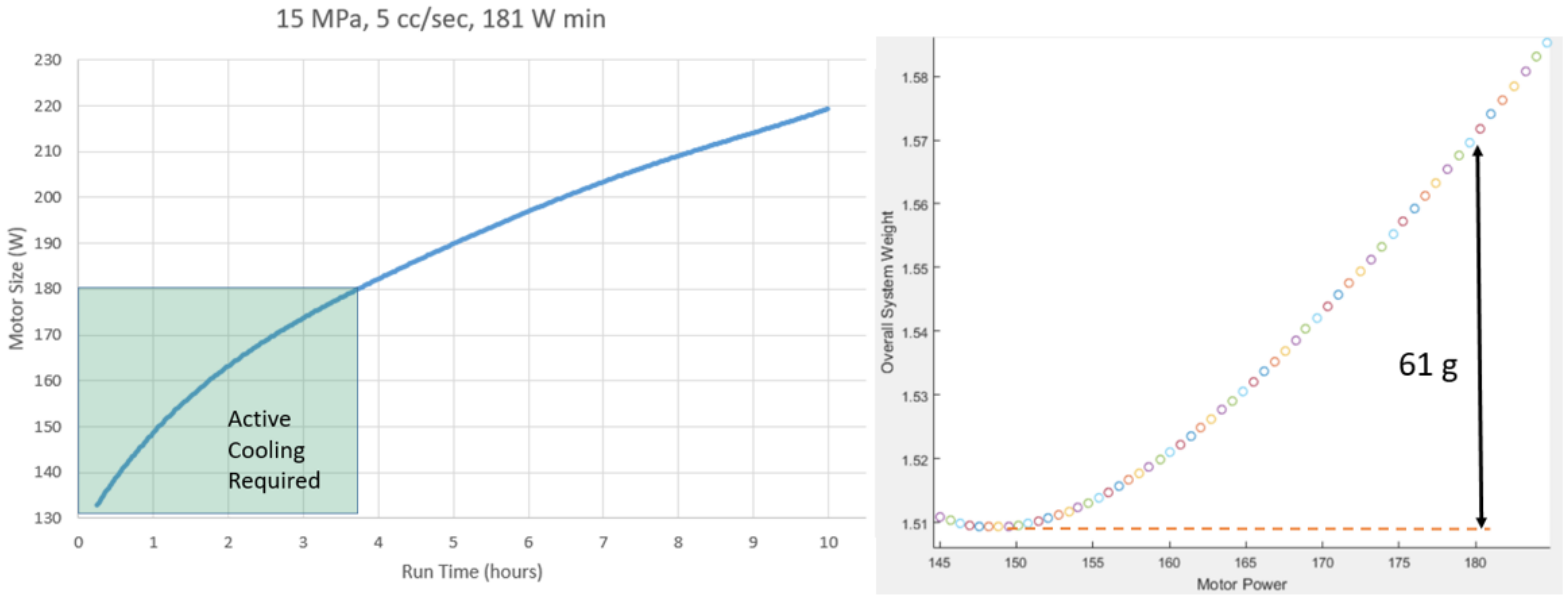

- Minimum motor size: $101 \mathrm{~W}, 5 \mathrm{MPa}, 10 \mathrm{cc} / \mathrm{sec}$
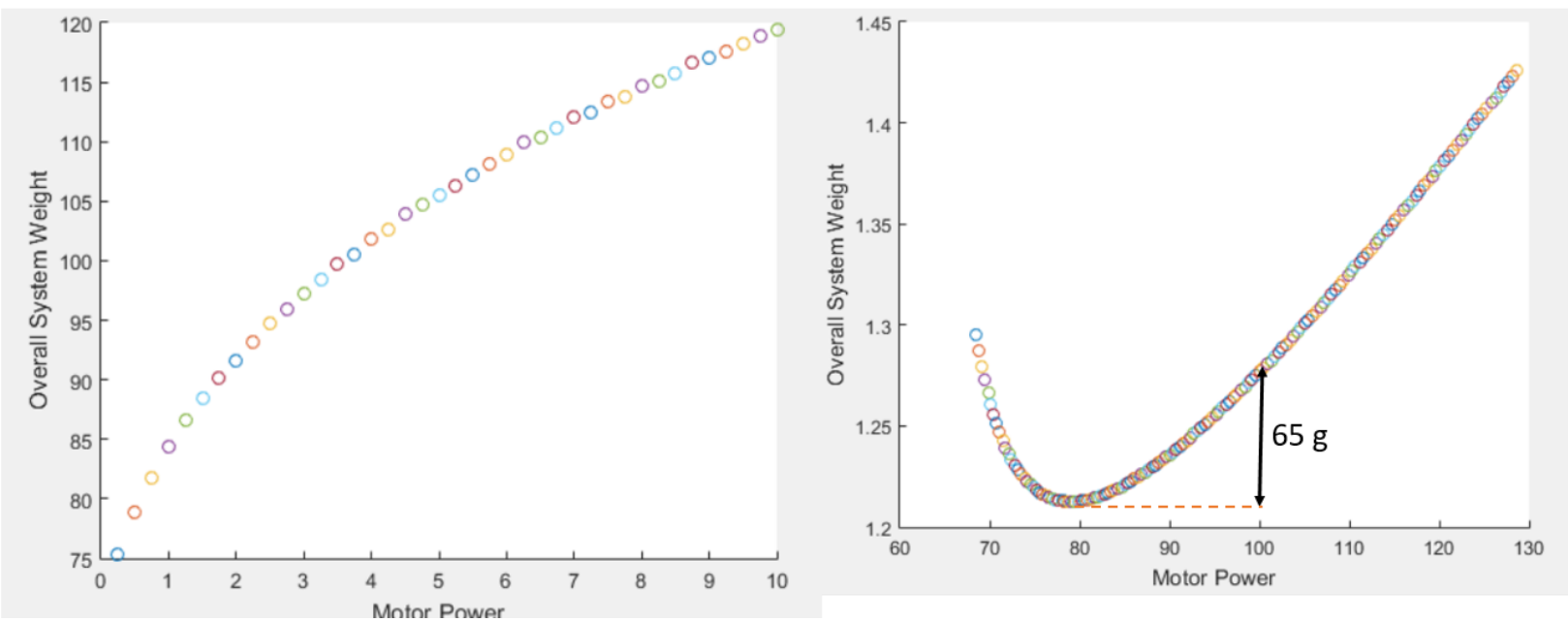

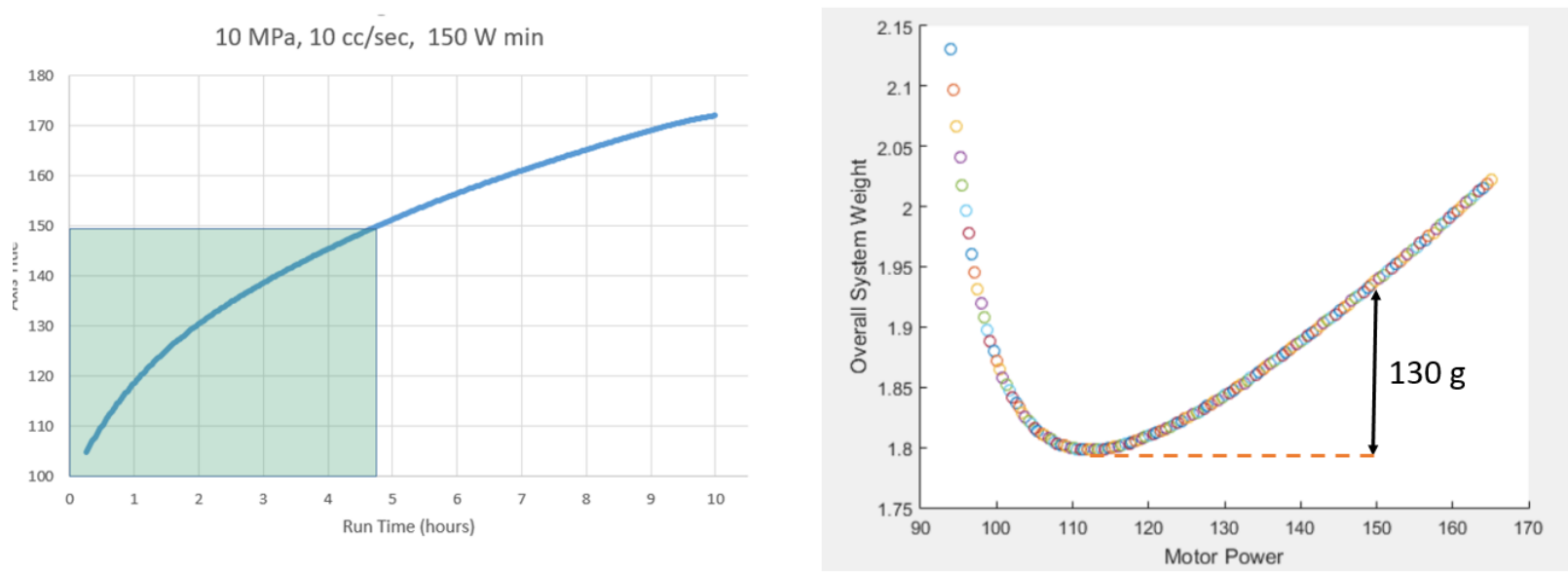

\section{D: Test Stand Data}

\subsection{Mpa, $5 \mathrm{cc} / \mathrm{sec}$}

\begin{tabular}{|c|c|c|c|}
\hline Swashplate Angle & 5.23 & 7.65 & 10.05 \\
\hline Torque (Nm) & 0.129 & 0.161 & 0.199 \\
\hline Speed (rad/sec) & 189.9 & 129.3 & 97.9 \\
\hline rpm & 1813 & 1235 & 935 \\
\hline
\end{tabular}

\section{Results: Current (A)}

\begin{tabular}{|c|c|c|c|}
\hline Swashplate Angle & $\mathbf{5 . 2 3}$ & $\mathbf{7 . 6 5}$ & 10.05 \\
\hline $\mathbf{7 0} \mathrm{W}$ & 1.103 & 1.160 & 1.255 \\
\hline $\mathbf{1 0 0} \mathrm{W}$ & 0.948 & 0.956 & 1.040 \\
\hline $\mathbf{1 8 0 ~ W}$ & 1.220 & 0.843 & 0.778 \\
\hline
\end{tabular}


$5 \mathrm{Mpa}, 5 \mathrm{cc} / \mathrm{sec}$

\begin{tabular}{|l|r|r|r|}
\hline Swashplate Angle & 5.23 & 7.65 & 10.05 \\
\hline Torque $(\mathrm{Nm})$ & 0.168 & 0.219 & 0.276 \\
\hline Speed $(\mathrm{rad} / \mathrm{sec})$ & 191.9 & 130.7 & 98.98 \\
\hline rpm & 1833 & 1248 & 945 \\
\hline
\end{tabular}

Results: Current (A)

\begin{tabular}{|c|c|c|c|}
\hline Swashplate Angle & $\mathbf{5 . 2 3}$ & $\mathbf{7 . 6 5}$ & $\mathbf{1 0 . 0 5}$ \\
\hline $\mathbf{7 0} \mathrm{W}$ & 1.514 & 1.749 & 1.927 \\
\hline $\mathbf{1 0 0 \mathrm { W }}$ & 1.290 & 1.364 & 1.598 \\
\hline $\mathbf{1 8 0} \mathrm{W}$ & 1.544 & 1.086 & 1.081 \\
\hline
\end{tabular}

$3.5 \mathrm{Mpa}, 10 \mathrm{cc} / \mathrm{sec}$

$\begin{array}{lrrr}\text { Swashplate Angle } & 5.23 & 7.65 & 10.05 \\ \text { Torque (Nm) } & 0.165 & 0.185 & 0.218 \\ \text { Speed (rad/sec) } & 375 & 255.4 & 193.4 \\ \text { rpm } & 3581 & 2438 & 1847\end{array}$

Results: Current (A)

\begin{tabular}{|c|c|c|c|}
\hline Swashplate Angle & 5.23 & 7.65 & 10.05 \\
\hline $70 \mathrm{~W}$ & 2.121 & 2.142 & 2.098 \\
\hline $100 \mathrm{~W}$ & 2.086 & 1.805 & 1.784 \\
\hline $180 \mathrm{~W}$ & 2.245 & 1.770 & 1.584 \\
\hline
\end{tabular}


$7 \mathrm{Mpa}, 5 \mathrm{cc} / \mathrm{sec}$

\begin{tabular}{l|rrr} 
Swashplate Angle & $\mathbf{5 . 2 3}$ & $\mathbf{7 . 6 5}$ & $\mathbf{1 0 . 0 5}$ \\
\hline Torque $(\mathrm{Nm})$ & 0.221 & 0.296 & 0.379 \\
\hline Speed (rad/sec) & 194.6 & 132.5 & 100.4 \\
\hline rpm & 1858 & 1265 & 958
\end{tabular}

Results: Current (A)

\begin{tabular}{|c|c|c|c|}
\hline Swashplate Angle & $\mathbf{5 . 2 3}$ & 7.65 & 10.05 \\
\hline $\mathbf{7 0} \mathrm{W}$ & 2.204 & 2.480 & 4.554 \\
\hline $100 \mathrm{~W}$ & 2.305 & 1.840 & 1.980 \\
\hline $180 \mathrm{~W}$ & 1.987 & 1.523 & 1.397 \\
\hline
\end{tabular}

